\title{
ELECTROOSMOTIC DEWATERING OF BENTONITE SUSPENSIONS
}

\author{
by
}

SHUOHUI JU

A thesis submitted to the Faculty of Graduate Studies and Research in partial fulfillment of the requirements for the Degree of Master of Engineering

Department of Chemical Engineering

McGill University

Montreal, Quebec

Canada

July 1990 


\begin{abstract}
Electroosmotic dewatering of Bentonite suspensions under conditions of constant DC voltage and constant DC current was investigated experimentally in a column $5 \mathrm{~cm}$ in diameter. The suspensions were prepared with $\mathrm{CaCl}_{2}$ in distilled water with concentrations up to $1 \mathrm{M}$. The initial solid content was between $9.1 \mathrm{wt} \%$ and $26 \mathrm{wt} \%$ and the initial bed height ranged from $1.0 \mathrm{~cm}$ to $5.2 \mathrm{~cm}$. Constant voltages from 4.0 $\mathrm{V}$ to $8.0 \mathrm{~V}$ and constant currents from $90 \mathrm{~mA}$ to $110 \mathrm{~mA}$ were used.

Electroosmosis removed $20-60 \%$ of the water with energy expenditures well below the energy required to vaporize the water. Higher voltages or currents removed more water. Removal rates were increased by the addition of $\mathrm{CaCl}_{2}$. The lowest bed height $(1 \mathrm{~cm})$ gave the lowest energy of dewatering, but the final water removal was low. For constant voltage experiments with an initial field strength of $2.8 \mathrm{~V} / \mathrm{cm}$, bed heights around $2 \mathrm{~cm}$ gave the highest water removal. The initial solid content had little effect on the final solid content. The Helmholtz/Smoluchowski theory did not predict correctly the effects of electrolyte concentration, solid content and bed height on the rate of electroosmotic dewatering.
\end{abstract}




\section{Résumé}

La déshydratation par électro-osmose de suspensions de Bentonite a été éludiéc expérimentalement dans une colonne de $5 \mathrm{~cm}$ de diametre a tension et courants continus constants. Les suspensions ont été préparées avec du $\mathrm{CaCl}_{2}$ et de l'eau distilleé, la concentration allant jusqu' à une Mol/l. Le pourcentage initial de solide variait entre $9.1 \%$ et $26 \%$ par poids, et la hauteur initiale du lit était comprise entre 1 et $5 \mathrm{~cm}$. La tension utilisée était compreise entre 4 et $8 \mathrm{~V}$, tandis que le courant était compris entre 90 et $110 \mathrm{~mA}$.

Par électro-osmose, 20 à $60 \%$ de l'eau a été retirée, et ceci avec des énergies bien inférieures à l'énergie de vaporisation de l'eau. L'augmentation du courant ou de la tension a contribué à augmenter le taux de déshydratatıon; l'addition de $\mathrm{CaCl}_{2}$ également. L'énergie de séchage la plus faible a été obtenue avec le lit le plus mince, mais le taux de retrait final était minime. Dans le cas d'expériences sous tension constante, pour des champs électriques de $2.8 \mathrm{~V} / \mathrm{cm}$, la déshydratation était optimale pour des hauteurs de lit d'environ $2 \mathrm{~cm}$. Les effects de la concentration de l'électrolyte, du pourcentage initial du solide, et de la hauteur du lit sur le taux de

déshydratation par électr-osmose n'a pas été correctement prévu par la théorie de Helmholtz/Smoluchowski. 


\section{ACKNOWLEDGMENT}

I would like to express my sincere appreciation and gratitude to my research supervisors, Professor M. E. Weber and Professor A. S. Mujumdar for their advice, guidance and encouragement throughout the course of this work.

I also wish to thank all the staff of the Chemical Engineering Department without whom this work may not have been accomplished. 


\section{TABLE OF CONTENTS}

Abstract

Page

Résumé

Acknowledgements

List of Figures

iii

List of Tables

vi

ix

Chapter 1 Introduction 1

1.1 Helmholtz/Smoluchowski Theory for Electroosmosis 1

1.2 Experiments on Electroosmosis 6

1.3 Experiments on Electroosmotic Dewatering 7

1.4 Objectives

Chapter 2 Experimental Methods and Material

2.1 Experimental Apparatus

2.2 Experimental Variables

2.3 Properties of Bentonite

2.4 Experimental Procedure

2.5 Treatment of Data

Chapter 3 Electroosmotic Dewatering under Constant Voltage

3.1 General Features of Dewatering

3.2 Effect of Salt Concentration

3.3 Effect of Applied Voltage

38

3.4 Effect of Initial Bed Height

3.5 Effect of Initial Solid Content 
Chapter 4 Electronsmotic Dewatering under Constant Current

4.1 General Features of Dewatering 55

4.2 Effect of Salt Concentration 62

4.3 Effect of Applied DC Current 62

4.4 Effect of Initial Solid Content 67

$\begin{array}{lll}\text { Chapter } 5 & \text { Discussion and Conclusions } & 76\end{array}$

5.1 Ion Exchange \& Electrode Processes 76

5.2 Comparison with Helmholtz/Smoluchowski Theory 79

5.3 Effect of Voltage or Current 81

5.4 Effect of Electrolyte Concentration 85

5.5 Effect of Initiai Bcủ Height 88

5.6 Effect of Initıal Solid Content 90

5.7 Conclusions 93

References $\quad 94$

$\begin{array}{ll}\text { Nomenclature } & 96\end{array}$ 


\section{LIST OF FIGURES}

Page

Figure 1-1 Electroosmosis in a capillary 3

Figure 1-2 Electroosmosis in a porous material 5

Figure 2-1 Electroosmotic dewatering apparatus $\quad 12$

$\begin{array}{lll}\text { Figure 2-2 Particle size distribution of Bentonite } & 17\end{array}$

Figure 2-3 Zeta potential of Bentonite as a function of $\mathrm{pH} \quad 19$

Figure 3-1 Volume of water removed vs time 25

Figure 3-2 Variation of current vs time 26

Figure 3-3 Variation of voltage drop across three sections of bed vs time $\quad 27$

Figure 3-4 Variation of water removal with total charge 29

Figure 3-5 Water flux per unit charge vs percent water removal 30

Figure 3-6 Energy of dewatering vs percent water removal 31

Figure 3-7 Water removal and current vs time for various $\mathrm{CaCl}$. concemtrations 33

Figure 3-8 Variation of water removed with total charge 34

Figure 3-9 Variation of water transported per unit charge with percent water removed 35

Figure 3-10 Energy of dewatering vs percent water removed 36

Figure 3-11 Energy of dewatering vs average sold content of the bed 37

Figure 3-12 Water removed and current vs time for varous appled voltage 39

Figure 3-13 Variation of water removal with total charge

Figure 3-14 Variation of water transported per unıt charge with percent water removed $\quad 42$

Figure $=15$ Energy of dewatering vs percent water removal 43

Figure 3-16 Volume of water removed vs time for different initial heights

Figure 3-17 Voltage difference across sections of the bed 46 
Figure 3-18 Voltage difference across sections of the bed

Figure 3-19 Current vs time for different initial height of the bed

Figure 3-20 Variation of water transported per unit charge with percent water removed

Figure 3-21 Energy of dewatering vs percent water removed

Figure 3-2? Average solid content of bed vs time

Figure 3-23 Variation of water transporied per unit charge with average solid content of the bed

Figure 3-24 Energy of dewatering vs average solid content of the bed 54

Figure 4-1 Volume of water removed vs time

Figure 4-2 Varration of overall voltage vs time

Figure 4-3 Varration of voltage drop across three sections of bed vs time

Figure 4-4 Water flux per unit charge vs percent water removed 60

Figure 4-5 Energy of dewatering vs percent water removed

Figure 4-6 Water removed and voltage vs tıme for varıous $\mathrm{CaCl}_{2}$ concentrations

Figure 4-7 Variation of water removed with total charge

Figure 4-8 Variation of water transported per unit charge with percent water removed

Figure 4-9 Energy of dewatering vs percent water removed

Figure 4-10 Water removed and voltage vs time for various applied current

Figure 4-11 Variation of water removed with total charge

Figure 4-12 Variation of water transported per unit charge with average solid content

Figure 4-13 Energy of dewatering vs percent water removed

Figure 4-14 Variation of solid content with time $\quad 72$

Figure 4-15 Variation of water transported per unit charge with average solid content

Figure 4-16 Energy of dewatering vs average solid content 
Figure 5-1 Schematic of bed with electrode reactions

Figure 5-2 Relation between final water removal, miltal strength and current per unit area

Figure 5-3 Water flux per unit charge at constant voltage

Figure 5-4 Energy of dewatering at constani voltage

Figure 5-5 Water flux per unit charge ai constani current

Figure 5-6 Final solid content vs $\mathrm{CaCl}_{2}$ concentration

(i)

Figure 5-7 Final water removal vs initial bed height at constant current

Figure 5-8 Valiation of water flux per unit charge with water corlent 


\section{LIST OF TABLES}

Page

'Table 1-1 Experimental parameters 'b' and 'rn' for Illitic clay 7

Table 2-1 Experimental conditions for constant voltage 15

Table 2-2 Experimental conditions for constant current 16

Table 5-1 pH of $9.1 \mathrm{wt} \%$ Bentonite suspension 76

Table 5-2 Comparison of data with Eqs. (5-7) and (5-8) 81

Table 5-3 Final solid content in different layers of dewatered cake 93 


\section{CHAPTER 1}

\section{INTRODUCTION}

Large quantities of aqueous suspensions of fine-grained materials are produced by many industries. Mechanical dewatering methods such as gravitational settling, filtration and centrifugation may not be effective in dewatering suspensions of particles smaller than $10 \mu \mathrm{m}$. As water is removed, the partucles move closer together, thus decreasing the size of the pores ihrough which the water must flow and reducing the rate of water removal. Often expensive thermal drying is required to obtain the final desıred moisture content.

Electroosmosis is based on the surface charge characteristics of collondal particles. When an electric current is passed through a water-filled porous medium which has an electrical double layer, water is transported through the medium. Dewatering hy electroosmosis has been known for decades, but the industrial application of this method has been limited.

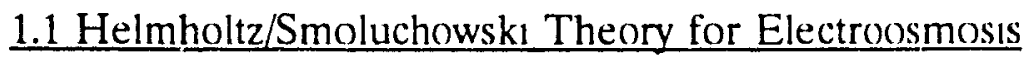

The Helmholtz/Smoluchowski theory. originally developed for a straight cylindrical capillary, is based on the following assumptions [Hiemenz (1986), Ellıs (1976)]:

1. The radius of the capillary is much larger than the thickness of the electrical double layer. This is conventionally written as: 
where $\mathbf{k}^{1}$ is the Debye thickness and $\mathrm{R}$ is the capillary radius.

2. The walls of the capillary are nonconducting.

3. The fraction of the current carried by ions in the double layer is negligible (i.e. negligible surface conductance).

The situation is illustrated in Fig. 1-1. The velocity outside the double layer is uniform and is, in SI units, given by:

$$
u_{e}-\frac{-\zeta D \epsilon_{o}}{\eta \lambda}\left(\frac{i}{a}\right)
$$

where $\zeta$ = zeta potential, (V)

$\mathrm{D}=$ dielectric constant of the bulk fluid

$\epsilon_{0}=$ permitivity of free space $\left(8.85 \times 10^{-12} \mathrm{~A}^{2} \mathrm{~s}^{4} / \mathrm{kg} \mathrm{m}^{3}\right)$

$\eta=$ viscosity of the bulk fluid, $(\mathrm{kg} / \mathrm{m} \mathrm{s})$

$\lambda=$ specific conductance of the bulk fluid, $(\mathrm{S} / \mathrm{m})$

$\mathrm{i}=$ electric current, (A)

$\mathrm{a}=$ cross sectional area of the cap iary $\left(\mathrm{m}^{2}\right)$

Since the field strength, E, and the current are related by:

$$
E=\frac{i}{\lambda a}
$$

Eq. (1-2) can be written:

$$
u_{e}-\frac{-\zeta D \epsilon_{o} E}{\eta}
$$




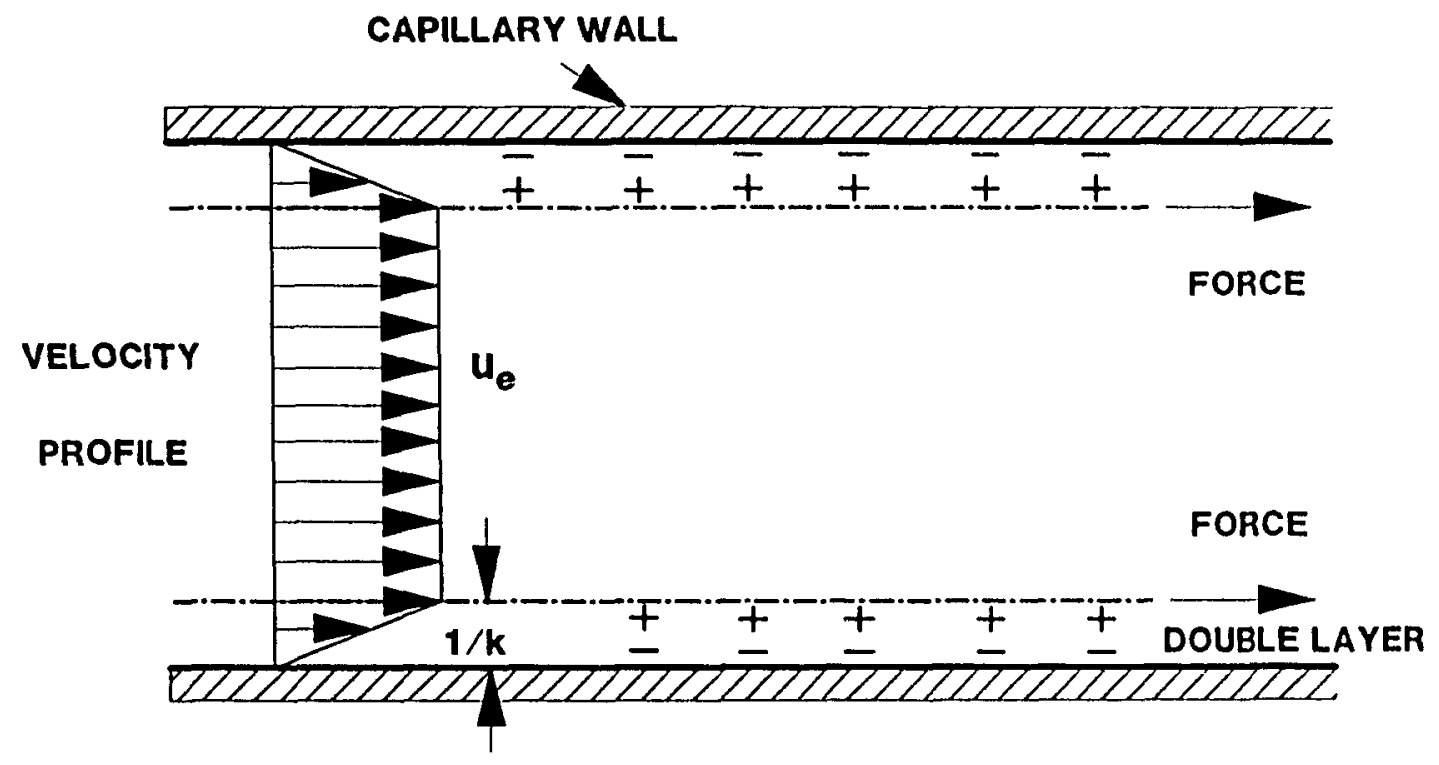

Figure 1-1 Electroosmosis in a Capillary 
Electroosmotic transport in a porous material is carried out by applying a voltage across a bed or "plug" as depicted in Fig. 1-2. The applied field $E_{\mathrm{a}}$ is given by

$$
E_{a} \cdot \frac{V_{1}-V_{2}}{H}
$$

Smoluchouski showed that eq. (1-1) applies to a porous material composed of nonconducting particles in a liquid medium if $u_{c}$ is defined as the cross section average velocity of the fluid (i.e. the superficial velocity or the volumetric flux density). For a porous material:

$$
u_{e}=\frac{-\zeta D \epsilon_{o}}{\eta \lambda}\left(\frac{i}{A}\right)
$$

where $\mathrm{A}$ is the cross sectional area of the porous plug and $\lambda$ is the conductance of the bulk liquid in the pores. If $\mathrm{Q}$ is the volume of water removed from the porous material by electroosmosis, then:

$$
u_{e}-\frac{1}{A} \frac{d Q}{d t}
$$

The relationship between $i / \Lambda$ and the strength of the applied field, $E_{a}$, depends upon the void fraction and the structure of the porous material. The relationship between $\mathrm{u}_{\mathrm{e}}$ and $\mathrm{E}_{\mathrm{a}}$ may be written:

$$
u_{e}-\frac{-\zeta D \epsilon_{o} E_{a}}{\eta} f\left(\epsilon_{+}\right)
$$




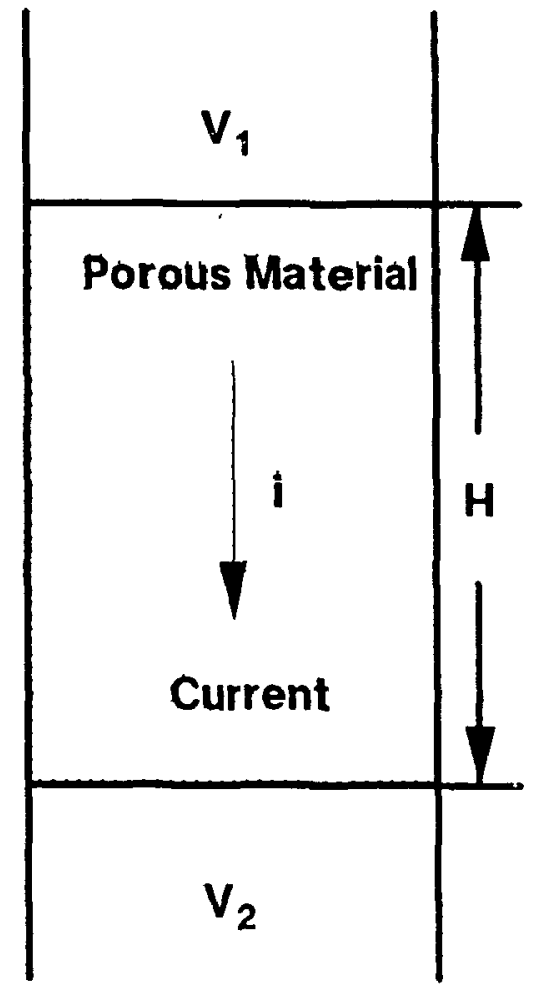

Figre 1-2 Electroosmosis in a Porous Material 
where $f\left(\epsilon_{+}\right)$is a function of the void fraction, $\epsilon_{+}$. This function has been determined for several model structures. For example, if a porous plug of length $\mathrm{H}$ contains straight cylindrical pores of length $H, f\left(\epsilon_{+}\right)=\epsilon_{+}$. O'Brien (1986) showed that $f\left(\epsilon_{+}\right)=0.343$ for a porous material composed of uniform spheres in a simple cubic array where $c_{+}=0.476$.

Electroosmosis is attractive as a method of dewatering because eq. (1-6) indicates that the rate of water removal is not a function of the water content (or void fraction) if the current is maintained constant. This equation and eq. (1-8) are subject to the assumptions listed above. The most important of these is that the pore radii are very much larger than the thicknoss of the double layer.

Yukawa and colleagues (1978) developed a model of electroosmotic dewatering in which a voltage is applied to a sludge bed and the water is moved downward with the electroosmotic velocity $u_{c}$. They assumed that the sludge bed contained two layers: an upper dewatered layer and a lower layer which has the same water content as the original bed. Weber, Witwit and Mujumdar (1987) derived a simpler model by assuming that the bed dewatered uniformly. Both models were based upon eq. (1-6).

\subsection{Experiments on electroosmosis}

Gray's work (1966, 1967) concerned the relationship between the rate of electroosmotic water transport and the water content of several clays. The experimental flow cell contained a clay plug between two solution compartments. The voltage was applied using reversible electrodes so that no gases were evolved. A constant current was imposed across the slay plug and the resulting flow of water was measured. The rate of electroosmotic transport per unit charge and the water 
content were related by

$$
W-b\left(\frac{w}{10}\right)^{m}
$$

where $\mathrm{W}=$ water flux per unit charge, (moles/Faraday)

$w=$ water content in weight percent

The coefficients ' $m$ ' and ' $b$ ' were correlated with the exchange capacity of the clay and the concentration of the external electrolyte solution. This correlation was quite good for the illite clays. The results are given in Table 1-1.

Table 1-1 Experimental Parameters ' $b$ ' and 'm' for Illitic Clay

\begin{tabular}{|c|c|c|}
\hline $\begin{array}{c}\text { Electrolyte } \\
(\mathrm{NaCl}) \mathrm{M}\end{array}$ & $\mathrm{b}$ & $\mathrm{m}$ \\
(mole/Faraday) & 31 & 1.06 \\
\hline $10^{-3}$ & 35 & 0.76 \\
\hline $10^{-2}$ & & \\
\hline
\end{tabular}

\subsection{Experiments on Electroosmotic Dewatering}

A number of studies has been reported for electroosmotic dewatering of fine-particle suspensions. Only those related to the dewatering of clays are reviewed here.

Yoshida et al. (1985) dewatered gelatinous Bentonite suspensions under conditions of constant voltage and constant current. The apparatus was similar to that described in Ch.pter 2. The diameter of the bed was $7.2 \mathrm{~cm}$ and its inital height wass $5.4 \mathrm{~cm}$. 
Using their vajue for the density of the Bentonite particles, $2.767 \mathrm{~g} / \mathrm{cm}^{3}$, the initial volume fraction of water was 0.917 . In constant voltage runs, four voltages were applied: $2.5,5,10$ and $15 \mathrm{~V}$. At a voltage of $10 \mathrm{~V}$ and above, the current rose to a maximum and then fell dramatically. For lower voltage the current was relatively constant. The largest applied voltage did not remove the most water. There was an optimum for voltage at which the water removed was a maximum. In constant current runs, three currents were used: 50, 100 and $200 \mathrm{~mA}$. In all cases, the voltage fell slowly as water was removed and then increased rapidly near the end of dewatering.

Lockhart (1983) studied the electroosmotic dewatering of sodium kaolinite suspensions to determine the influence of voltage, salt content, $\mathrm{pH}$, clay type and electrode material. In most runs the initial solid content was $18 \mathrm{wt} \%$. His apparatus was also similar to that described in Chapter 2. He began with a constant voltage, then when dewatering essentially stopped, the voltage was increased to a higher value which was maintained until the dewatering rate fell off again and the procedure was reported. A typical sequence was $2 \mathrm{~V}, 3 \mathrm{~V}, 25 \mathrm{~V}$ and $50 \mathrm{~V}$. The suspensions were made with water and with $\mathrm{NaCl}$ and $\mathrm{HCl}$ at concentrations from $10^{-3}$ to $10^{1} \mathrm{M}$. Salt or acid concentrations up to about $10^{2} \mathrm{M}$ usually allowed dewatering to proceed at lower voltages or permitted more complete dewatering at the same voltages, than suspensions prepared with water. Lockhart found that the water flow per unit of charge passed through the bed was not inversely proportional to the concentration of ions, nor was it proportional to the zeta potential. These conclusions are largely contrary to the theory outlined above. 


\subsection{Objectives}

The theory reviewed above suggests that the following variables are important in electroosmotic dewatering:

-. the zeta potential of the particles

-- the current or voltage

-- the conductivity of the suspension

Previous experiments on electroosmotic dewatering indicate that the following additional variables are important:

-- the original solid content of the suspension

-- the original height of the bed before dewatering

-- the content of electrolyte in the water used to prepare the suspension

The objectives of this thesis were to determine the effects of these varables on the rate of electroosmotic dewatering and on the final water content.

Bentonite clay was used in all experiments. This material contans largely silica and alumina with smaller amounts of the oxides of potassium, magnesium, calcium and sodium. The latter three cations comprise the bulk of the exchangeable ions. Bentonite was chosen because suspensions contaning as little as $10 \mathrm{wt} \%$ solid are easy to prepare and water will not drain from them by gravity. In addition, earher studies are available for Bentonite or other clays. The salt used in the present work was $\mathrm{CaCl}_{3}$.

The independent variables in the study were:

-- original solid content

-- original salt concentration 
-- original bed height

-- current (in constant current experiments) or voltage (in constant voltage experiments)

The dependent variables were:

-- volume of water removed

-- voltage drop over the top, middle and lower seculuns of the bed

-- current (in constant applied voltage experiments) or overall voltage drop (in constant applied current experiments) 


\section{CHAPTER 2}

\section{EXPERIMENTAL METHODS AND MATERIAIS}

\subsection{Experimental Apparatus}

A schematic diagram of the electroosmotic dewatering apparatus is shown in Fig. 2-1. The suspension was held in a vertical acrylic cylinder (1), $5 \mathrm{~cm}$ ID and $45 \mathrm{~cm} \mathrm{long,}$ with flanges on each end. A flanged funnel-shaped base (A) was bolted to the lower flange and a cap (B) was bolted to the upper flange. The base (A) held a porous acrylic cylindrical plate (2) to support the lower electrode (3). The porous support had 90 holes of $3 \mathrm{~mm}$ diameter drilled on a square pattern with $4.8 \mathrm{~mm}$ between centers of the holes. The plate was $63 \mathrm{~mm}$ in diameter and $7 \mathrm{~mm}$ thick. An electrical wire was soldered to the edge of the lower electrode and passed through a small channel on top of base (A). A filter sheet (5) above the lower electrode was held in place by an O-ring clamped between the two lower flanges. The filter sheet, which was made of Nylon with $5.0 \mu \mathrm{m}$ pore size, wals supplied by Micron Separation Inc (Westborough, MA). A hollow tube passed through cap (B). An acrylic cylindrical plate with 29 holes of $2 \mathrm{~mm}$ dameter drilled through it and distributed to match the diamond pattern of opening in the electrode was fixed to the end of the tube. The upper electrode (4) was attached to this plate. An electrical wire, which passed through the hollow tube, was soldered to the upper electrode. The hollow tube was suspended by using a pulley system (11) above the 


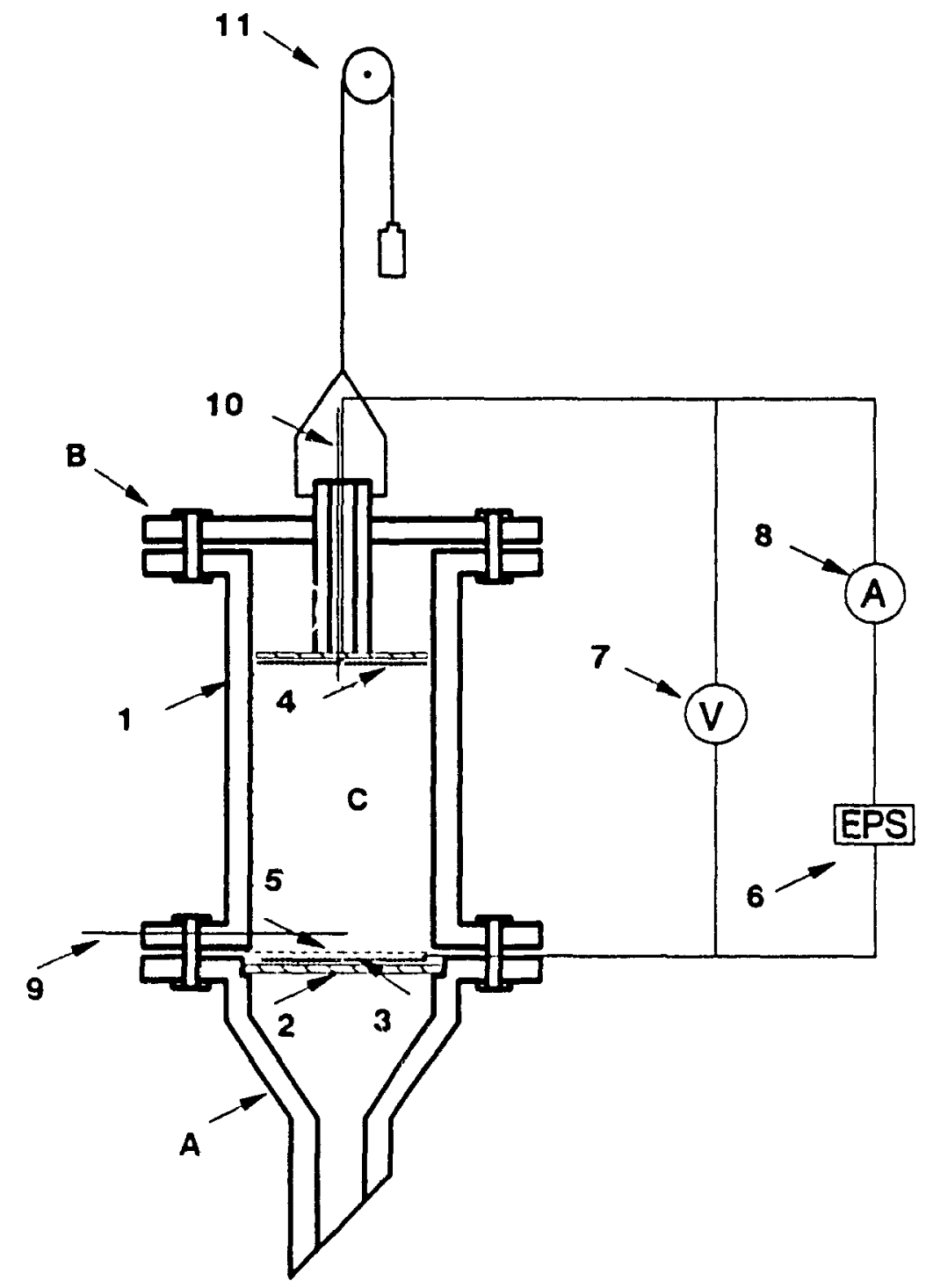

1. Acrylic resin cylinder

2. Bed support

3. Lower electrode

4. Upper electrode

5. Filter paper

6. DC power supply

7. Voltmeter

8. Ammoter

9. Lower pin electrode

10. Top pin electrode

11. Pulley

Figure 2-1 Electroosmotic Dewatering Apparatus 
apparatus. A counterweight of $200 \mathrm{~g}$ was used to balance the weight of hollow fube and the top electrode so that electrode did not compress the bed, but was free to move downward as water removed.

Each electrode was a circular piece of titanium mesh coated with platmum to a thickness of $2.5 \mu \mathrm{m}$ to prevent electrode corrosion. The wires forming the mesh were flattened in cross section. The openings in the mesh were damond-shaped and the open area was about $50 \%$ of the total cross section. These electrodes were supplied by Eagelhard Corporation USA (Edison, NJ). Since the Bentonite had a negative charge, the upper electrode was made the anode so that water migrated downward. A constant voltage or a constant current was applied to the electrodes by a regulated DC power supply (6). Voltage and current were measured as functons of tme using voltmeter (7) and ammeter (8). In order to measure the voltage drop near the electrodes two pin electrodes were installed, $1 \mathrm{~mm}$ from the tor electrode and $1 \mathrm{~mm}$ from the bottom electrode $[(9)$ and $(10)]$. The pins were stanless steel of $1.0 \mathrm{~mm}$ diameter. The top pin electrode was inserted vertically into the suspension through the hollow tube so that its tip was $1 \mathrm{~mm}$ below the top electrode. The lower pin was inserted horizontally through a rubber joint in the lower section of the acrylic cylinder.

The water removed by electroosmosis was collected in a graduated cylinder (not shown in Fig. 2-1) held below the funnel (A). The volume of water wals measured as a function of time. Occasionally the $\mathrm{pH}$ of the water was measured. 


\subsection{Experimental Variables}

The independent varables were:

1. concentration of $\mathrm{CaCl}_{2}\left(\mathrm{C}_{\mathrm{o}}\right)$ in the distilled water used to prepare the Bentonite suspension

2. initial solid content of the suspension $\left(S_{0}\right)$

3. Initial height of bed $\left(\mathrm{H}_{\mathrm{o}}\right)$

4. magnitude of the constant applied DC voltage $\left(\mathrm{V}_{\mathrm{o}}\right)$ or the constant applied DC current (i)

The experimental conditions are listed in Table 2-1 for constant voltage and in Table 2-2 for constant applied current.

The following varrables were measured as functions of time during dewatering:

1. volume of water removed

2. voltage drop over the top, middle and lower sections of the bed

3. current (in constant applied : oltage experiments)

4. overall voltage drop (in constant applied current experiments) 
Table 2-1 Experimental Conditions for Constant Voltage

\begin{tabular}{||c|c|c|c||}
\hline $\begin{array}{c}\mathrm{CaCl}_{2} \\
\text { concentration } \\
\mathrm{M}\end{array}$ & $\mathrm{v}$ & $\begin{array}{c}\text { initial bed } \\
\text { height } \\
\mathrm{cm}\end{array}$ & $\begin{array}{c}\text { initial solid } \\
\text { content } \\
\text { w\% } \%\end{array}$ \\
\hline 0 & 5.5 & 2.0 & 9.1 \\
\hline $10^{3}$ & 5.5 & 2.0 & 91 \\
\hline $10^{2}$ & 5.5 & 2.0 & 9.1 \\
\hline $10^{-1}$ & 5.5 & 2.0 & 18.6 \\
\hline 1 & 6.6 & 2.4 & 24.6 \\
\hline 0 & 5.6 & 2.0 & 9.1 \\
\hline 0 & 4.0 & 2.0 & 9.1 \\
\hline 0 & 8.0 & 2.0 & 9.1 \\
\hline $10^{3}$ & 2.8 & 1.0 & 9.1 \\
\hline $10^{-3}$ & 4.2 & 1.5 & 9.1 \\
\hline $10^{3}$ & 5.8 & 2.1 & 9.1 \\
\hline $10^{3}$ & 7.8 & 2.8 & 9.1 \\
\hline $10^{-3}$ & 14.6 & 5.2 & 9.1 \\
\hline $10^{-2}$ & 5.5 & 2.0 & 9.1 \\
\hline $10^{2}$ & 5.5 & 2.0 & 15.1 \\
\hline
\end{tabular}


Table 2-2 Experimental Conditions for Constant Current

\begin{tabular}{|c|c|c|c|}
\hline $\begin{array}{c}\mathrm{CaCl}_{2} \\
\text { concentration } \\
\mathrm{M}\end{array}$ & $\mathrm{Current}$ & $\begin{array}{c}\text { initial bed } \\
\text { height } \\
\mathrm{cm}\end{array}$ & $\begin{array}{c}\text { initial solid } \\
\text { content } \\
\text { wt\% }\end{array}$ \\
\hline 0 & 70 & 2.0 & 9.1 \\
\hline $10^{3}$ & 70 & 2.0 & 9.1 \\
\hline $10^{2}$ & 70 & 2.0 & 9.1 \\
\hline 0 & 90 & 2.0 & 9.1 \\
\hline 0 & 110 & 2.0 & 9.1 \\
\hline $10^{-2}$ & 70 & 2.0 & 12.0 \\
\hline
\end{tabular}

\section{$\underline{2.3 \text { Properties of Bentonite }}$}

The purified grade Bentonite powder was supplied by Fisher Scientific Co. (Pittsburgh, PA). The particle size distribution of the Bentonite was measured with a Malvern 2600 Particle Sizer (Malvern Instruments, Malvern, England). The instrument is based on the diffraction of laser light. As a particle passes through the laser beam, it scatters light with a unique light intensity characteristic at different angles of observation. A particle scatters light predominantly at a favoured scattering angle which is related to its diameter. By assuming the particles are spherical, the analyzer produces the volumetric particle size distribution.

Figure 2-2 shows the volumetric size distribution of the Bentonite. Fifty percent of the particles were smaller than $7 \mu \mathrm{m}$. The specific surface area was $1.1 \mathrm{~m}^{2} / \mathrm{cm}^{3}$. The mean diameter, $\mathrm{D}(4,3)$, derived from the volume distribution was $8.8 \mu \mathrm{m}$, where 


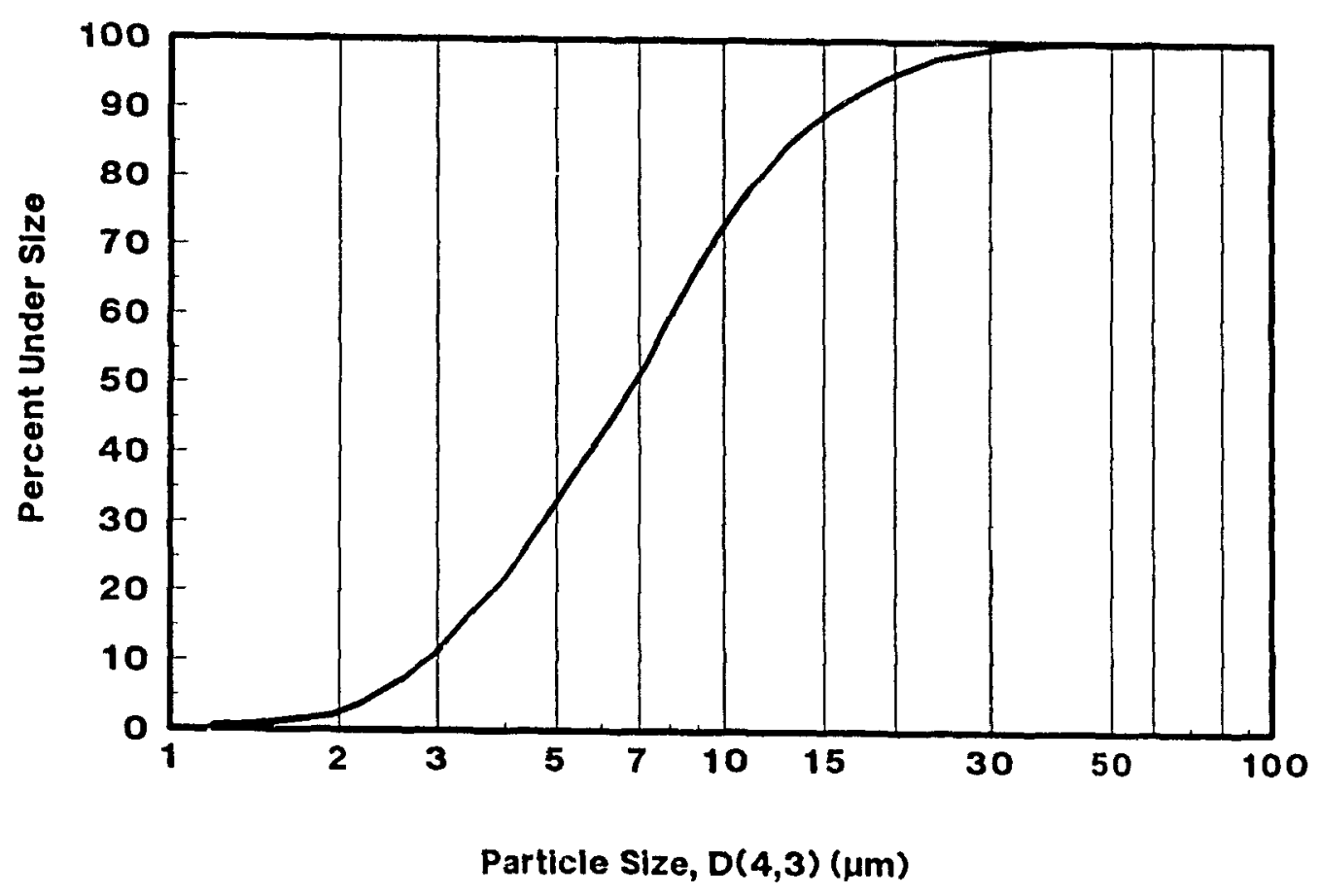

Figure 2-2 Particle Size Distribution of Bentonite 


$$
D(4,3)-\left[\frac{\int_{D_{e}}^{D_{m}} D^{4} n(D) d D}{\int_{D_{0}}^{D_{m}} D^{3} n(D) d D}\right]
$$

The zeta potential of the Bentonite particles was measured with a Particle Micro-electrophoresis Apparatus Mark II (Rank Brothers, United Kingdom). This instrument determines the electrophoretic mobility of particles in suspension by observation of their motion under a DC electric field. To reduce timing errors the voltage is set so that the time for particles to move one unit on the microscope screen (corresponding to $100 \mu \mathrm{m}$ ) is $6-8$ seconds. The electrophoretic mobility, $u$, is calculated from:

$$
u-\frac{\text { particle velocity }}{\text { potential gradient }}=\frac{d / \bar{t}}{V / l}
$$

where $d=$ distance travelled by the particles $(m)$

$\bar{t}=$ average time for a number of particles to travel the distance $d(s)$

$\mathrm{V}=$ applied voltage in electrostatic units (V)

$1=$ distance between electrodes $(\mathrm{m})$

The zeta potential, 5 , is calculated from:

$$
\zeta-\frac{4 \pi u \eta(300)^{2}}{\varepsilon_{+}}
$$

where $\eta=$ the viscosity of the suspending liquid $\left(\mathrm{cm}^{2} / \mathrm{s}\right)$

$$
\epsilon_{+}=\text {the permittivity of the suspending liquid }
$$

and the factor $(300)^{2}$ converts e.s.u. volts to absolute volts. The zeta potential data are shown in Fig. 2-3. 


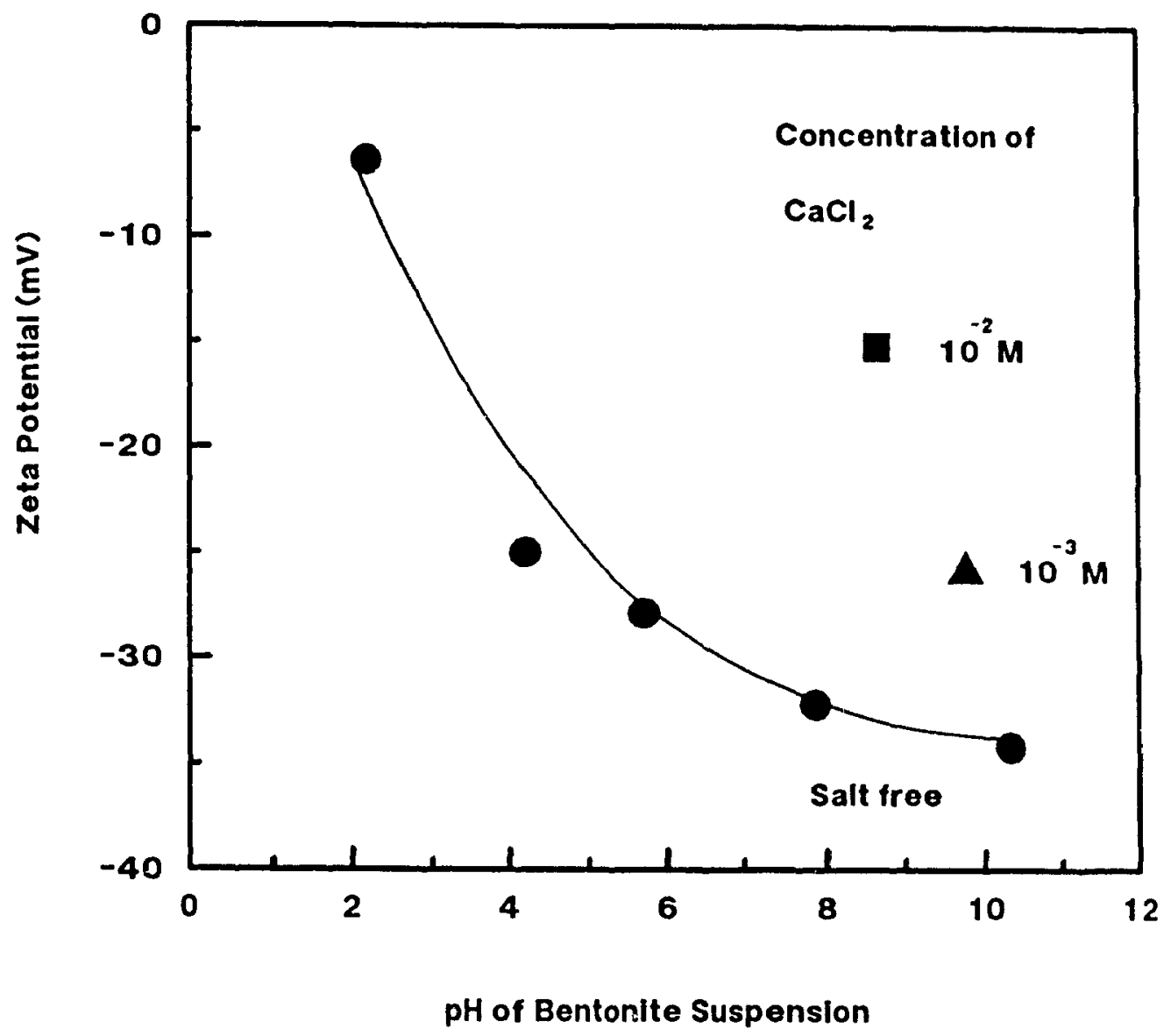

Figure 2-3 Zeta Potential of Bentonite as a Function of $\mathrm{pH}$ 
The zeta potential of Bentonite particles was measured over a range of $\mathrm{pH}$ values by adding $1 \mathrm{M} \mathrm{HCl}$ or $1 \mathrm{M} \mathrm{NaOH}$ to the suspension. As shown in Fig. 2-3 the zeta potential was negative for $\mathrm{pH}>2$. As the $\mathrm{pH}$ increased the zeta potential became more negative. Two measurements were made in suspensions which contained $\mathrm{CaCl}_{2}$. The zeta potential increased from $-34 \mathrm{mV}$ in a salt-free suspension to -14 $\mathrm{mV}$ at $10^{-2} \mathrm{M} \mathrm{CaCl}_{2}$. When the concentration of $\mathrm{CaCl}_{2}$ solution was $10^{-1} \mathrm{M}$, the particles coagulated rapidly and sedimentation was so fast that the particle mobility could not be measured. At $\mathrm{pH}<2$, the same phenomena occurred. In both cases coagulation occurred as the zeta potential approached zero.

\subsection{Experimental Procedure}

A suspension was prepared from a weighed amount of oven-dried Bentonite and a weighed amount of $\mathrm{CaCl}_{2}$ solution prepared from reagent grade $\mathrm{CaCl}_{2}$ and distilled water. Dry Bentonite was weighed in a beaker and the necessary amount of solution was weighed in a second beaker. The water was added to the Bentonite and the total weight of the beaker containing the liquid and solid was recorded. The suspension was homogenized for 15 minutes using a magnetic stirrer.

A fresh filter sheet was wetted with methanol and fixed in place. If the sheets were not wetted, water flow was retarded at the beginning of a run. The lower pin electrode was inserted into the bed so that its tip was in the center of the cylinder. The suspension was then poured into the cylinder to the designed height. The beaker containing the remaining suspension was weighed and the weight of the suspension in the bed was determined by difference. The upper electrode was fixed so that it contacted the top of the bed. 
At low $\mathrm{CaCl}_{2}$ concentration no gravity drainage of water occurred and electroosmotic dewatering began immediately. For $\mathrm{CaCl}_{2}$ concentrations equal to $10^{\prime} \mathrm{M}$ or higher, water was allowed to drain by gravity before the voltage or current was applied.

For the first 10 minutes after the voltage or current was applied, the volume of water removed by electroosmosis was recorded every minute, then every five minutes and near the end of dewatering, every ten minutes. With a constant applied voltage the current was recorded every ten minutes. The voltage drops across the upper, middle and lower sections of the bed were recorded every ten minutes for both constant voltage and constant current. Periodically the pH of the collected water was measured. In a few runs a sample of the total water collected was analyzed for metals by atomic absorption spectroscopy.

In a few runs the cake at the end of dewatering was sectioned for moisture determination. The dewatered cake was carefully pushed out of the disissembled cylinder and cut it into three slices perpendicular to its axis. Each slice of the cake was weighed as soon as it was cut and then it was dried at $105{ }^{\circ} \mathrm{C}$ to a constant weight. The mass of water in each slice was calculated by difference.

\subsection{Treatment of Data}

A parameter used subsequently to present the data is the total charge passed through the bed per unit cross sectional area. The total charge passed per unit area, denoted, $\mathrm{q}_{\mathrm{T}}$, was computed from the current and time by:

$$
q_{T}-\frac{1}{A} \int_{0}^{t} i d t
$$


where $\mathrm{i}=$ current $(\mathrm{A})$

$\mathrm{t}=$ time $(\mathbf{s})$

$A=$ cross section area of bed $\left(\mathrm{m}^{2}\right)$

The integral was computed by Simpson's rule for runs at constant voltage.

Two important parameters related to the effectiveness of electroosmotic dewatering are:

1) the water flux per unit charge

and

2) the energy of dewatering

Both parameters require the rate of water removal, $\dot{Q}$. This rate represents the time variation dewater of the volume of water collected, $Q$ :

$$
\dot{Q}-\frac{d Q}{d t}
$$

The volume versus time data were fitted to a second order polynomial by least squares and the derivative was calculated analytically. The polynomial was fitted to all but the last two or three data points.

The water flux per unit charge, denoted W, was computed from

$$
W-9.65 \times 10^{4}(\dot{Q} \rho / M i)
$$

where $\rho$ is the density of water, $M$ is the molecular weight of water $(=18.0 \mathrm{~g} / \mathrm{mole}$ ) and one Faraday of charge is $9.65 \times 10^{4}$ Coulombs. The units of $\mathrm{W}$ are moles of water per Faraday. 
The energy of dewatering, denoted $e_{d}$, is defined as

$$
e_{d}=\frac{\text { electrical power }}{\text { rate of water removal }}
$$

Hence,

$$
e_{d}=\frac{i V_{0}}{\dot{Q}_{\rho} / M}
$$

where $V_{0}$ is the overall voltage. The units of $e_{d}$ are kilojoules per mole. 


\section{CHAPTER 3}

\section{ELECTROOSMOTIC DEWATERING UNDER CONSTANT VOLTAGE}

The electroosmotic dewatering of Bentonite suspensions under conditions of constant applied DC voltage was studied experimentally in the apparatus described in Chapter 2.

\subsection{General Features of Dewatering}

For each experiment the following data were recorded as functions of time: the volume of water removed, the current and the voltage drop across the upper, middle and lower sections of the bed. These data for three replicates of a typical experiment are plotted in Figs. 3-1, 3-2 and 3-3. Figure 3-1 shows that water was removed up to 150 minutes. The current went through a maximum at about 40 minutes and then decreased to a constant value (see Fig. 3-2). The voltage differences measured across the top, middle and lower sections of the bed are shown in Fig. 3-3. Although the applied voltage was $5.5 \mathrm{~V}$, the voltage drop across the middle section of the bed was only about $3 \mathrm{~V}$. This middle section of the bed had an initial height of $1.0 \mathrm{~cm}$. There were appreciable voltage drops very near the upper and lower electrodes as shown in upper and lower panels of Fig. 3-3. The voltage drop near each electrode was measured over a distance of $0.1 \mathrm{~cm}$. The upper and lower voltage differences were approximately 1.5 and $1 \mathrm{~V}$, respectively. 


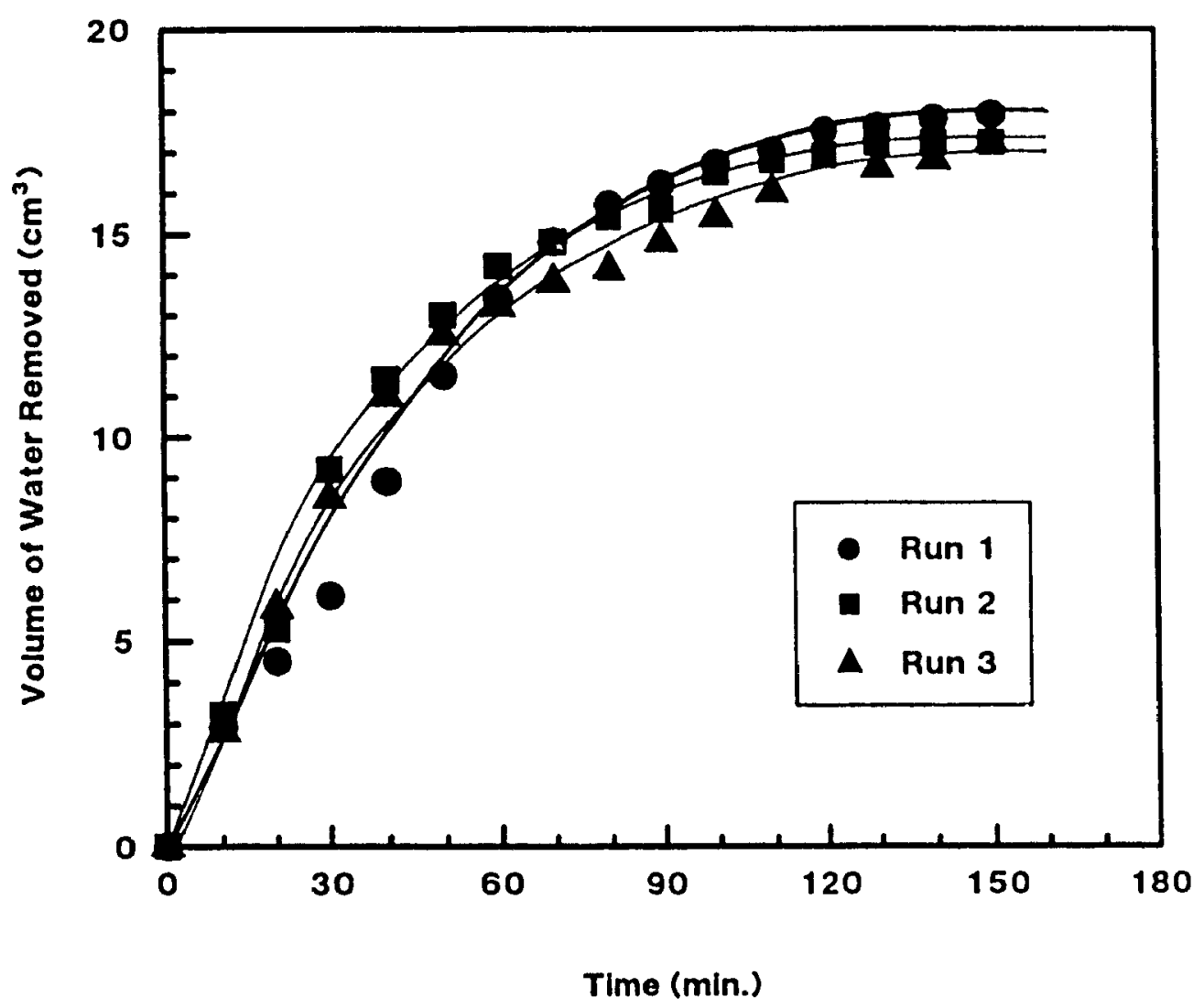

$\left(S_{0}=9.1 \mathrm{wt} \% ; C_{0}=0 \mathrm{M} ; H_{0}=2.0 \mathrm{~cm} ; V_{0}=5.5 \mathrm{~V}\right)$

Figure 3-1 Volume of Water Removed vs Time 


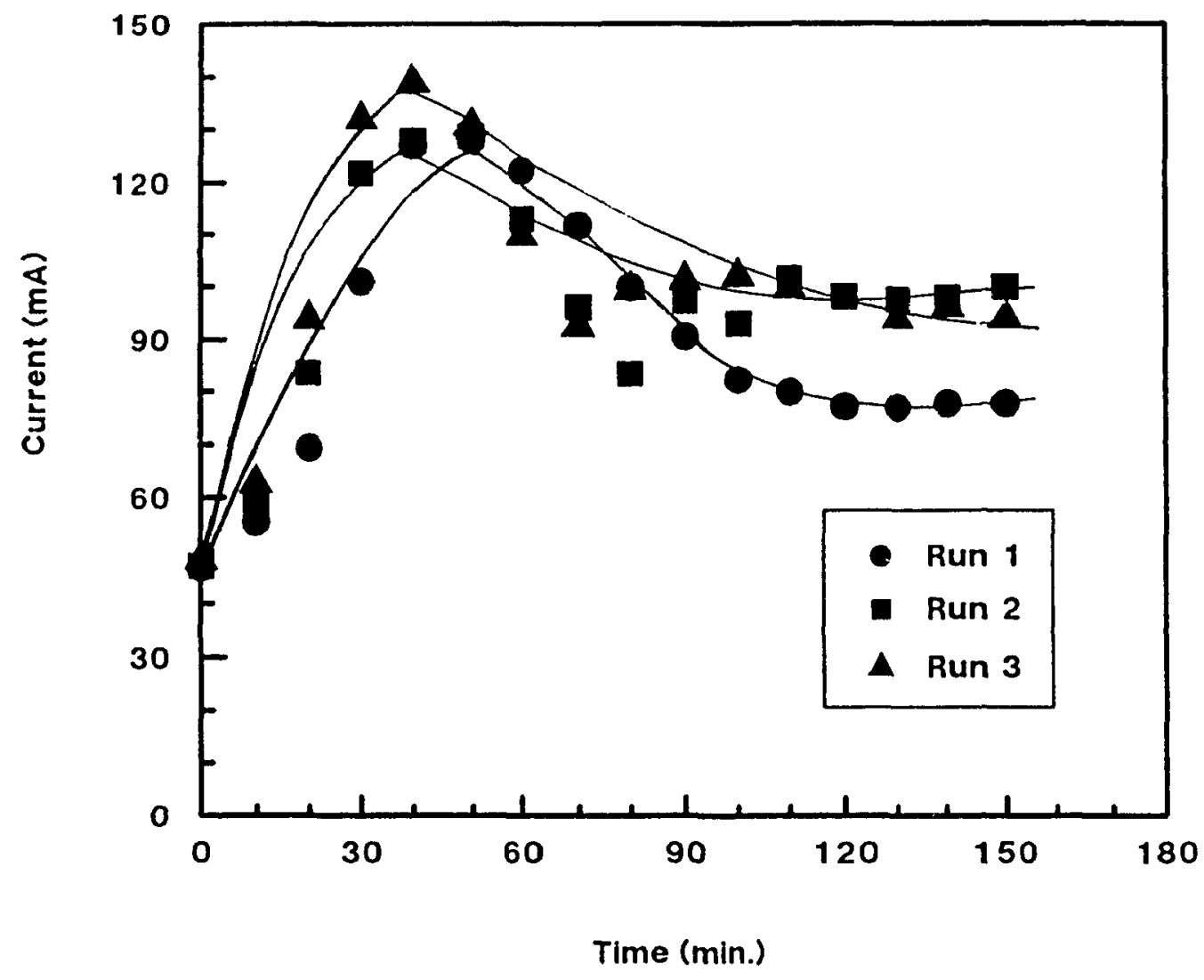

$\left(S_{0}=9.1 w t \% ; C_{0}=O M ; H_{0}=2.0 \mathrm{~cm} ; V_{0}=5.5 \mathrm{v}\right)$

Figure 3-2 Variation of Current vs Time 


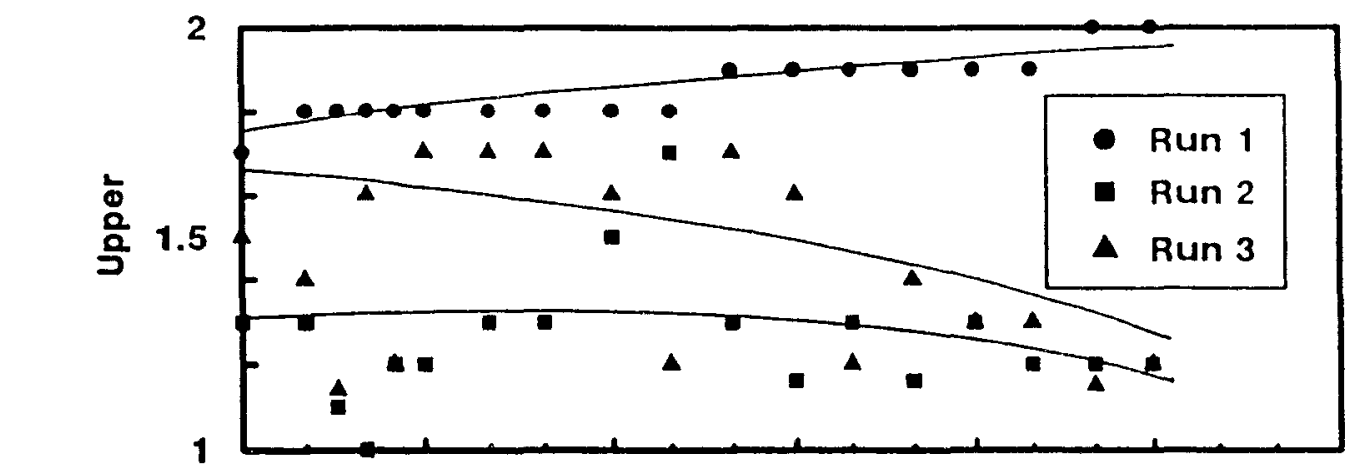

$\frac{0}{0}$
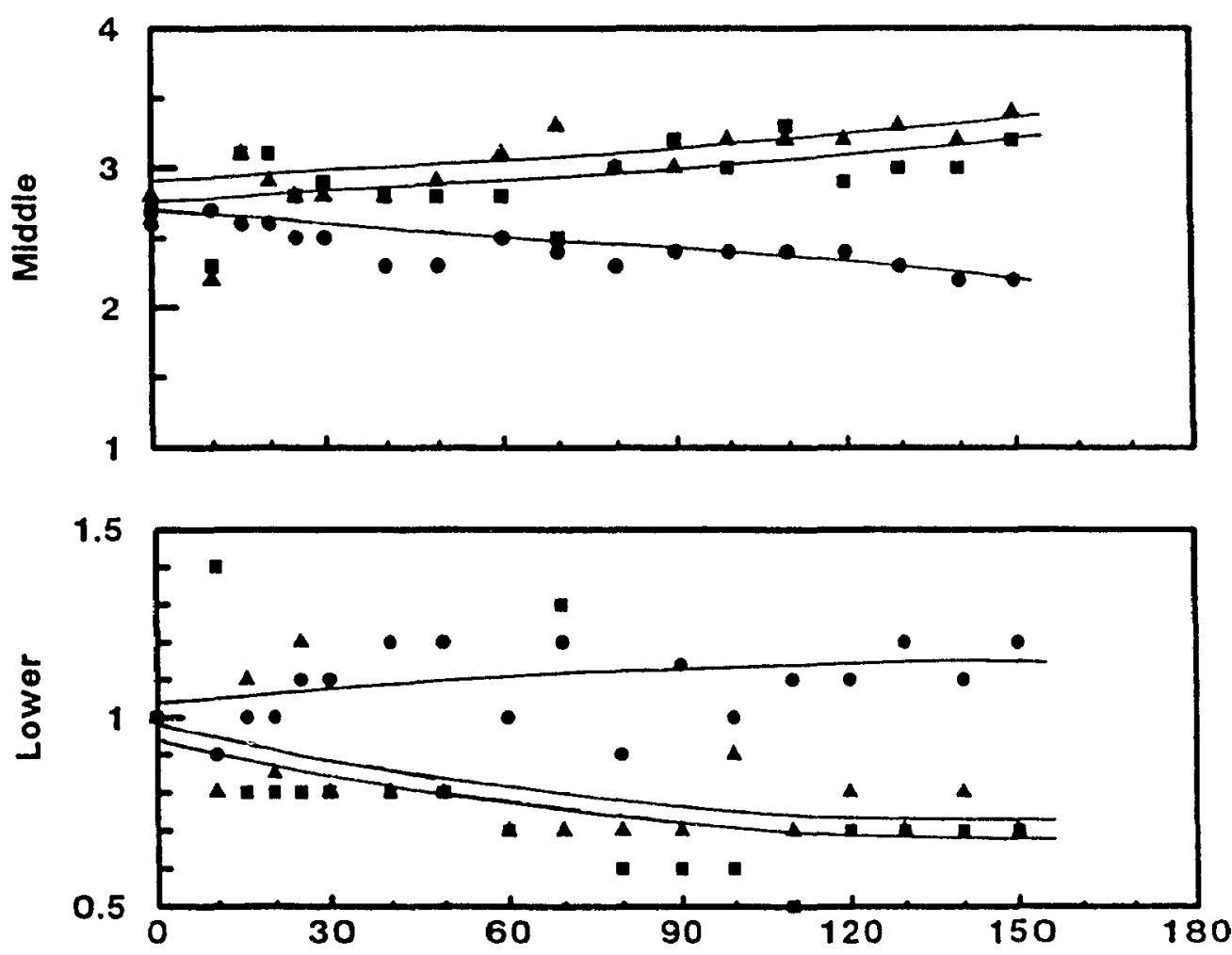

Time (min.)

$\left(S_{0}=9.1 w t \% ; C_{0}=0 \mathrm{M} ; H_{0}=2.0 \mathrm{~cm} ; V_{0}=5.5 \mathrm{~V}\right)$

Figure 3-3 Variation of Voltage Drop Across Three Sections of Bed vs time 
Replicate data for water removed, Fig. 3-1, and current, Fig. 3-2, show good agreement. For water removed the reproducibility was approximately $\pm 5 \%$, while for the current it was approximately $\pm 10 \%$. The voltage data, Fig. $3-3$, were the least reproducible because the pin electrorle measured the voltage at a point in the bed cross section. The voltage measured at a point was sensitive to local nonuniformitıes, such as the development of a crack in the cake or the presence of a gas bubble. Since these data are not very reproducible, only general trends could be observed.

Data from the replicate runs are presented in different formats in Figs. 3-4 to 3-6. These plots are used to present the effect of different variables in later sections. See Chapter 2 for a description of the method of calculation of the parameters from the recorded data. Figure 3-4 shows the volume of water removed per unit bed cross section area as a function of the total charge passed per unit bed cross section area. On this plot the ordinate was reproducible to about $\pm 5 \%$ at a fixed value of the abscissa. Figure 3-5 shows the variation of the water flux per unit charge versus the percent water removed. The energy of dewatering, i.e. the energy required to remove a mole of water, is plotted in Fig. 3-6 against the percent of water removed. Since the calculations for both figures involved differentiation of the data, the reproducibility was only $\pm 30 \%$ for Fig. $3-5$ and $\pm 25 \%$ for Fig. 3-6.

The general characteristics of dewatering under constant voltage are shown in Fig. 3-1 to 3-6. The rate of water removal was intially constant and then decreased with time as the bed dried- see Fig. 3-1. The current increased in the early period of dewatering and then decreased. The electrical resistance of the bed increases as the percentage of solids, which are nonconducting, increases but it decreases as the 


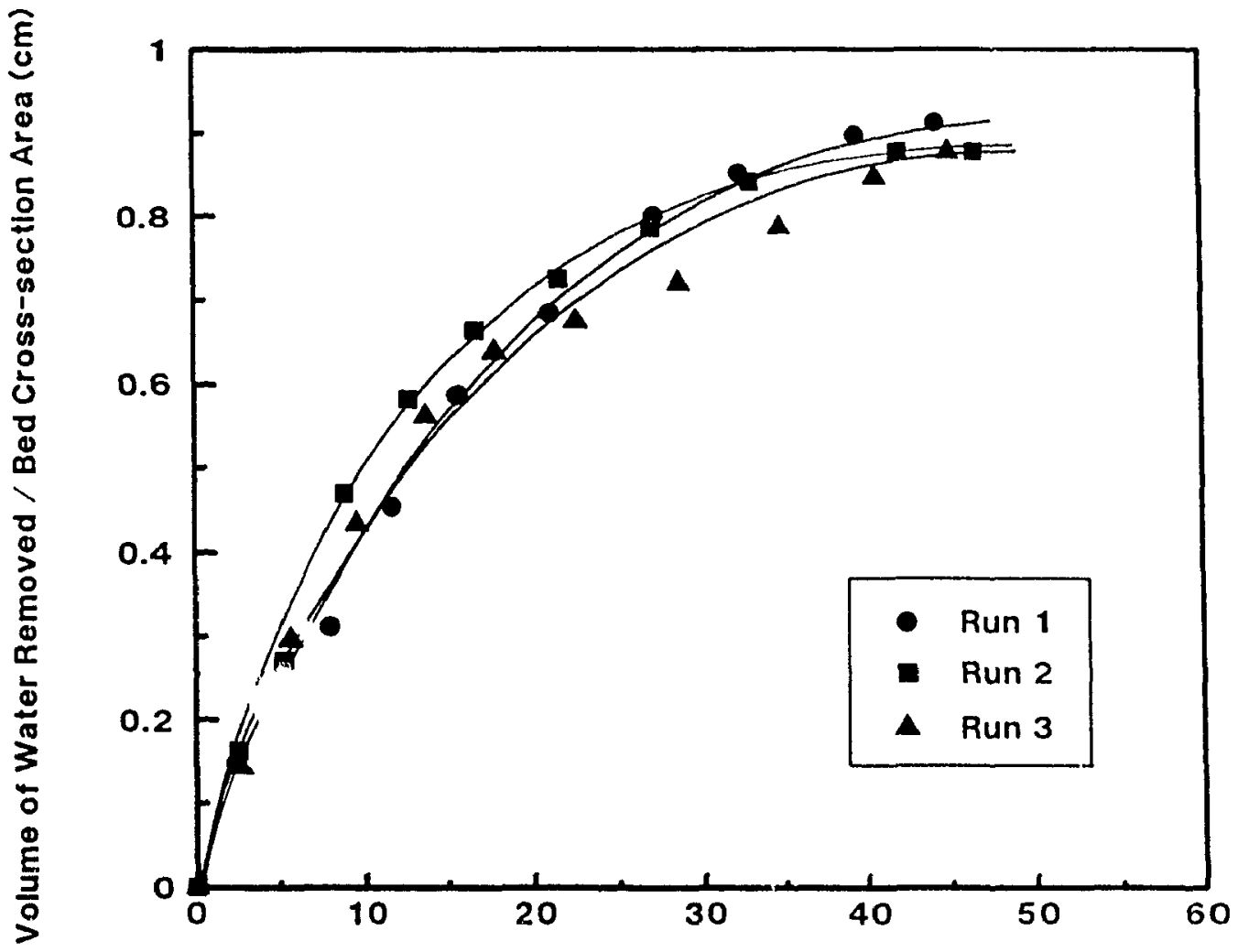

Total Charge Passed / Bed Cross-section Area $\left(A \cdot s, \mathrm{~cm}^{2}\right)$

$$
\left(S_{0}=9.1 w t \% ; C_{0}=0 \mathrm{M} ; H_{0}=2.0 \mathrm{~cm} ; V_{0}=5.5 \mathrm{v}\right)
$$

Figure 3-4 Variation of Water Removal with Total Charge 


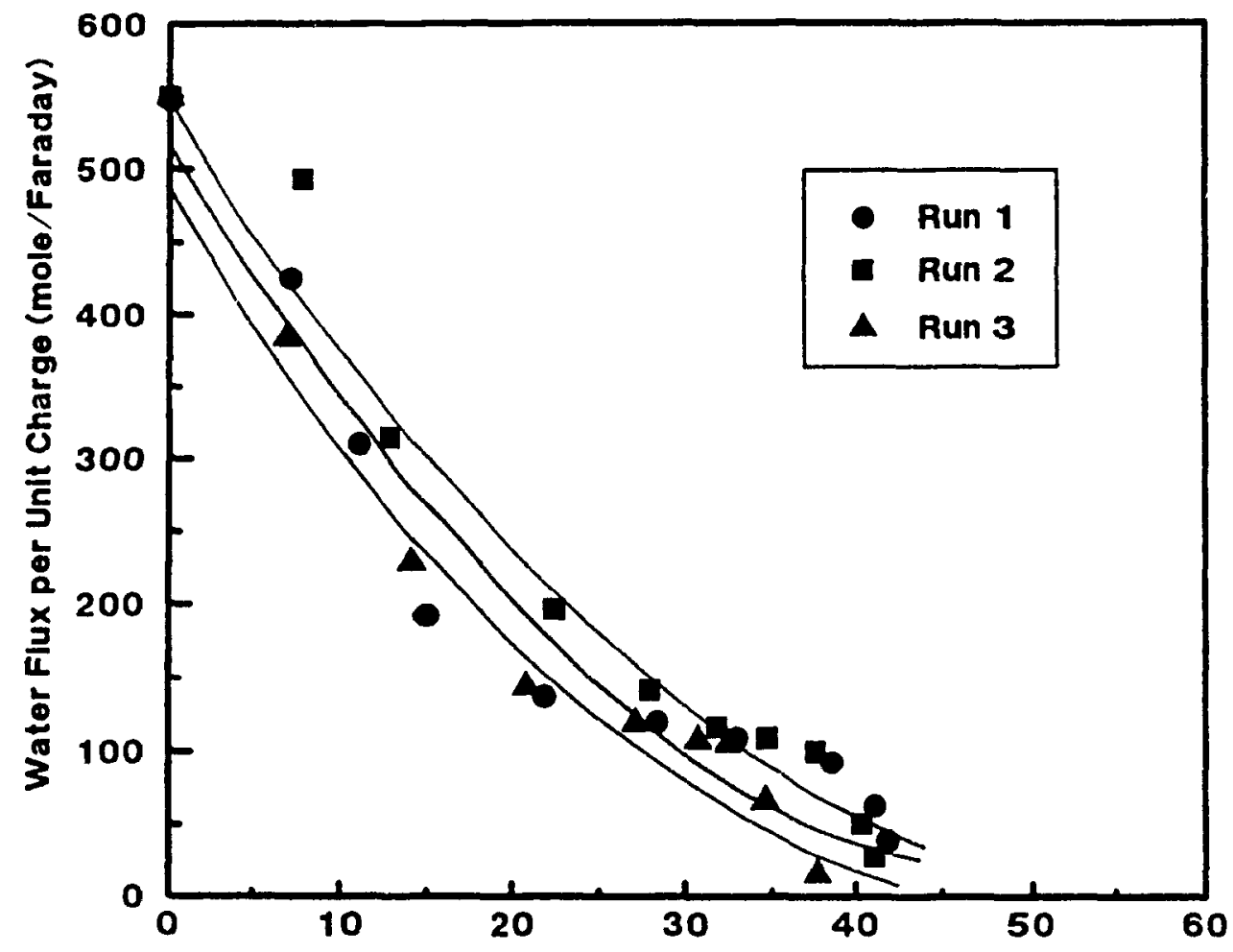

Percent Water Removed (\%)

$\left(S_{0}=9.1 w t \% ; C_{0}=O M ; H_{0}=2.0 \mathrm{~cm} ; V_{0}=5.5 \mathrm{~V}\right)$

Figure 3-5 Water Flux per Unit Charge vs Percent Water Removed 


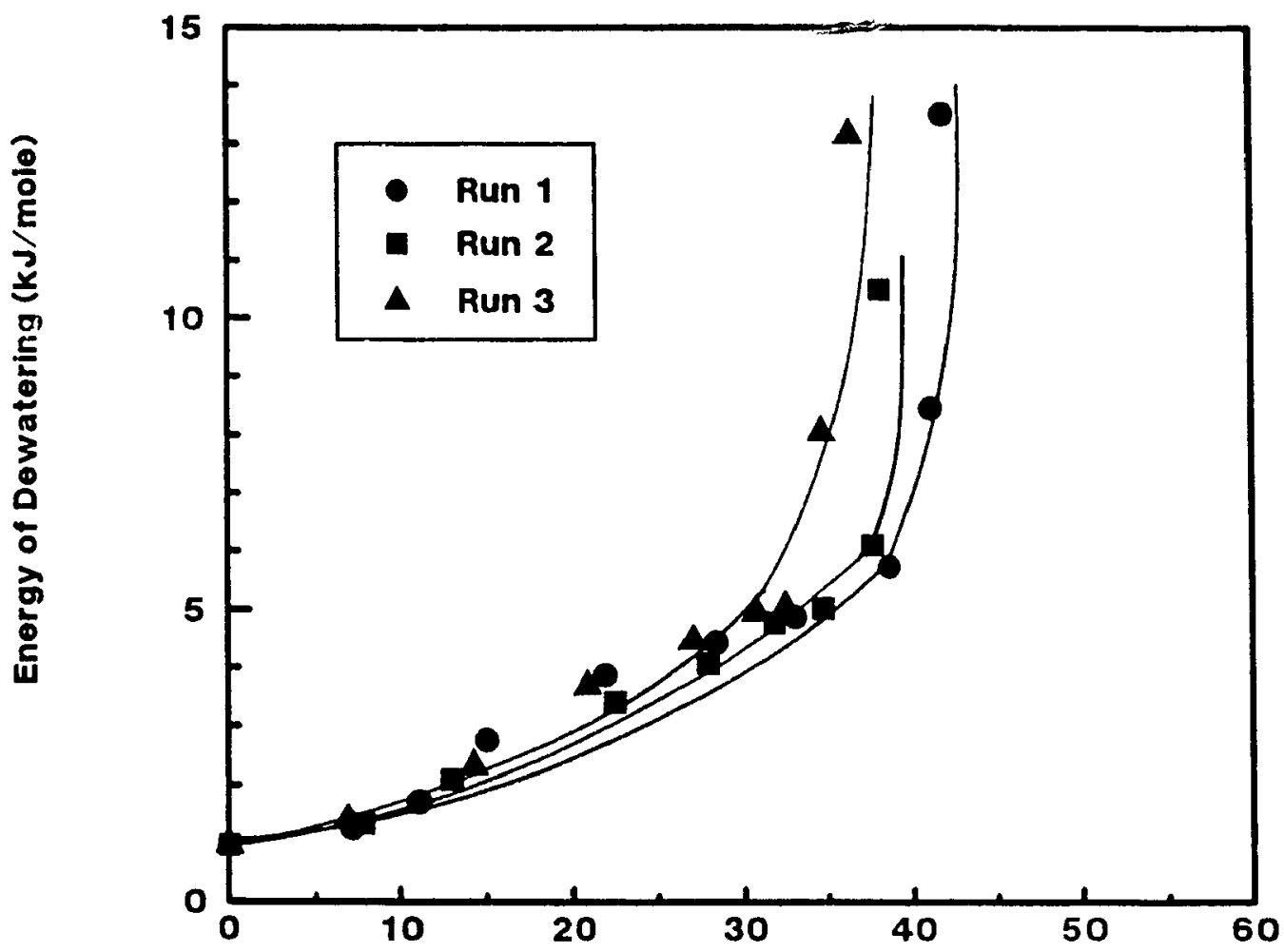

Percent Water Removed (\%)

$\left(S_{0}=9.1 w t \% ; C_{0}=0 M ; H_{0}=2.0 \mathrm{~cm} ; V_{0}=5.5 \mathrm{~V}\right)$

Figure 3-6 Energy of Dewatering vs Percent Water Removed 
height decreases. The maximum in the current reflects these two opposing trends. In addition, gas evolved at the upper electrode may interfere with the electrical contact between the upper electrode and the bed. The fluctuations in the upper voltage drop in Fig. 3-3 reflect gas bubble generation. As water was removed the volume of the bed and the sizes of the pores decreased making water more difficult to remove as shown in Figs. 3-5 and 3-6.

\subsection{Effect of Salt Concentration}

Figures 3-7 to 3-11 show the effect on dewatering of the $\mathrm{CaCl}_{2}$ concentration in the distilled water used to make up the suspension. All data, except those in Fig. 3-11 are for initial suspensions of $9.1 \%$ Bentonite with a height of $2.0 \mathrm{~cm}$. The applied voltage was constant at $5.5 \mathrm{~V}$.

The volume of water removed and the current are shown as functions of time in Fig. 3-7. Increasing the $\mathrm{CaCl}_{2}$ concentration increased the amount of water removed. For example, at 120 minutes $17.5,21.5$ and $26.5 \mathrm{~cm}^{3}$ of water were removed with 0 , $10^{3} \mathrm{M}$ and $10^{2} \mathrm{M} \mathrm{CaCl}_{2}$, respectively. Figure 3-8 shows the same data plotted as the volume of water removed against the total charge, both quantities divided by the cross sectional area of the bed. On the basis of total charge, more water was removed in the presence of $\mathrm{CaCl}_{2}$ than without this added s.9lt. Figure 3-9 shows the water flux per Faraday of charge as a function of the percent water removed. 'The moles of water carried per Faraday were highest with $10^{-3} \mathrm{M} \mathrm{CaCl}_{2}$ and lowest without $\mathrm{CaCl}_{2}$. As water was removed each Faraday transported less water, however the decrease was more rapid when no $\mathrm{CaCl}_{2}$ was present.

Figures 3-10 and 3-11 show the variation of the energy of dewatering as a function 


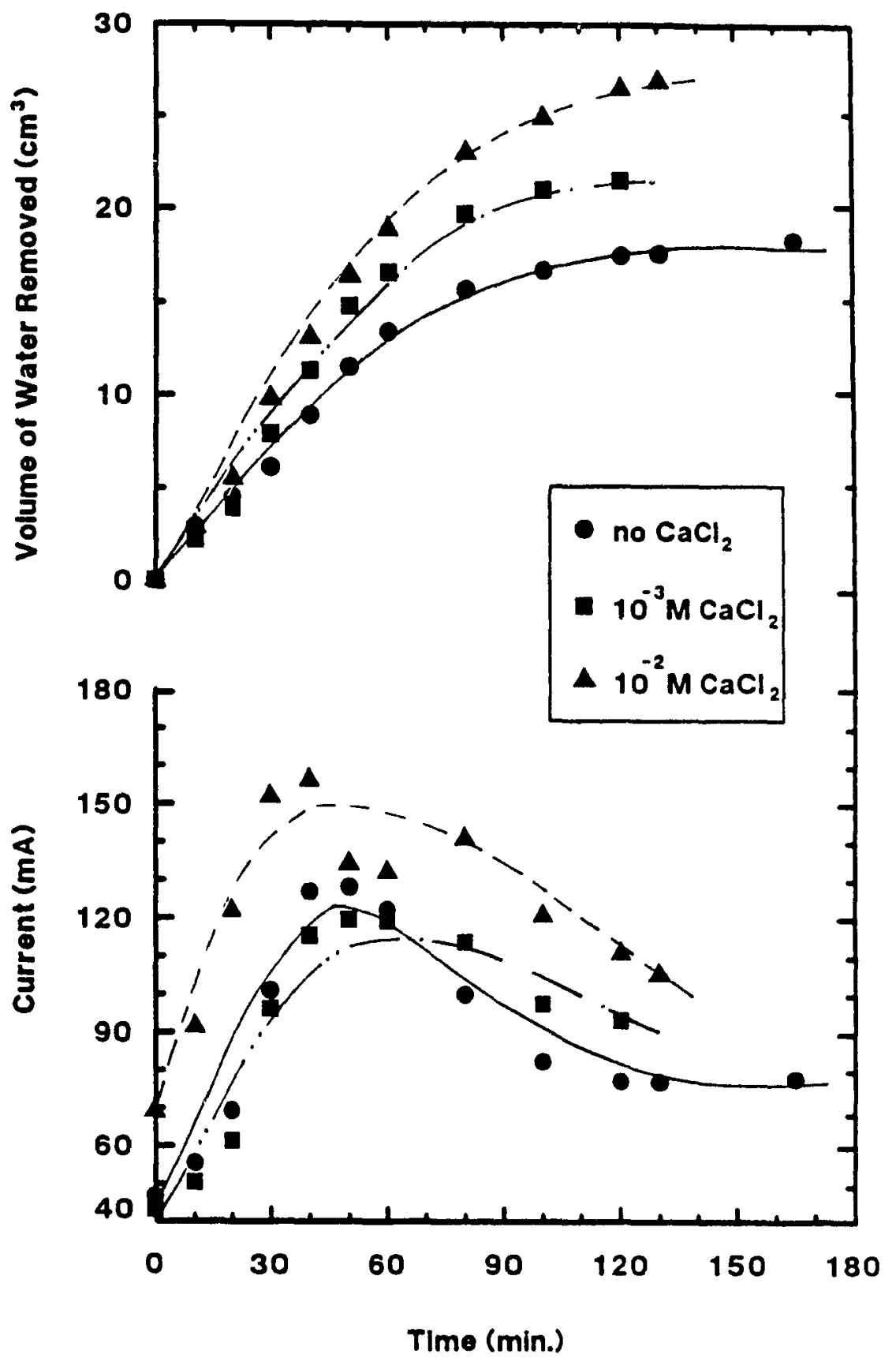

$\left(S_{0}=9.1 w+\% ; H_{0}=2.0 \mathrm{~cm} ; V_{0}=5.5 \mathrm{~V}\right)$

Figure 3-7 Water Removed and Current vs Time for Various $\mathrm{CaCl}_{2}$ Concentrations 


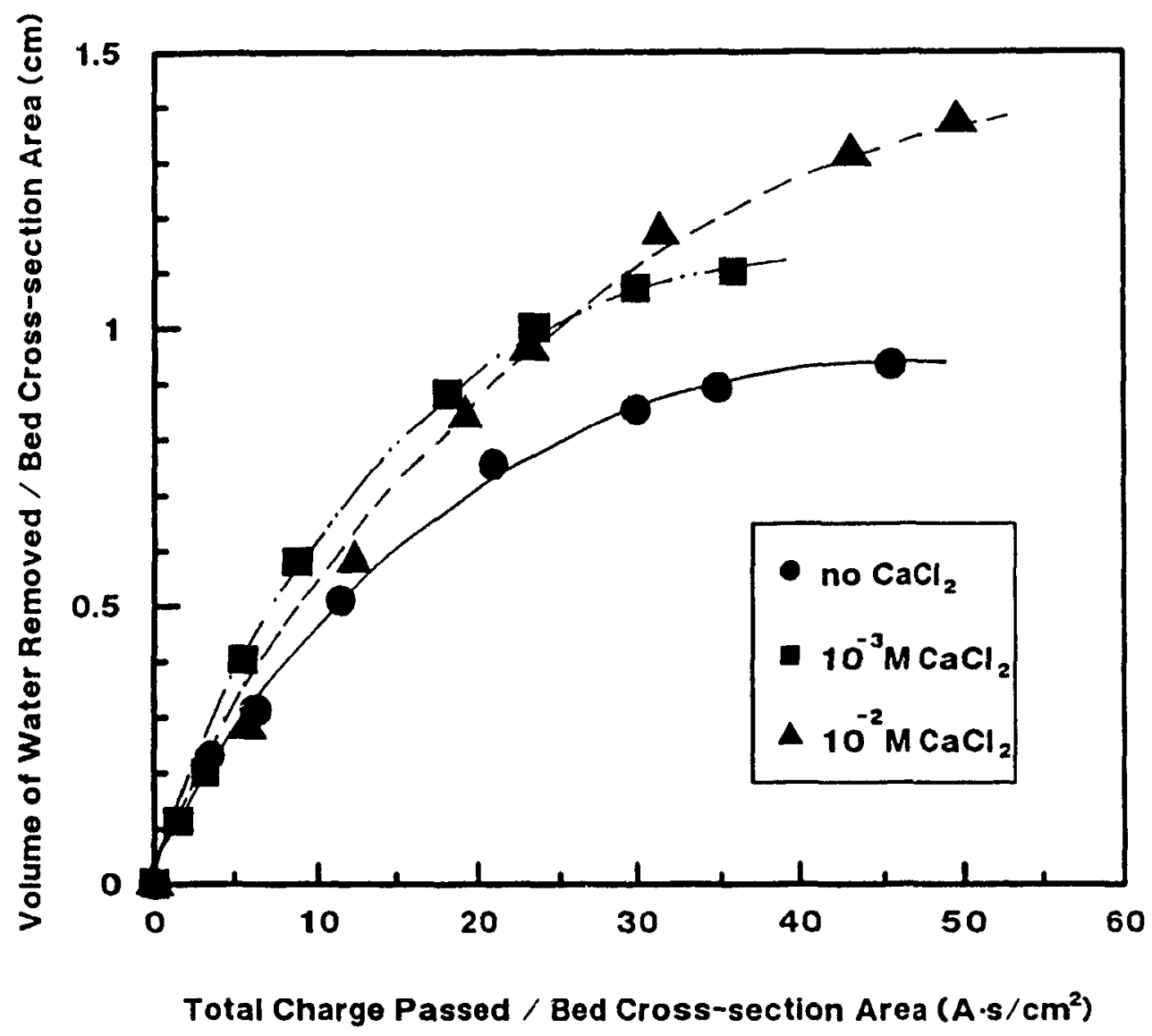

$$
\left(S_{0}=9.1 w t \% ; H_{0}=2.0 \mathrm{~cm} ; V_{0}=5.5 \mathrm{v}\right)
$$

Figure 3-8 Variation of Water Removal with Total Charge 


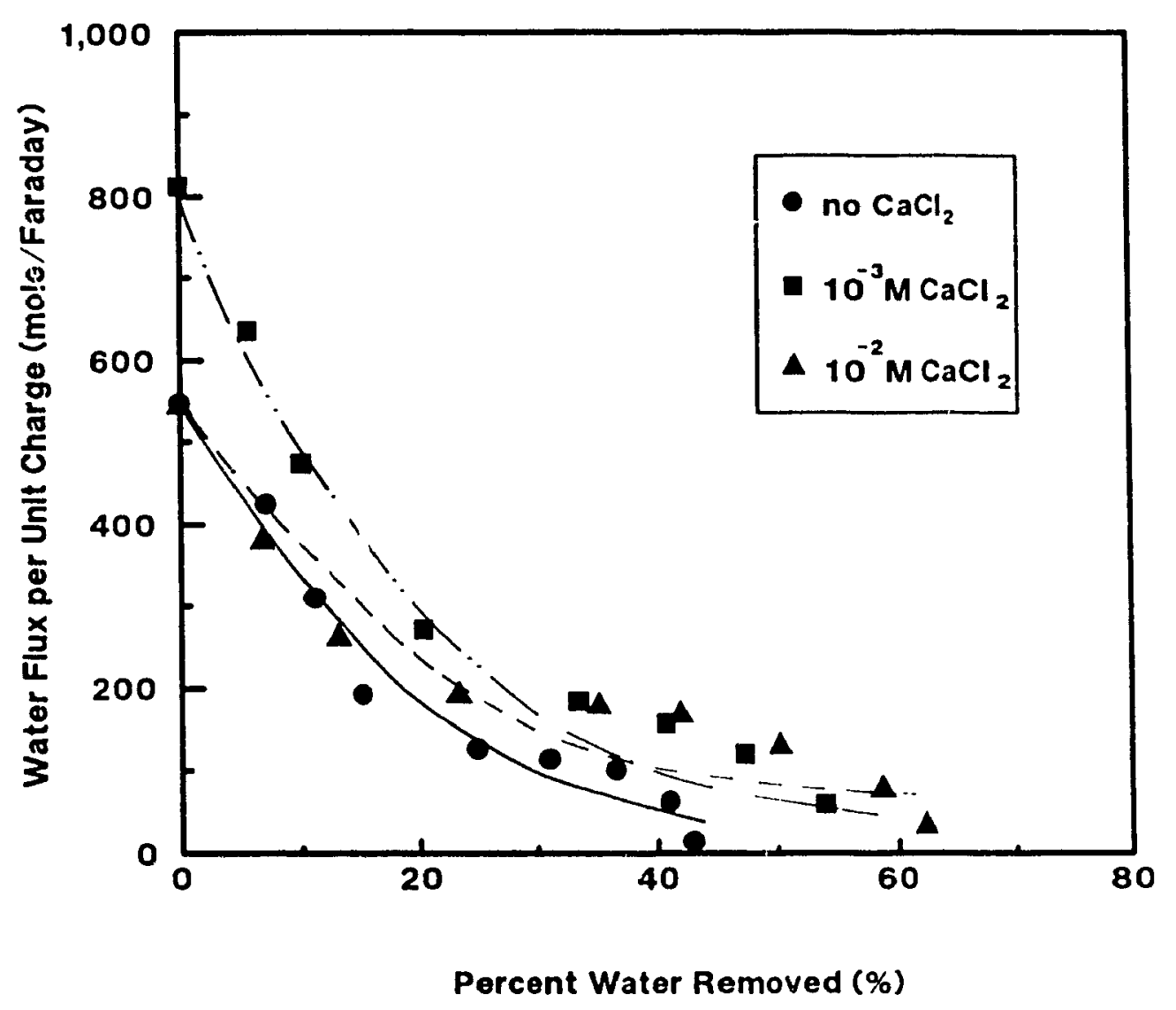

$\left(S_{0}=9.1 w t \% ; H_{0}=2.0 \mathrm{~cm} ; V_{0}=5.5 \mathrm{~V}\right)$

Figure 3-9 Variation of Water Transported per Unit Charge with Percent Water Removed 


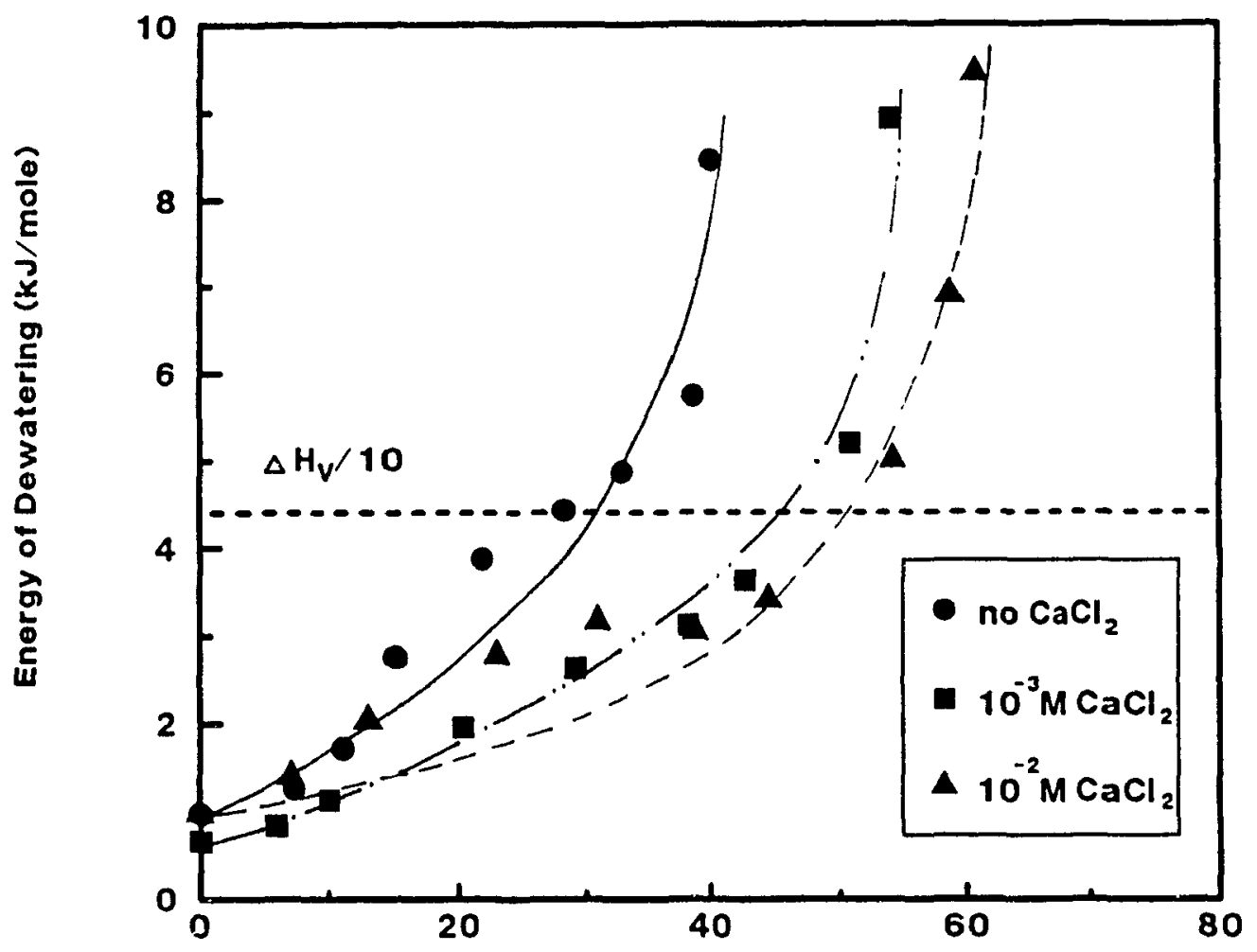

Percent Water Removed (\%)

$\left(S_{0}=9.1 w t \% ; H_{0}=2.0 \mathrm{~cm} ; V_{0}=5.5 \mathrm{v}\right)$

Figure 3-10 Energy of Dewatering vs Percent Water Removed 


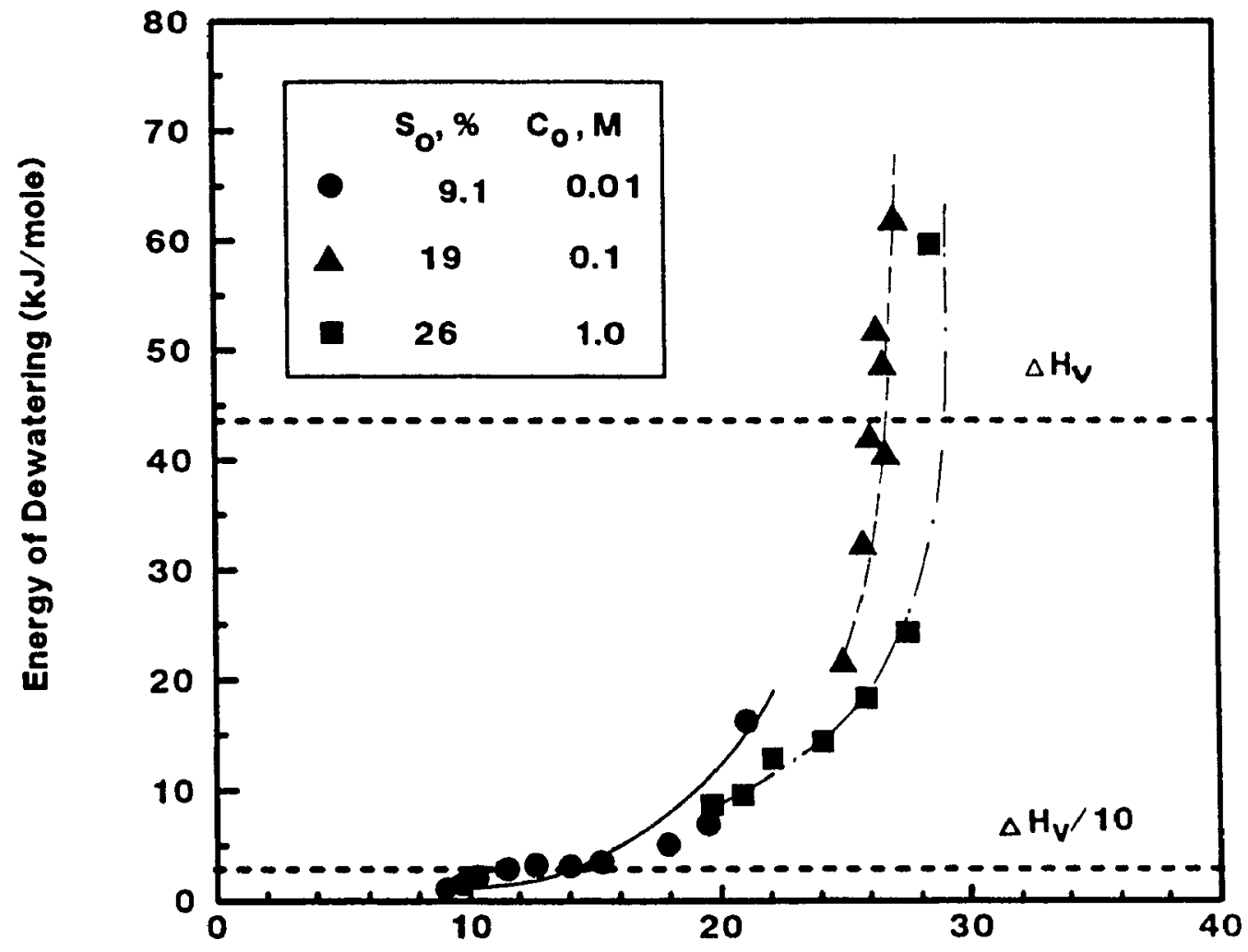

Average Solld Content of the Bed (wt\%)

Figure 3-11 Energy of Dewatering vs Average Solid Content of the Bed 
of percent water removed. The single dashed horizontal line in Fig.3-10 represents $10 \%$ of the latent heat of evaporation of water $\Delta \mathrm{H}_{v}$, which is $43.8 \mathrm{~kJ} / \mathrm{mole}$. Two horizontal lines are shown in Fig. 3-11; the lower one is at $10 \%$ of $\Delta \mathrm{H}_{v}$ while the upper one is at $\Delta \mathrm{H}_{v}$. These reference lines show that significant amounts of water were removed with low energy expenditure. As water removal continued, the energy expenditure increased dramatically. By the end of dewatering, the energy consumption exceeded the heat of vaporization. Figure 3-10 shows that, for $C_{o} \leq$ $10^{2} \mathrm{M} \mathrm{CaCl}_{2}$, the initial removal of a mole of water by electroosmosis required only about $2 \%$ of the energy of evaporation, but as water was removed, the energy of dewatering increased. Without $\mathrm{CaCl}_{2}$, the energy of dewatering exceeded the heat of vaporization of water at about $40 \%$ water removed while for $10^{3} \mathrm{M}$ it was about $54 \%$ and for $10^{2} \mathrm{M}$, about $63 \%$. Figure $3-11$ shows results for $0.01,0.1$ and $1 \mathrm{M}$ $\mathrm{CaCl}_{2}$. At the two higher concentrations there was considerable coagulation of the Bentonite particles and suspensions of 9.1 wt \% solids drained by gravity. Gravity drainage before electroosmotic dewatering gave cakes of $19 \mathrm{wt} \%$ and $26 \mathrm{wt} \%$ solids for 0.1 and $1 \mathrm{M} \mathrm{CaCl}_{2}$, respectively. Electroosmotic dewatering removed additional water, but Fig. 3-11 shows that the energy of dewatering was very high. The initial current was also very high, approximately $350 \mathrm{~mA}$, and the bed became warm by Joule heating.

\subsection{Effect of Applied Voltage}

Figures 3-12 to 3-15 show the effect of the applied voltage on dewatering. All data are for an initial suspension of $9.1 \mathrm{wt} \%$ Bentonite with a height of $2.0 \mathrm{~cm}$. Distilled water was used to make up the suspensions. 


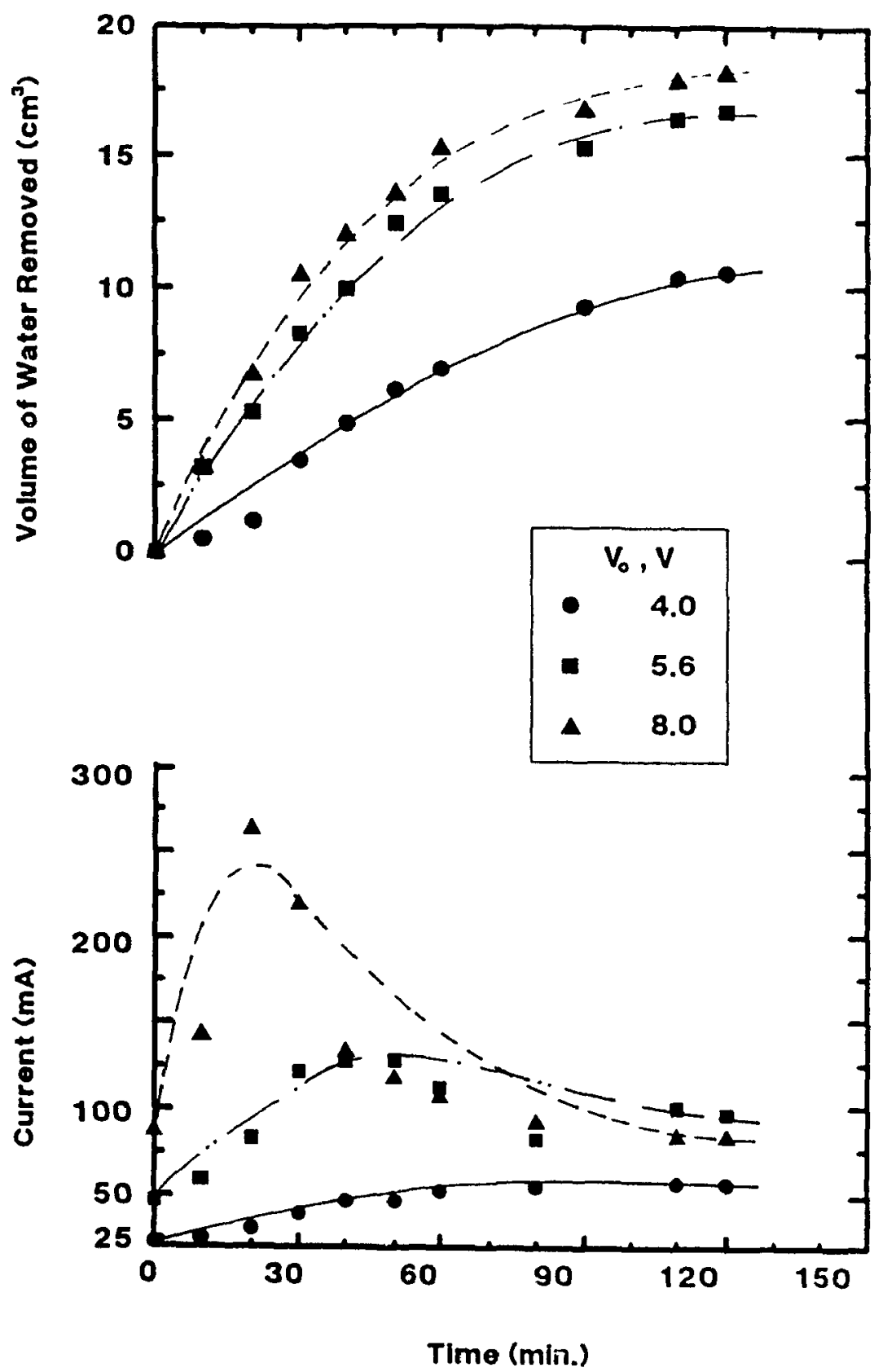

$\left(S_{0}=9.1 w t \% ; C_{0}=0 \mathrm{M} ; H_{0}=2.0 \mathrm{~cm}\right)$

Figure 3-12 Water Removed and Current vs Time for Various Applied Voltage 


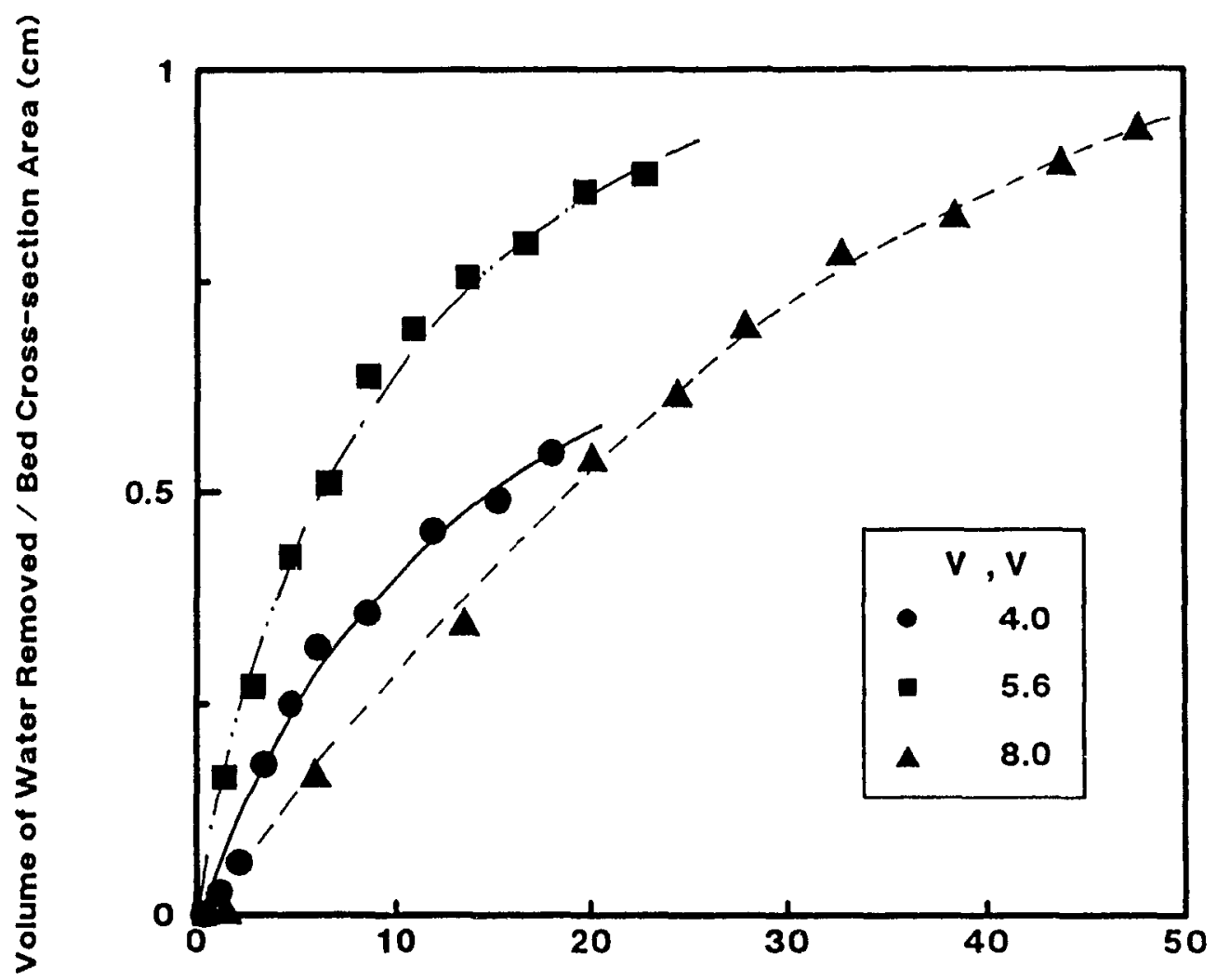

Total Charge Passed / Bed Cross-section Area $\left(A \cdot \mathbf{s} / \mathrm{cm}^{2}\right)$

$\left(S_{0}=9.1 w t \% ; C_{0}=0 \mathrm{M} ; H_{0}=2.0 \mathrm{~cm}\right)$

Figure 3-13 Variation of Water Removal with Total Charge 
Figure 3-12 shows the volume of water removed and the current as functions of time. The current and the amount of water removed were larger at higher applied voltages. At 120 minutes $10.7,16.8$ and $18.2 \mathrm{~cm}^{3}$ of water were removed at $4.0,5.5$ and $8.0 \mathrm{~V}$, respectively. In Fig. 3-13 the water removal data are plotted as volume of witer removed per unit bed cross sectional area against total charge passed per unit bed cross sectional area. For the same total charge, the voltage of $5.5 \mathrm{~V}$ gave highest water removal. Less water was removed at lower $(4.0 \mathrm{~V})$ and higher $(8.0 \mathrm{~V})$ voltages. Figure 3-14 shows the data plotted as the water flux per unit charge against percent water removed. The intermedate voltage of $5.5 \mathrm{~V}$ gave highest water flux until very near the end of the run. The water flux at the highest voltage was initially low, but it changed relatively little after $15 \%$ of the water was removed.

Figure 3-15 shows the variation of the energy of dewatering with percent water removed. A voltage of $8.0 \mathrm{~V}$, gave the highest energy expenditure. Both $4.0 \mathrm{~V}$ and 5.6 $\mathrm{V}$ applied voltage gave the same water removal with the same energy consumption until about $20 \%$ water removed.

\subsection{Effect of Initial Bed Height}

Figures 3-16 to 3-21 show the effect of the initial height of the bed on dewatering. In all cases the original suspensions contained 9.1 wt $\%$ Bentonite in $10{ }^{3} \mathrm{M} \mathrm{CaCl}_{2}$. A different voltage was applied for each height. The initial overall field strength, defined as the applied voltage divided by the initial bed height, was fixed at 2.75 $\mathrm{V} / \mathrm{cm}$. The voltage applied cross a bed of $1 \mathrm{~cm}$ initial height was $2.75 \mathrm{~V}$, across a bed of $2.1 \mathrm{~cm}$ height, $5.8 \mathrm{~V}$, etc.

Figure 3-16 shows the volume of water removed as function of time for varmus of 


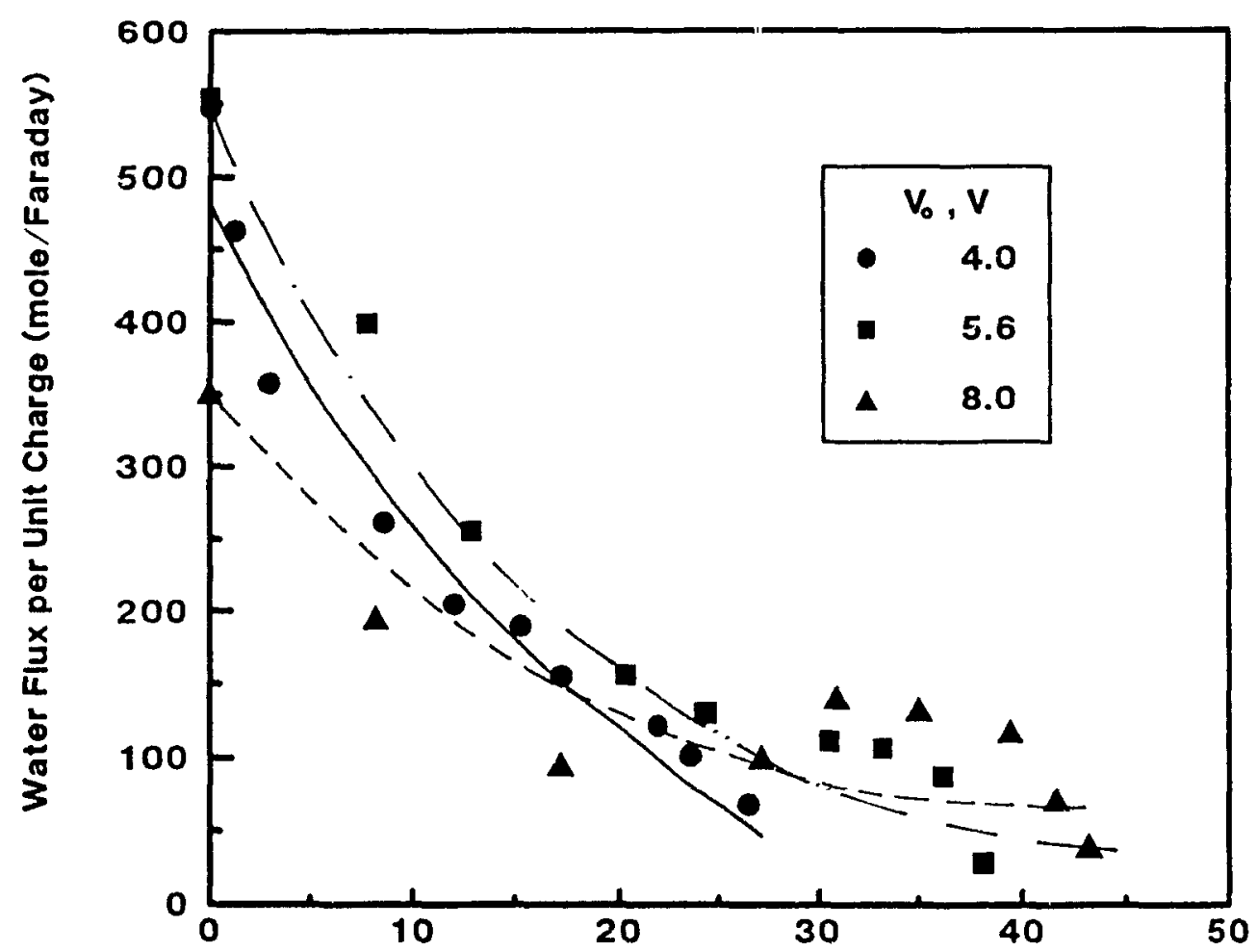

Percent Water Removed (\%)

$\left(S_{0}=9.1 w t \% ; C_{0}=0 \mathrm{M} ; H_{0}=2.0 \mathrm{~cm}\right)$

Figure 3-14 Variation of Water Transported per Unit Charge with Percent Water Removed 


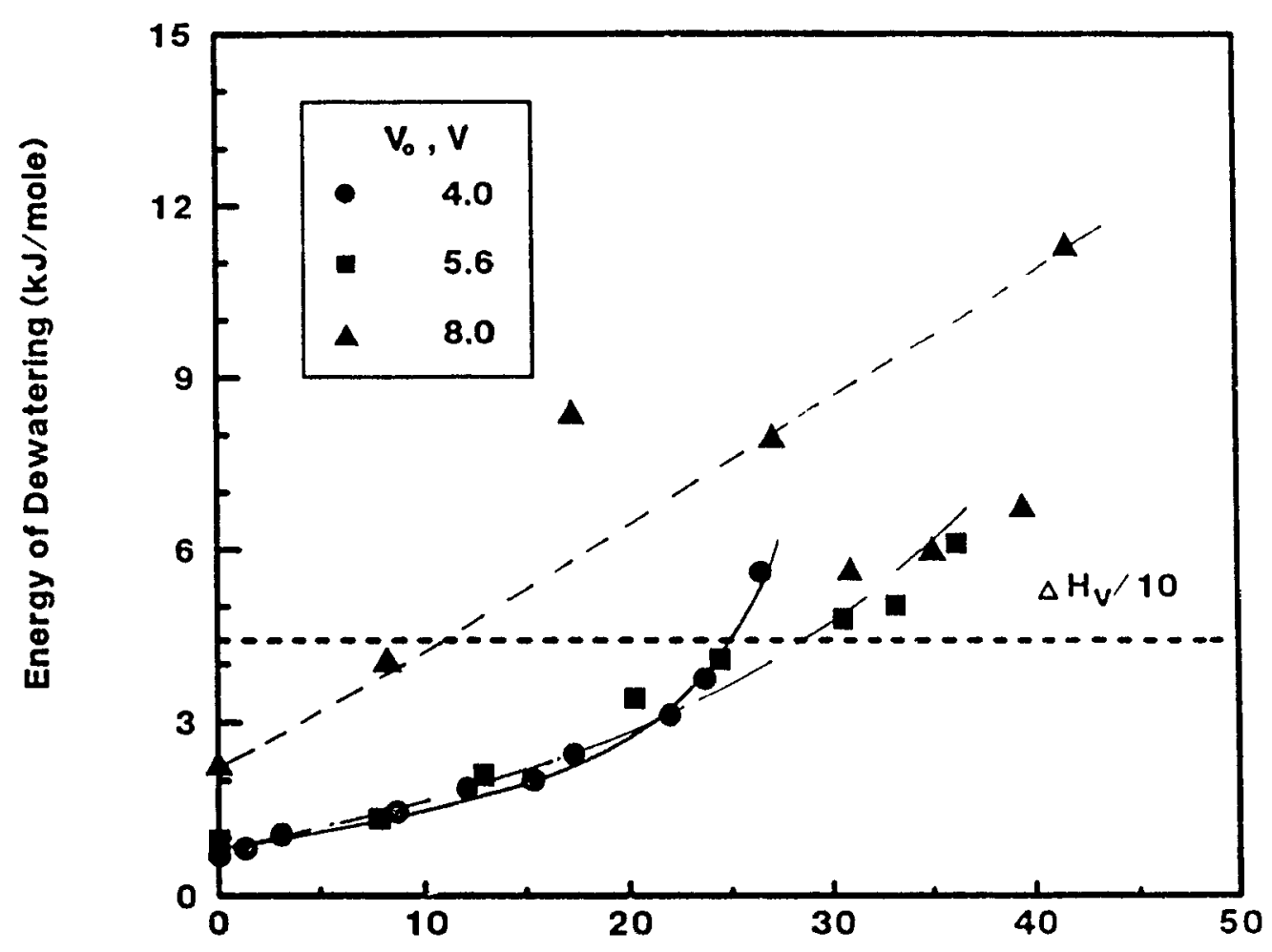

Percent Water Removed (\%)

$\left(S_{0}=9.1 w t \% ; C_{0}=0 M ; H_{0}=2.0 \mathrm{~cm}\right)$

Figure 3-15 Energy of Dewatering vs Percent Water Removed 


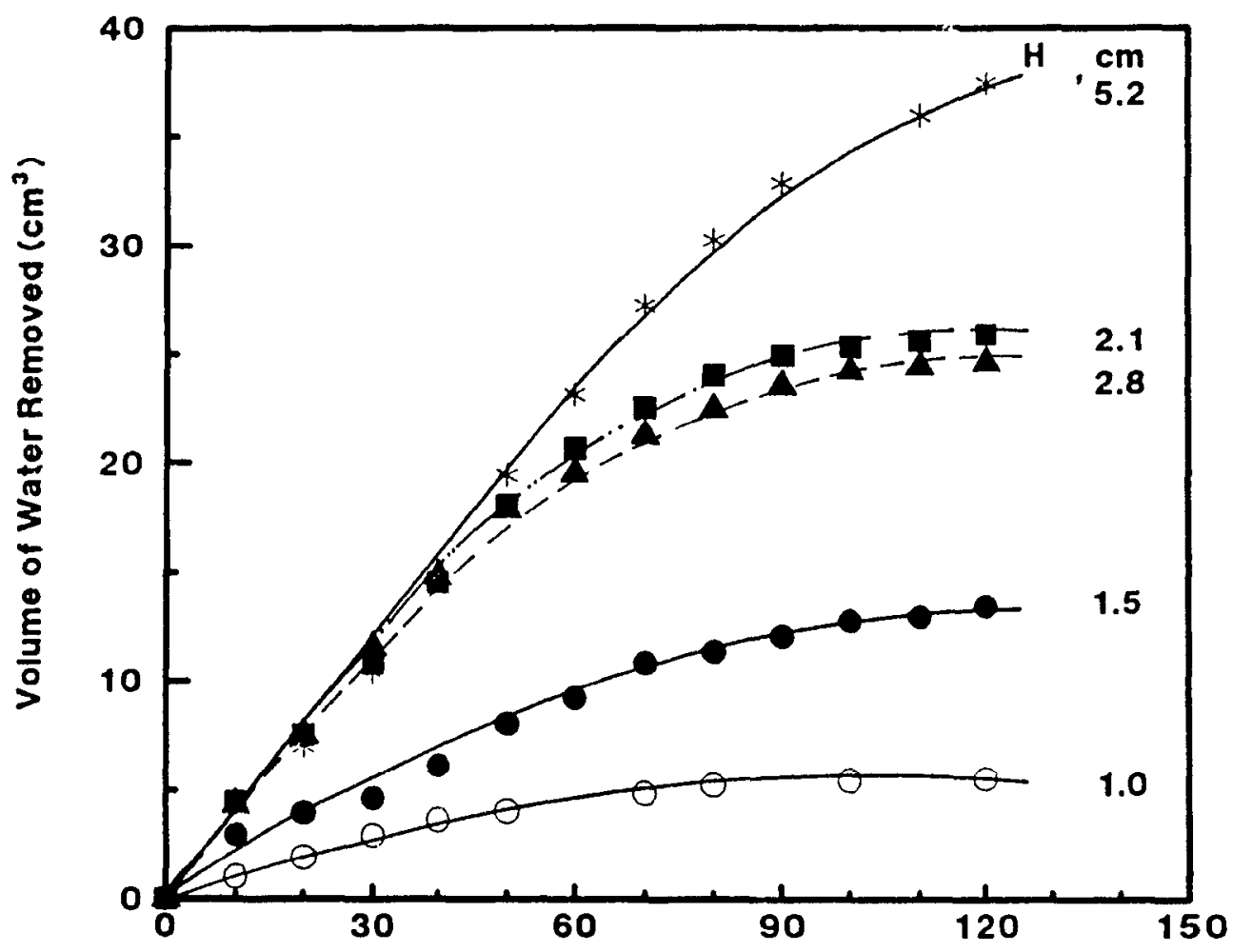

Time (min.)

$\left(S_{0}=9.1 w t \% ; C_{0}=10^{-3} \mathrm{M} ; E_{0}=2.8 \mathrm{~V} / \mathrm{cm}\right)$

Figure 3-16 Volume of Water Removed vs Time for Different Initial Heights 
initial bed heights. At any given time within the first 40 minutes of dewatering, the volumes of water removed are about the same for initial bed heights of $2.1,2.8$ and $5.2 \mathrm{~cm}$. Since the $5.2 \mathrm{~cm}$ initial bed height contained the largest amount of watter, the initial amount of water removed was highest for the $5.2 \mathrm{~cm}$ bed and lowest for the $1.0 \mathrm{~cm}$ bed. Figure 3-17 shows the voltage drops measures across the upper, middle and lower sections of the $1.0 \mathrm{~cm}$ height of bed. The large voltage drops near the electrodes reduced the field over the middle portion of the bed to about $0.9 \mathrm{~V} / \mathrm{cm}$ over the first 30 minutes of the run. Comparable data are shown in Figure 3-18 for the $2.1 \mathrm{~cm}$ high bed. The field over the middle portion of the bed was approximately $1.3 \mathrm{~V} / \mathrm{cm}$ for the first 30 minutes.

The variation of the current with time for four initial heights is shown in Figure 3-19. At a bed height of $1 \mathrm{~cm}$ the current is small and nearly constant. Large heights show the characteristic current maximum described earlier. At heights above about $2.1 \mathrm{~cm}$, large cracks appeared in the cake after about 30 minutes of electroosmotic dewatering. This led to large and erratic changes in the current as llustrated in the figure for the $2.8 \mathrm{~cm}$ bed. Under these conditions the rates of water removal were lower than for smaller heights.

Figure 3-20 shows the variation of the water flux per unit charge with water removal for several bed heights. The water flux per Faraday decreased with intial bed height. The smallest bed height $1.0 \mathrm{~cm}$ gave extremely large water fluxes per Faraday initially. Figure 3-21 shows the onergy of dewatering for several bed heights. In the $1.0 \mathrm{~cm}$ bed the energy of dewaterng was only $2-3 \%$ of the heat of vaporization, but dewatering stopped at about $23 \%$ water removed. For the $5.2 \mathrm{~cm}$ bed only about $6 \%$ of the water was removed before the energy of dewatering 


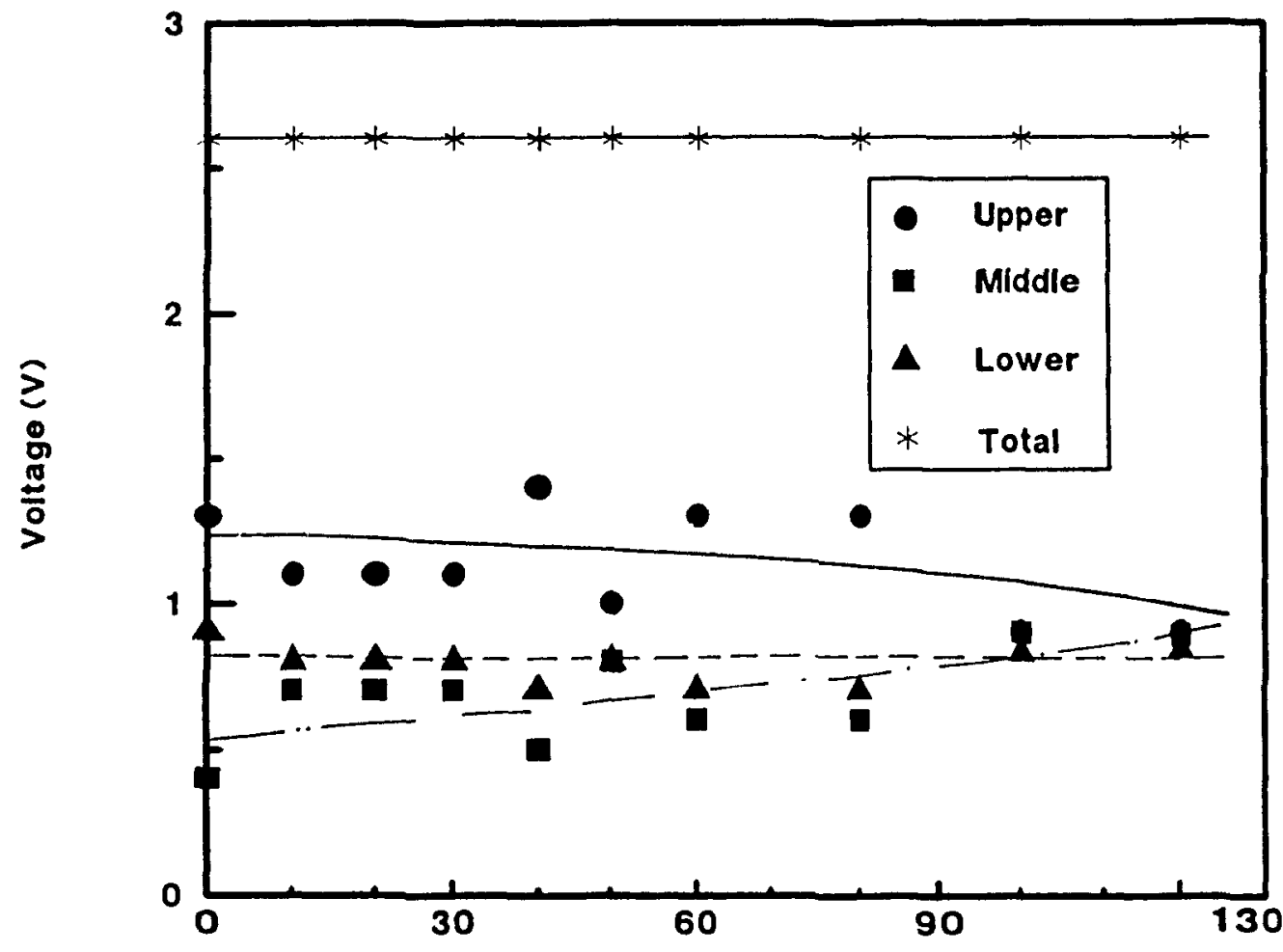

Time (min.)

$$
\left(S_{0}=9.1 w t \% ; C_{O}=10^{-3} \mathrm{M} ; H_{O}=1.0 \mathrm{~cm} ; V_{O}=2.8 \mathrm{~V}\right)
$$

Figure 3-17 Voltage Difference Across Sections of the Bed 


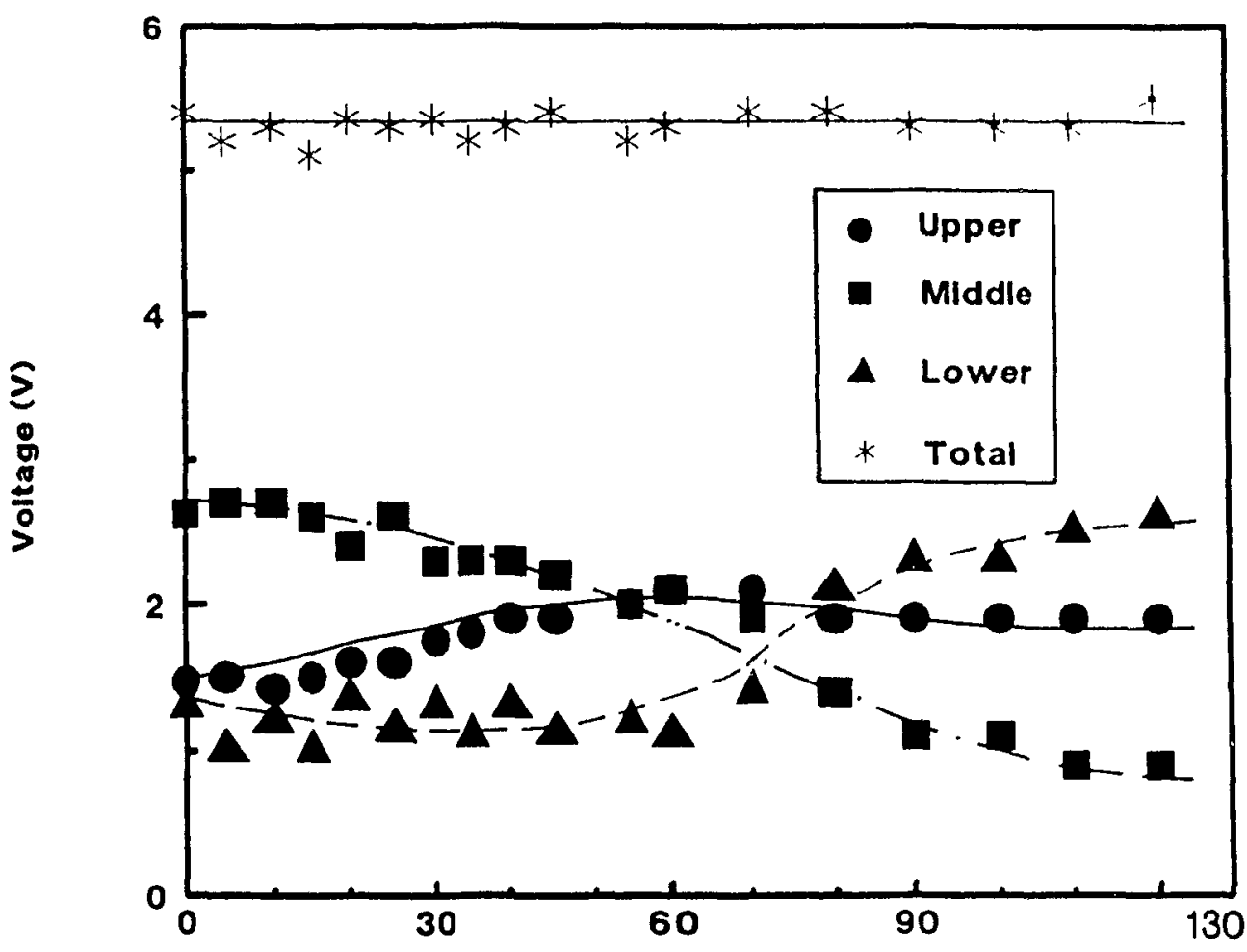

Time (min.)

$$
\left(S_{0}=9.1 w t \% ; C_{0}=10^{-3} M ; H_{0}=2.1 \mathrm{~cm} ; V_{0}=5.8 \mathrm{~V}\right)
$$

Figure 3- 18 Voltage Difference Across Sections of the Bed 


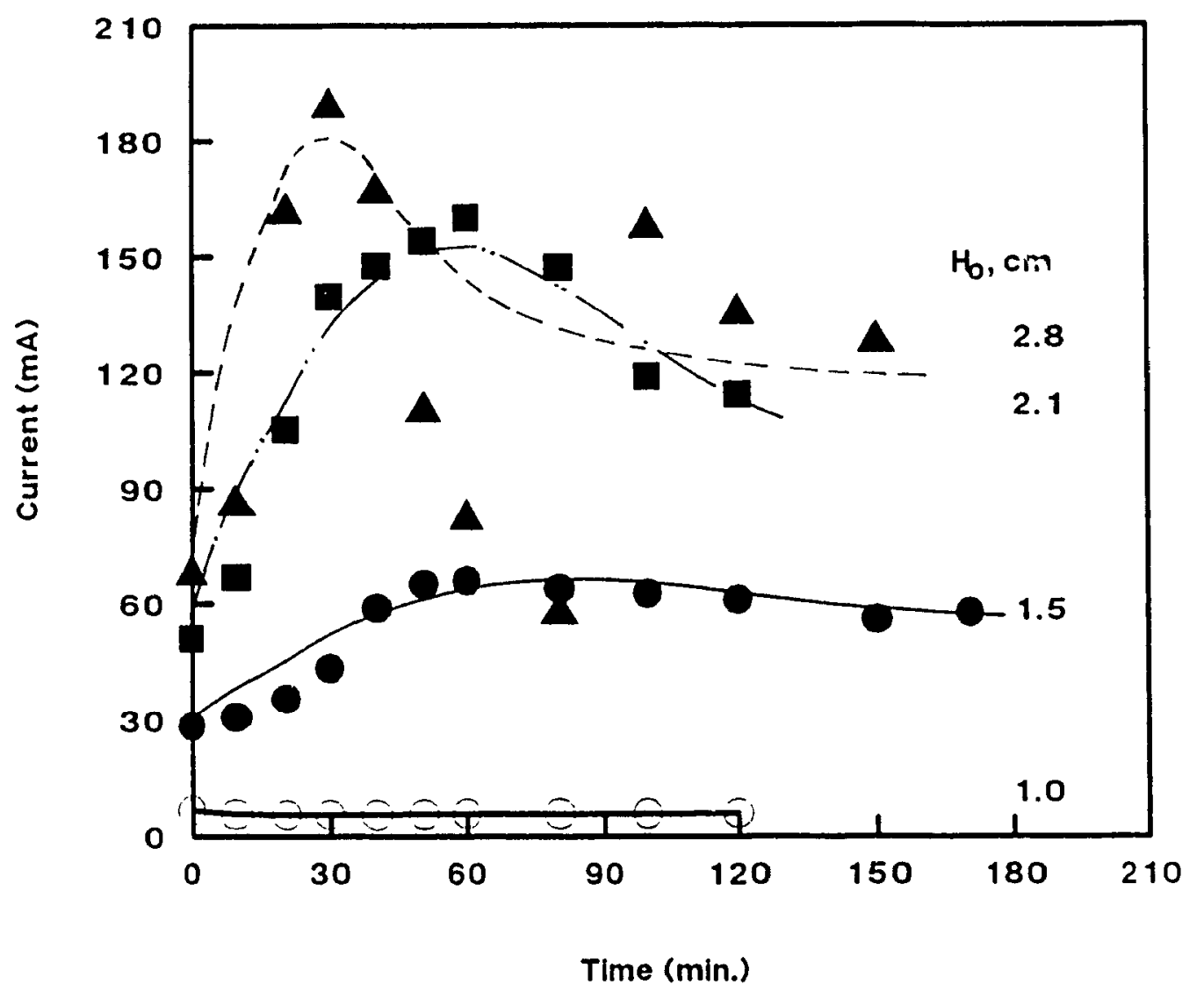

$\left(S_{0}=9.1 w t \% ; C_{0}=10^{-3} \mathrm{M} ; E_{0}=2.8 \mathrm{~V} / \mathrm{cm}\right)$

Figure 3-19 Current vs Time for Different Initial Height of the Bed 


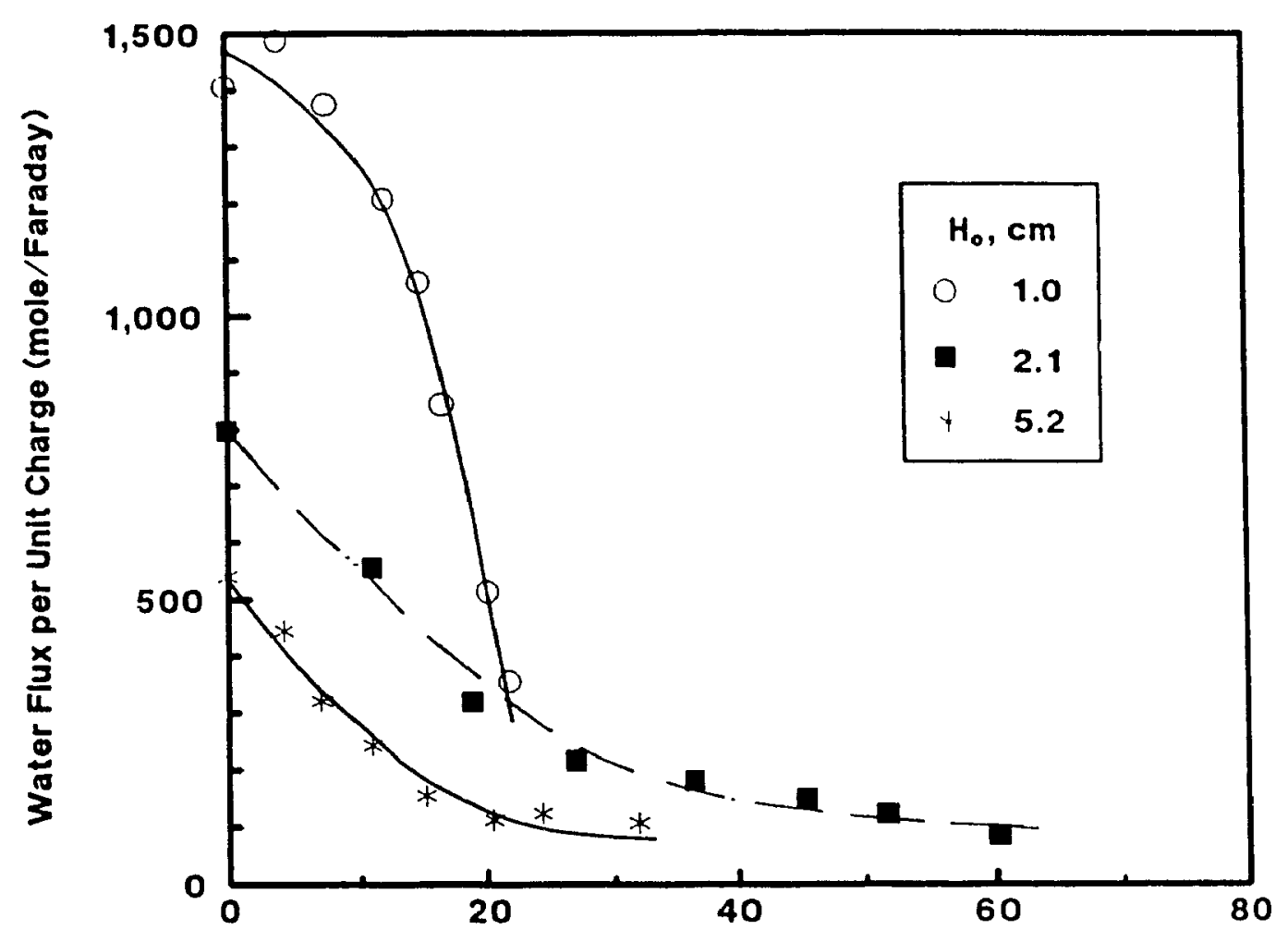

Percent Water Removed (\%)

$\left(S_{0}=9.1 w t \% ; C_{0}=10^{-3} M ; E_{0}=2.8 \mathrm{~V} / \mathrm{cm}\right)$

Figure 3-20 Variation of Water Transported per Unit Charge with Percent Water Removed 


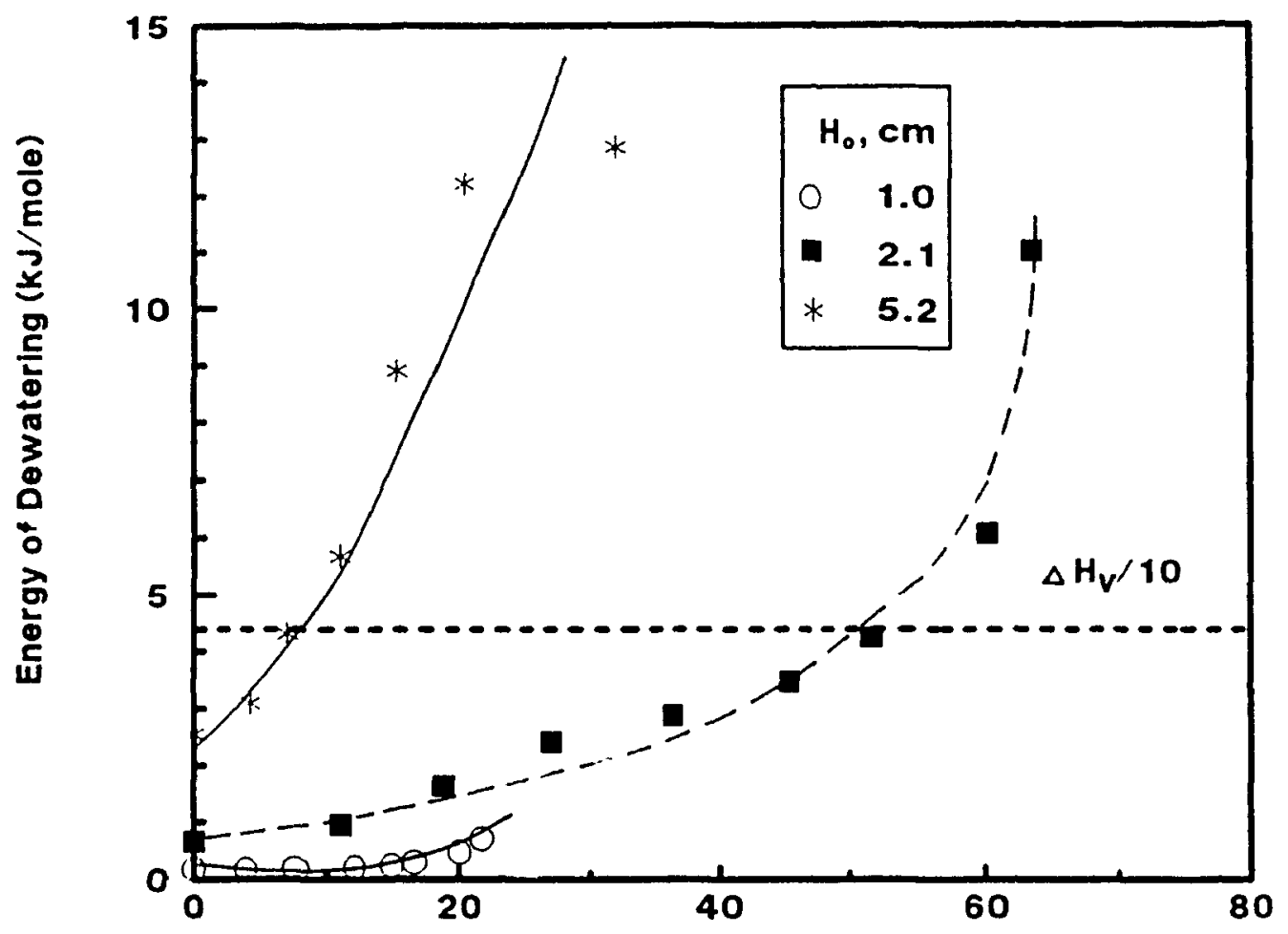

Percent Water Removed (\%)

$\left(S_{0}=9.1 w t \% ; C_{0}=10^{-3} \mathrm{M} ; E_{0}=2.8 \mathrm{~V} / \mathrm{cm}\right)$

Figure 3-21 Energy of Dewatering vs Percent Water Removed 
exceeded $10 \%$ of the heat vaporization. At an initial height of $2.1 \mathrm{~cm} 51 \%$ of the water removed was before the energy of dewatering exceeded $\Delta \mathrm{H}_{\mathrm{V}} / \mathrm{l}$ ).

\subsection{Effect of Initial Solid Content}

The effect of initial solid content is show'n in Figs. 3-22 to 3-24. Two initial solid contents were used: 9.1 and $15.0 \mathrm{wt} \%$ Bentonite in $10^{2} \mathrm{M} \mathrm{CaCl}_{2}$. The beds were initially $2.0 \mathrm{~cm}$ high and the applied voltage was $5.5 \mathrm{~V}$.

Figure 3-22 shows the course of dewatering as the average percent solids in the bed versus time. The two beds were initially uniform at 9.1 and $15.0 \mathrm{wt} \%$. Water was removed more rapidly from the bed containing the smaller initial percent solid until at 130 minutes both beds had similar average solıd contents. Figures 3-23 and 3-24 show that the water flux per unit charge and the energy of dewatering are functions of the average solid content of the bed essentially independent of the initial solid content. 


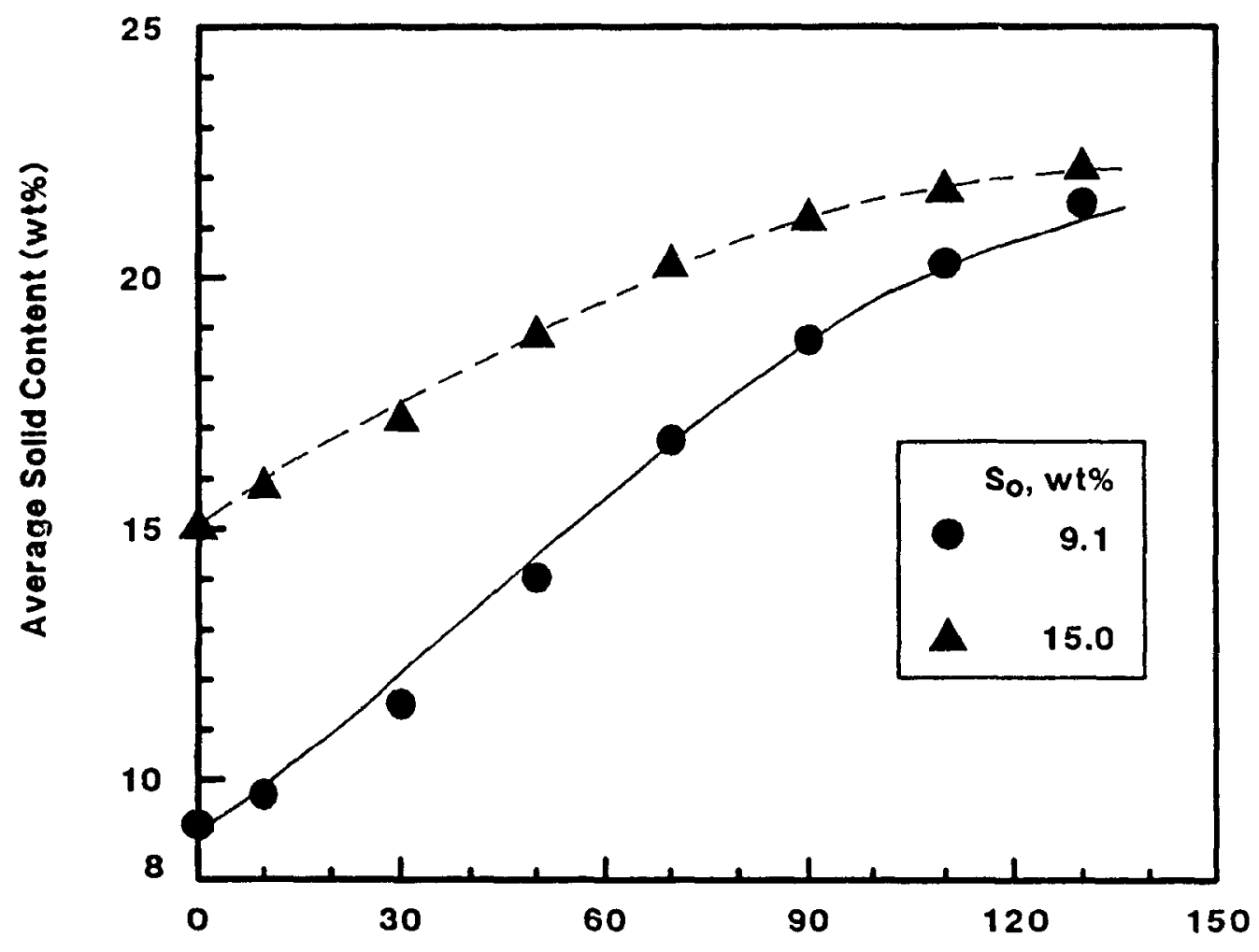

Time (min.)

$$
\left(C_{0}=10^{-2} \mathrm{M} ; H_{0}=2.0 \mathrm{~cm} ; V_{0}=5.5 \mathrm{~V}\right)
$$

Figure 3-22 Average Solid Content of Bed vs Time 


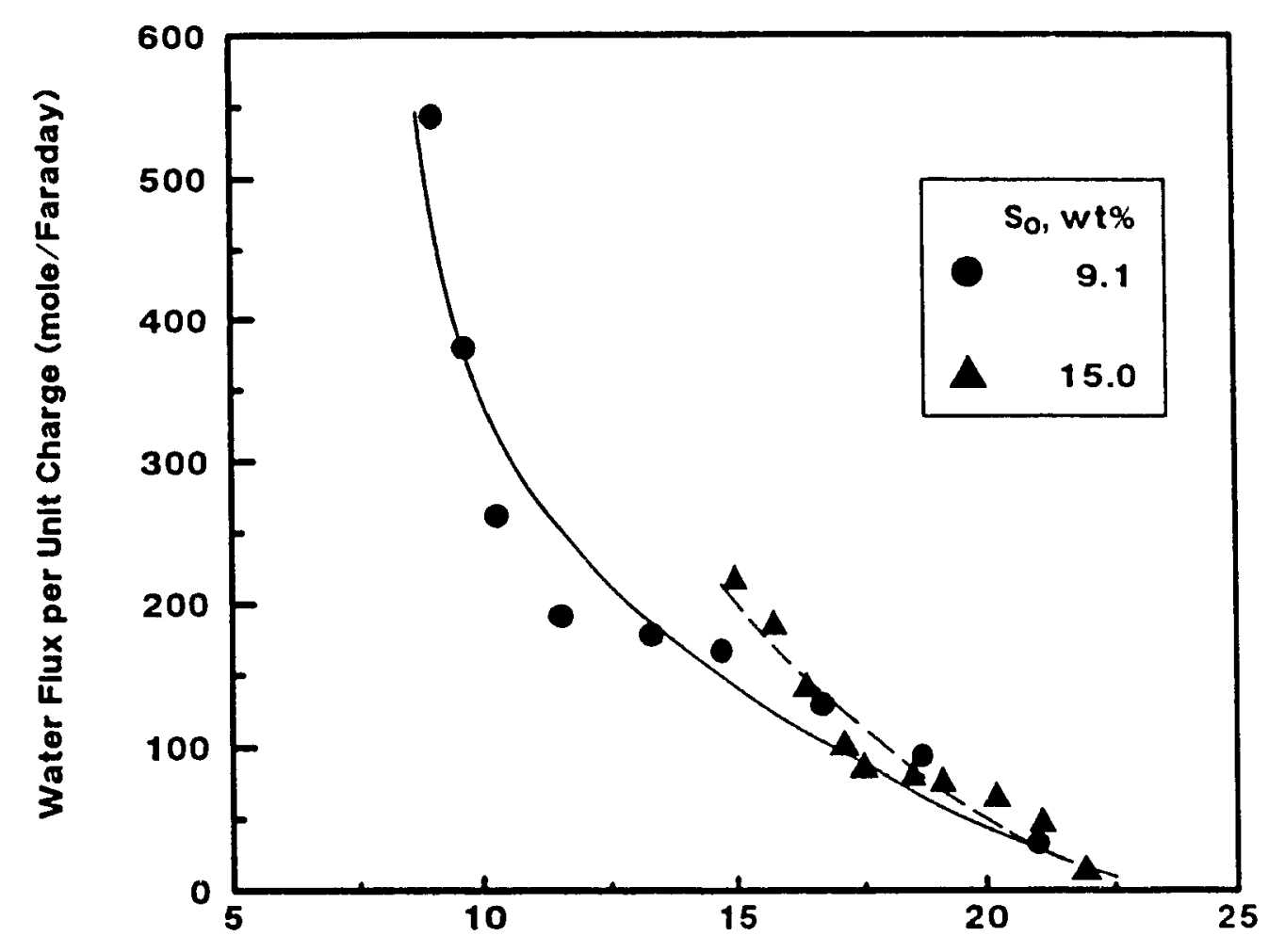

Average Solid Content (wt\%)

$$
\left(C_{0}=10^{-2} \mathrm{M} ; H_{0}=2.0 \mathrm{~cm} ; V_{0}=5.5 \mathrm{~V}\right)
$$

Figure 3-23 Variation of Water Transported per Unit Charge with Average Solid Content of Bed 


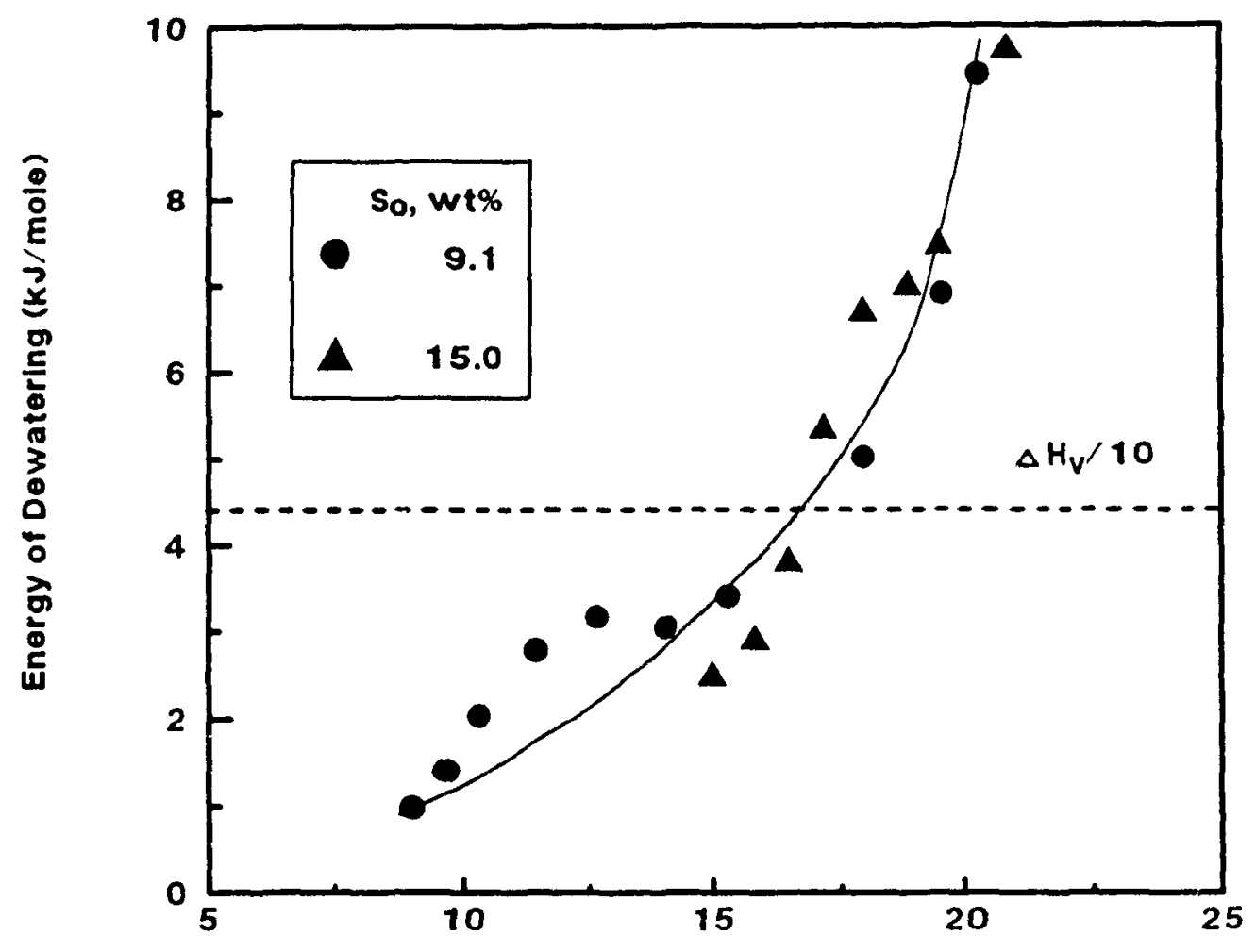

Average Solid Content (wt\%)

$$
\left(C_{0}=10^{-2} \mathrm{M} ; H_{0}=2.0 \mathrm{~cm} ; V_{0}=5.5 \mathrm{~V}\right)
$$

Figure 3-24 Energy of Dewatering vs Average Solid Content of Bed 


\section{CHAPTER 4}

\section{ELECTROOSMOTIC DEWATERING UNDER CONSTANT CURRENT}

The electroosmotic dewatering of Bentonite suspensions under constant applied DC current was studied experimentally and compared with under conditions of constant applied voltage.

\subsection{General Features of Dewatering}

For each experiment the following data were recorded as functions of time: the volume of water removed and the voltage drop across the upper, middle and lower sections of the bed. Three replicates of a typical experiment are presented in Figs 4-1 to $4-5$ for $90 \mathrm{~mA}$ current, $2.0 \mathrm{~cm}$ initial bed height, $9.1 \%$ initial solid content and no $\mathrm{CaCl}_{2}$.

Figure 4-1 shows that the volume of water removed increased approximately linearly for the first 40 minutes and then increased more slowly. The overall voltage drop decreased initially, reached a minimum and then increased (see Fig. 4-2). The voltage drop near the upper electrode was larger than at the lower electrode (see the upper and lower panel in Fig. 4-3). The voltage difference across the middle section of the bed, shown in the middle panel of Fig. 4-3, was approximately one-half of the overall voltage drop.

$-55-$ 


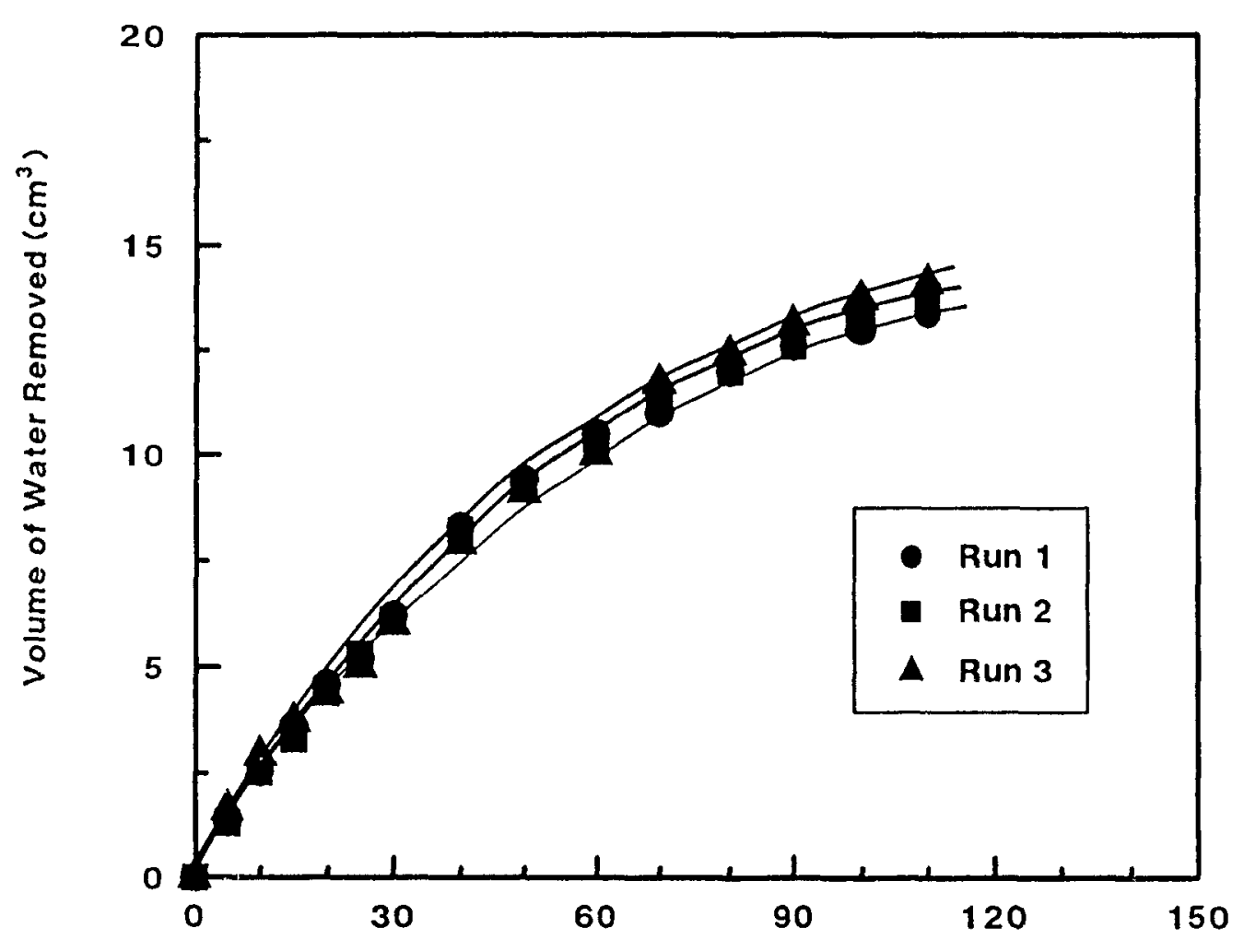

Time (min.)

$$
\left(S_{O}=9.1 w t \% ; C_{0}=O M ; H_{O}=2.0 \mathrm{~cm} ; 1=90 \mathrm{~mA}\right)
$$

Figure 4-1 Volume of Water Removed vs Time 


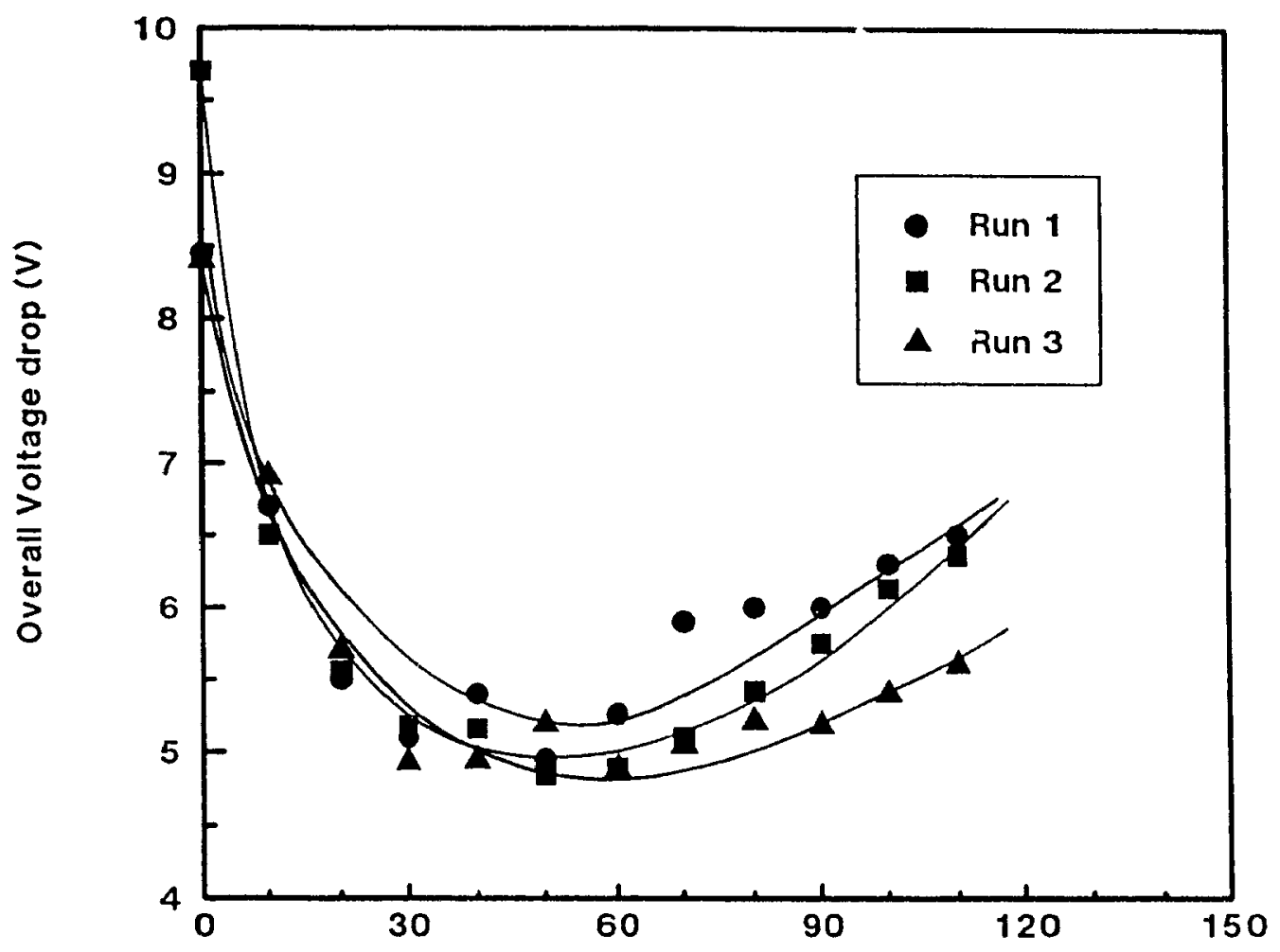

Time (min.)

$$
\left(S_{0}=9.1 w t \% ; C_{0}=0 M ; H_{0}=2.0 \mathrm{~cm} ; I=90 \mathrm{~mA}\right)
$$

Figure 4-2 Variation of Overall Voltage vs Time 

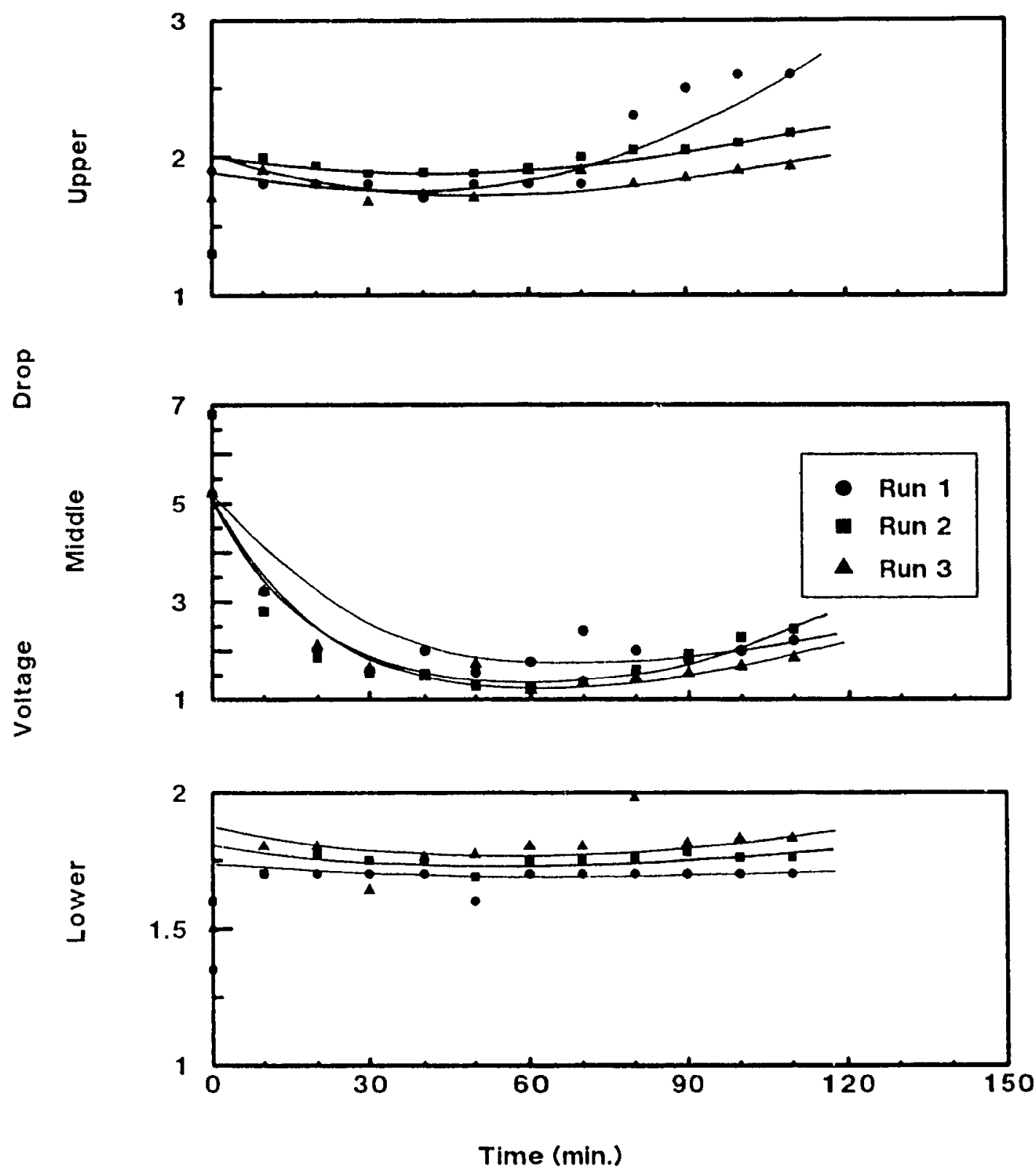

$$
\left(S_{O}=9.1 w t \% ; C_{O}=O M ; H_{O}=2.0 \mathrm{~cm} ; 1=90 \mathrm{~mA}\right)
$$

Figure 4-3 Variation of Voltage Drop Across Three Sections of Bed vs time 
Replicate data for water removed in Fig. 4-1 show good agreement, with the deviation of the data from the average value of approximately $\pm 3 \%$. As discussed in Chapter 3, the voltage data were less reproducible. The maxmum deviation of the data for voltags drop across the middle section was $1 \mathrm{~V}$ from the average value. For the upper and lower sections of the bed only a few points deviated from the average value of approximately $0.5 \mathrm{~V}$.

The data from the replicate runs are also presented in the format of the water flux per unit charge as a function of the percent water removed in Fig. 4-4. The methods of calculation of the parameters from the recorded data are given in Chapter 2. On this plot the deviation of the data from the average value was about $\pm 20 \%$ except very near the end of the run when water flux was small. The energy required to remove a mole of water by electroosmosis is plotted in Fig. 4-5 agannst the percent water removed. The data are reproducible to approximalely $\pm 20 \%$ except near the end of dewatering.

The generai characteristics of dewatering under constant current are shown in Fig. 4-1 to 4-3. The volume of water removed increased nearly linearly over the first 40 minutes whlle the voltage drop across the middle section decreased over the same period. Beyond 40 minutes the rate of water removal decreased while the voltage increased. The dewatering process may be considered to occur in two siages. In the first stage, where in 40 minutes approximately $20 \%$ of the water was removed, the moles of water transported per Faraday decreased about 25\% and the energy of dewatering was low. Beyond $20 \%$ removal the water transported per faraday decreased rapidly and the energy of dewatering increased rapidly. 


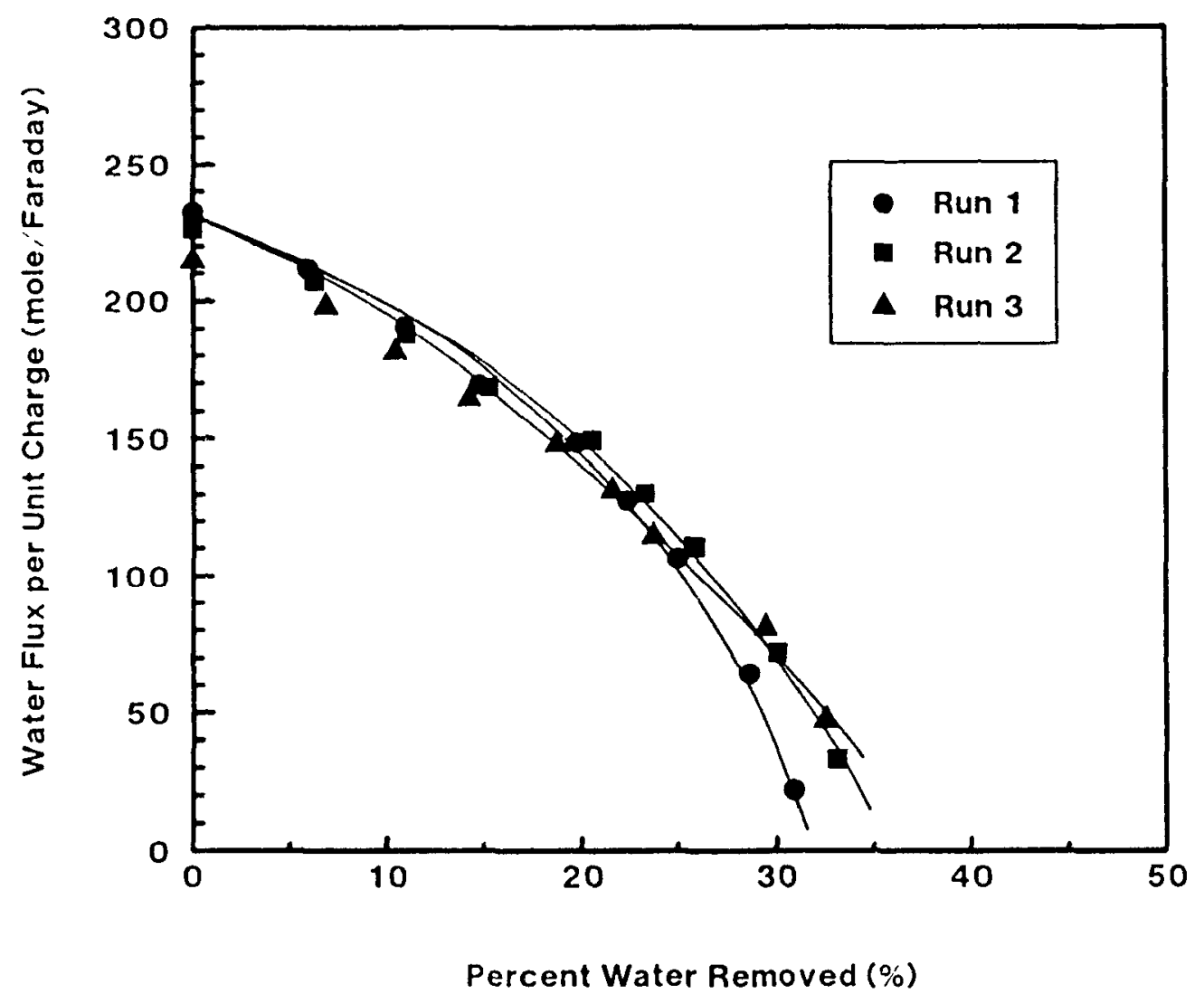

$\left(S_{O}=9.1 w t \% ; C_{O}=0 M ; H_{O}=2.0 \mathrm{~cm} ; \mathrm{I}=90 \mathrm{~mA}\right)$

Figure 4-4 Water Flux per Unit Charge vs Percent Water Removed 


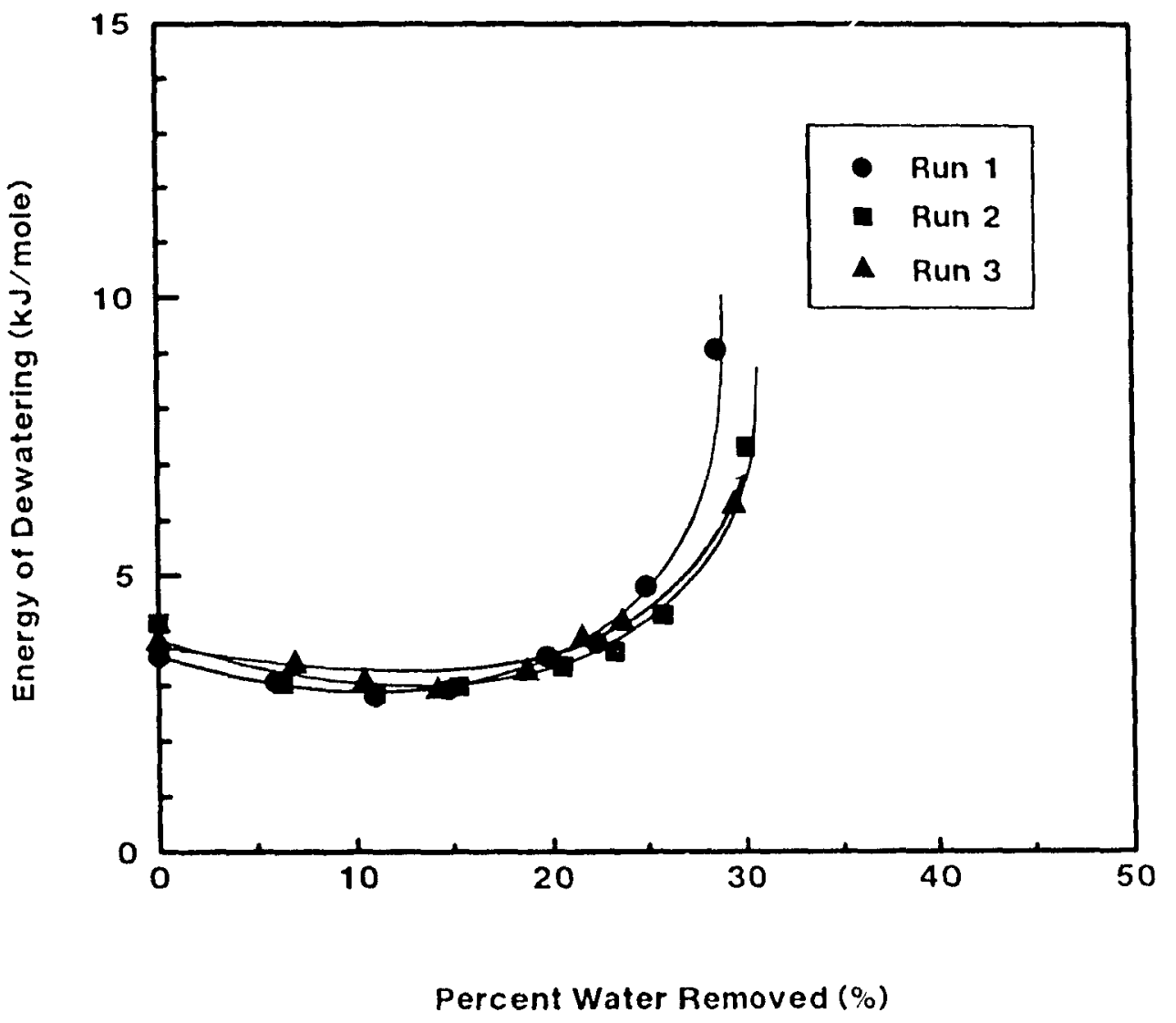

$\left(S_{O}=9.1 w t \% ; C_{0}=0 M ; H_{O}=2.0 \mathrm{~cm} ; 1=90 \mathrm{~mA}\right)$

Figure 4-5 Energy of Dwatering vs Percent Water Removed 


\subsection{Effect of salt concentration}

Figure 4-6 to 4-9 show the effect on dewatering of the $\mathrm{CaCl}_{2}$ concentration in the distilled water used to prepare the suspensions. All data are for an initial concentration of $9.1 \mathrm{wt} \%$ Bentonite, an initial height of $2.0 \mathrm{~cm}$ and a current of 70 $\mathrm{mA}$. The volume of water removed and the voltage drop across the middle section of the bed are shown as functions of time in Fig. 4-6. At higher $\mathrm{CaCl}_{2}$ concentration water is removed more rapidly. At 110 minutes, $13.5,14.8$ and $21.4 \mathrm{~cm}^{3}$ water were collected, corresponding to 33,36 and $42 \%$ water removed for $\mathrm{CaCl}_{2}$ concentrations of $0 \mathrm{M}, 10^{\prime} \mathrm{M}$ and $10^{2} \mathrm{M} \mathrm{CaCl}_{2}$, respectively. Figure 4-7 shows the same data plotted as the volume of water removed per unit bed cross sectional area against the total charge passed per unit bed cross sectional area. At higher $\mathrm{CaCl}_{2}$ concentrations, more water was removed per unit charge.

The data plotted as the water flux per Faraday of charge against the percent water removed are shown in Fig. 4-8. At higher $\mathrm{CaCl}_{2}$ concentrations more water transported per unit charge at the same percent water removed. Figure 4-9 shows that the energy of dewatering was not affected by salt concentration until $20-25 \%$ of the water was removed. With higher $\mathrm{CaCl}_{2}$ concentration more water was removed when dewatering stopped.

\subsection{Effect of applied DC current}

Figure 4-10 to 4-13 show the effect of applied current on dewatering. All data are for initial suspensions of $9.1 \mathrm{wt} \%$ Bentonite in distilled water with an initial height of 


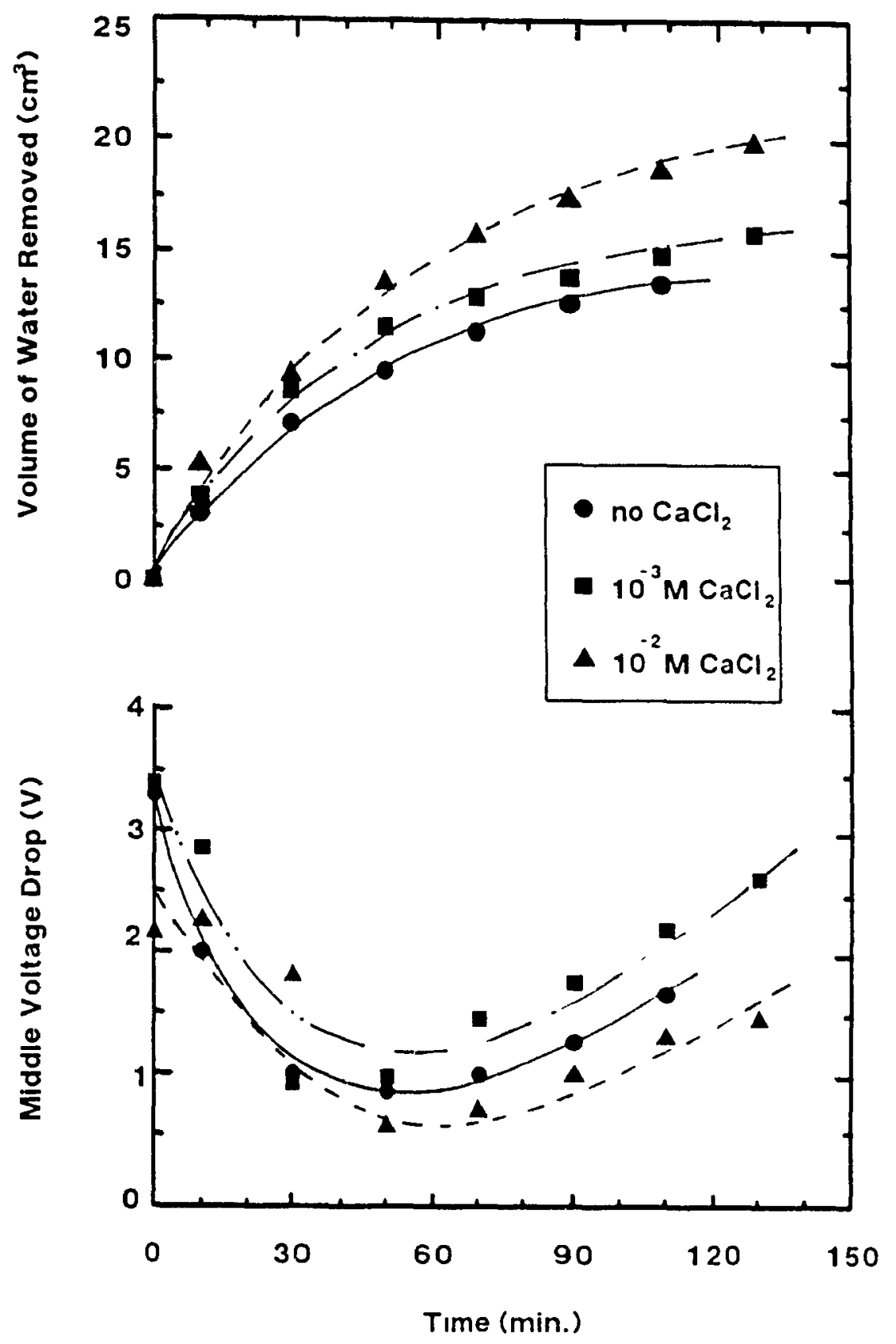

$$
\left(S_{0}=9.1 w t \% ; H_{0}=2.0 \mathrm{~cm} ; 1=70 \mathrm{~mA}\right)
$$

Figure 4-6 Water Removed and Voltage vs Time for Various $\mathrm{CaCl}_{2}$ Concentrations 


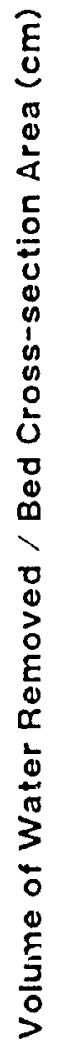

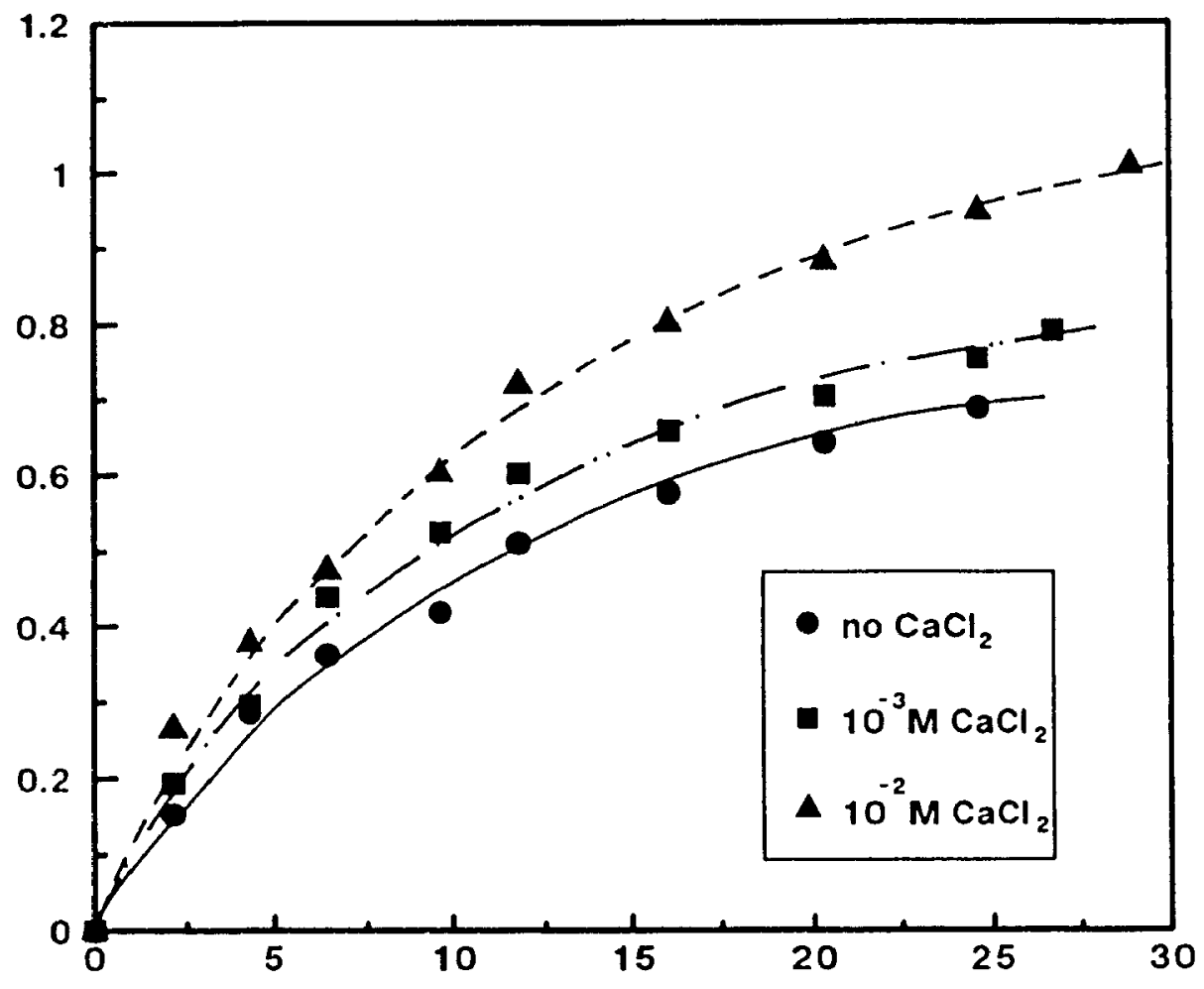

Total Charge Passed / Bed Cross-section Area (A.s/ $\mathrm{cm}^{2}$ )

$\left(S_{0}=9.1 w t \% ; H_{0}=2.0 \mathrm{~cm} ; 1=70 \mathrm{~mA}\right)$

Figure 4-7 Variation of Water Removal with Total Charge 


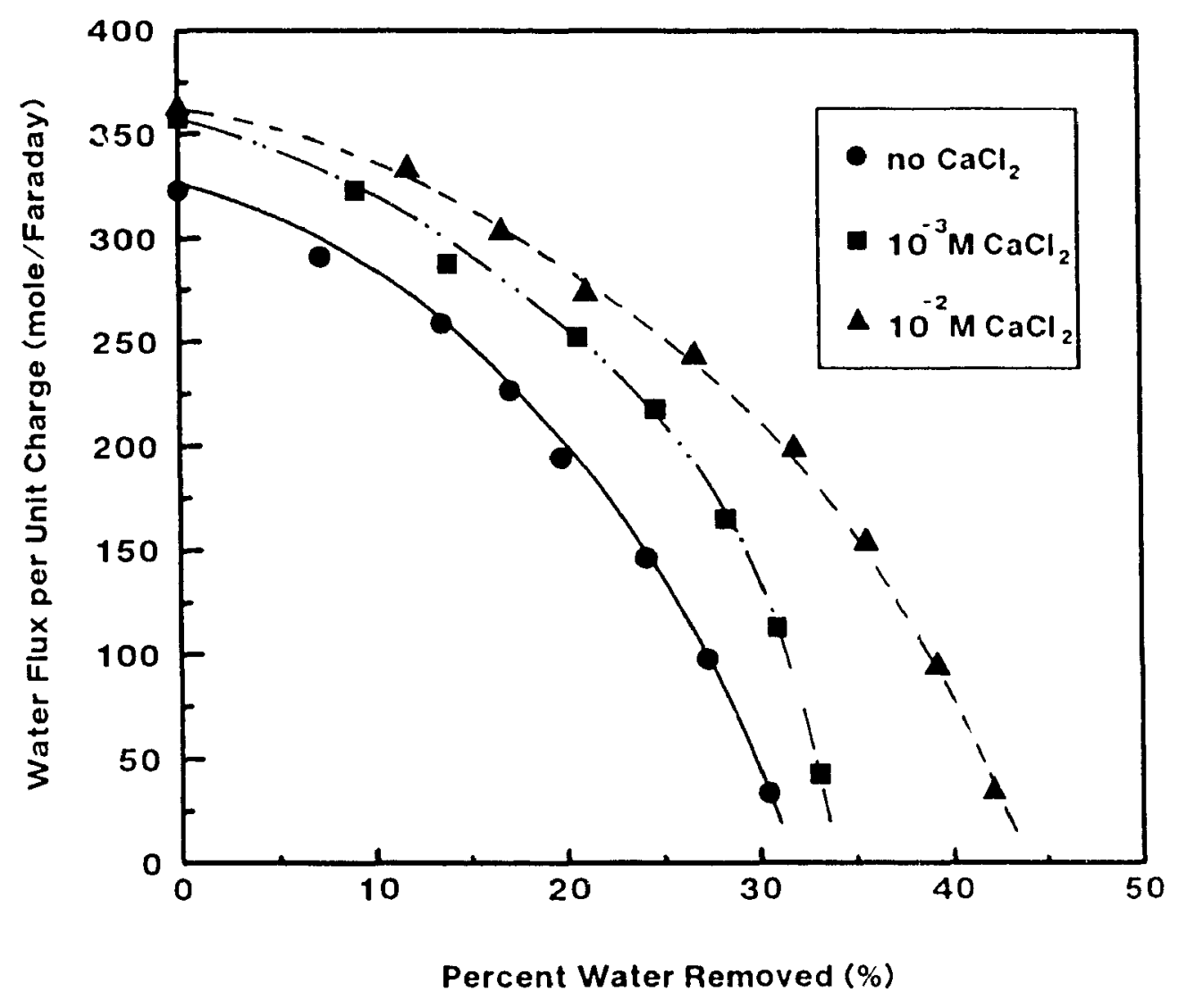

$\left(S_{0}=9.1 w t \% ; H_{0}=2.0 \mathrm{~cm} ; 1=70 \mathrm{~mA}\right)$

Figure 4-8 Variation of Water Transported per Unit Charge with Percent Water Removed 


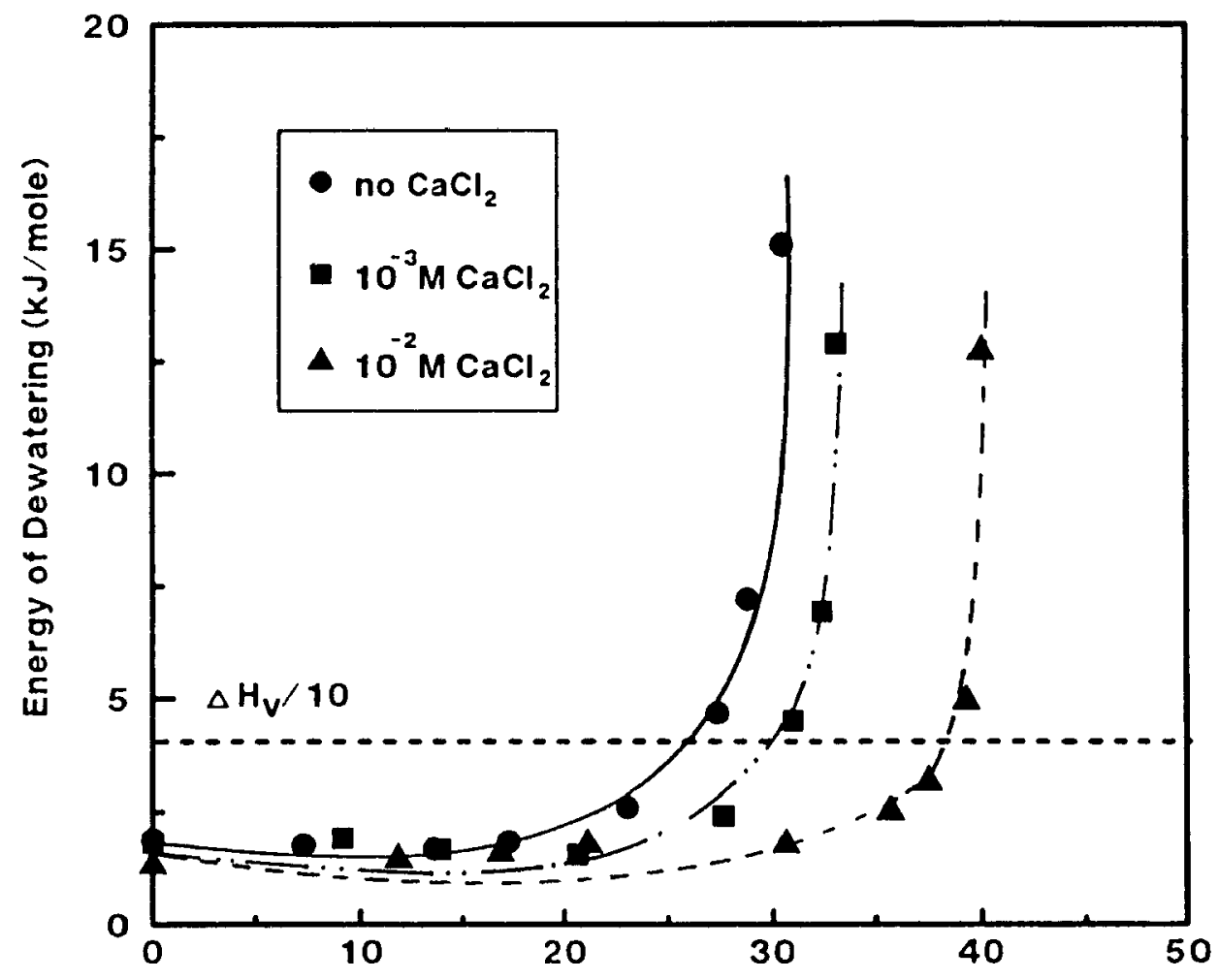

Percent Water Removed (\%)

$\left(S_{0}=9.1 w t \% ; H_{0}=2.0 \mathrm{~cm} ; 1=70 \mathrm{~mA}\right)$

Figure 4-9 Energy of Dewatering vs Percent Water Removed 
$2.0 \mathrm{~cm}$. Figure $4-10$ shows the water removed and the voltage drop across the middle section of the bed as functions of time. At higher applied current larger amounts of water were removed. At 110 minutes $10.6,13.8$ and $16.7 \mathrm{~cm}^{3}$ of water were removed, corresponding to 27,34 and $40 \%$ water removal, at currents of 70,90 and $110 \mathrm{~mA}$, respectively. In Figure 4-11 the water removal data are plotted as the volume of water removed per unit bed cross sectıonal area against the total charge passed divided by the cross sectional area. Near the beginning of dewatering approximately the same amount of water was removed by the same total charge for these three runs. With increasing current more water was removed at the end of dewatering. Figure 4-12 shows the data plotted as the water flux per unit charge against the percent water removed. A current of $90 \mathrm{~mA}$ gave highest water flux per unit charge initially while $110 \mathrm{~mA}$ gave lowest. However the decrease of water flux per unit charge was less drastic at a current $110 \mathrm{~mA}$. Figure 4-13 shows the variation of the energy of dewatering with percent water removed. The energy expenditure to remove $20 \%$ water was approximately the same for all runs and also was less than $10 \%$ of heat vaporization of water. Since more water was removed with higher current, the energy expenditure increased dramatically at about $25 \%$ removal for 70 $\mathrm{mA}$ and at about $35 \%$ removal for $110 \mathrm{~mA}$.

\subsection{Effect of initial solids content}

The effect of initial solid content is shown in Figs. 4-14 to 4-16. Two initial solid contents were used: 9.1 and $12.0 \mathrm{wt} \%$ Bentonite made up with $10^{2} \mathrm{M} \mathrm{CaCl}_{2}$ in distilled water. The initial bed height was $2.0 \mathrm{~cm}$ and the current was $70 \mathrm{~mA}$.

Figure 4-14 shows the average percent solid in the bed versus time. Water was 


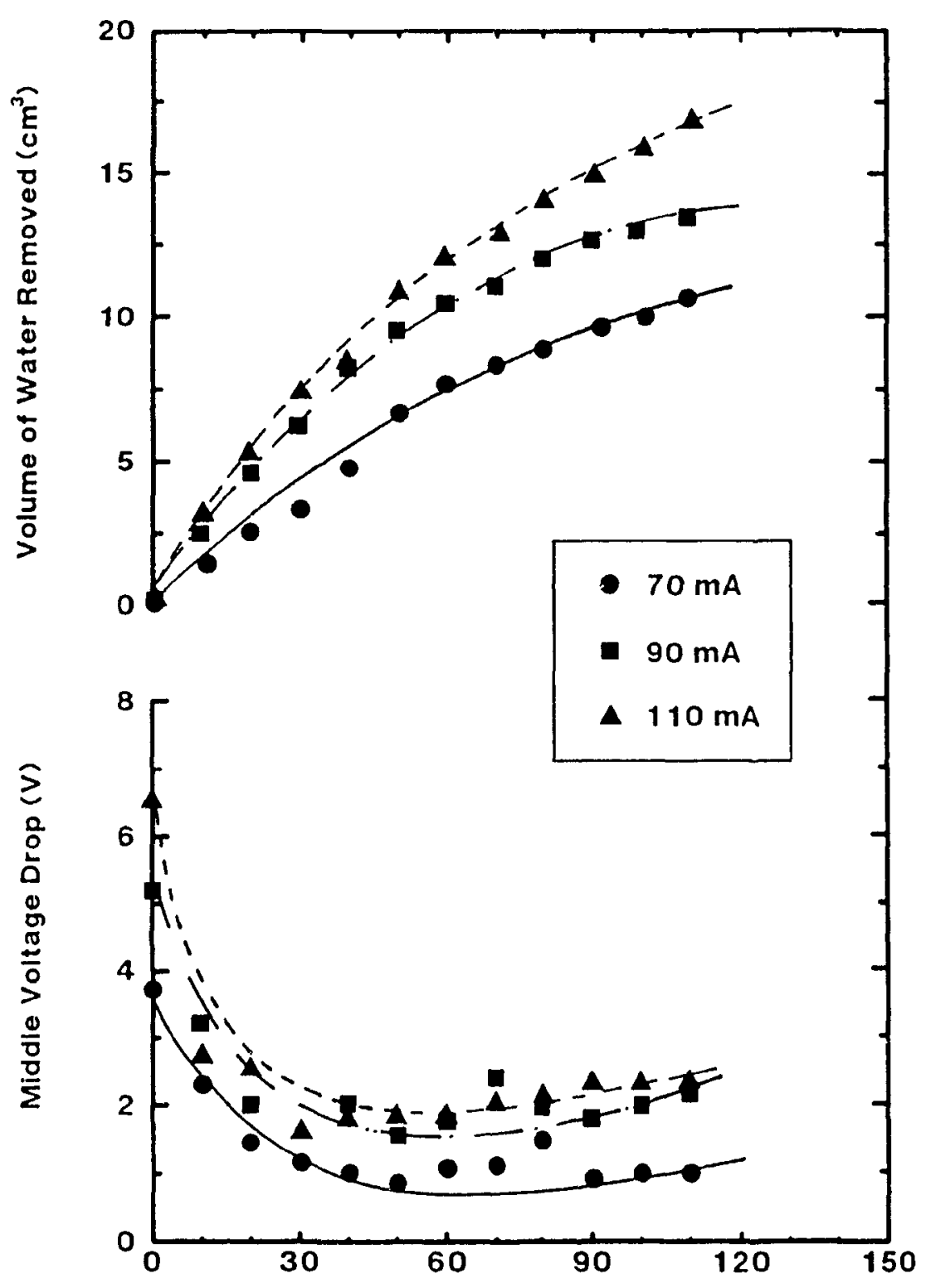

Time (min.)

$\left(S_{0}=9.1 w t \% ; C_{0}=0 \mathrm{M} ; H_{0}=2.0 \mathrm{~cm}\right)$

Figure 4-10 Water Removed and Voltage vs Time for Various Applied Current 


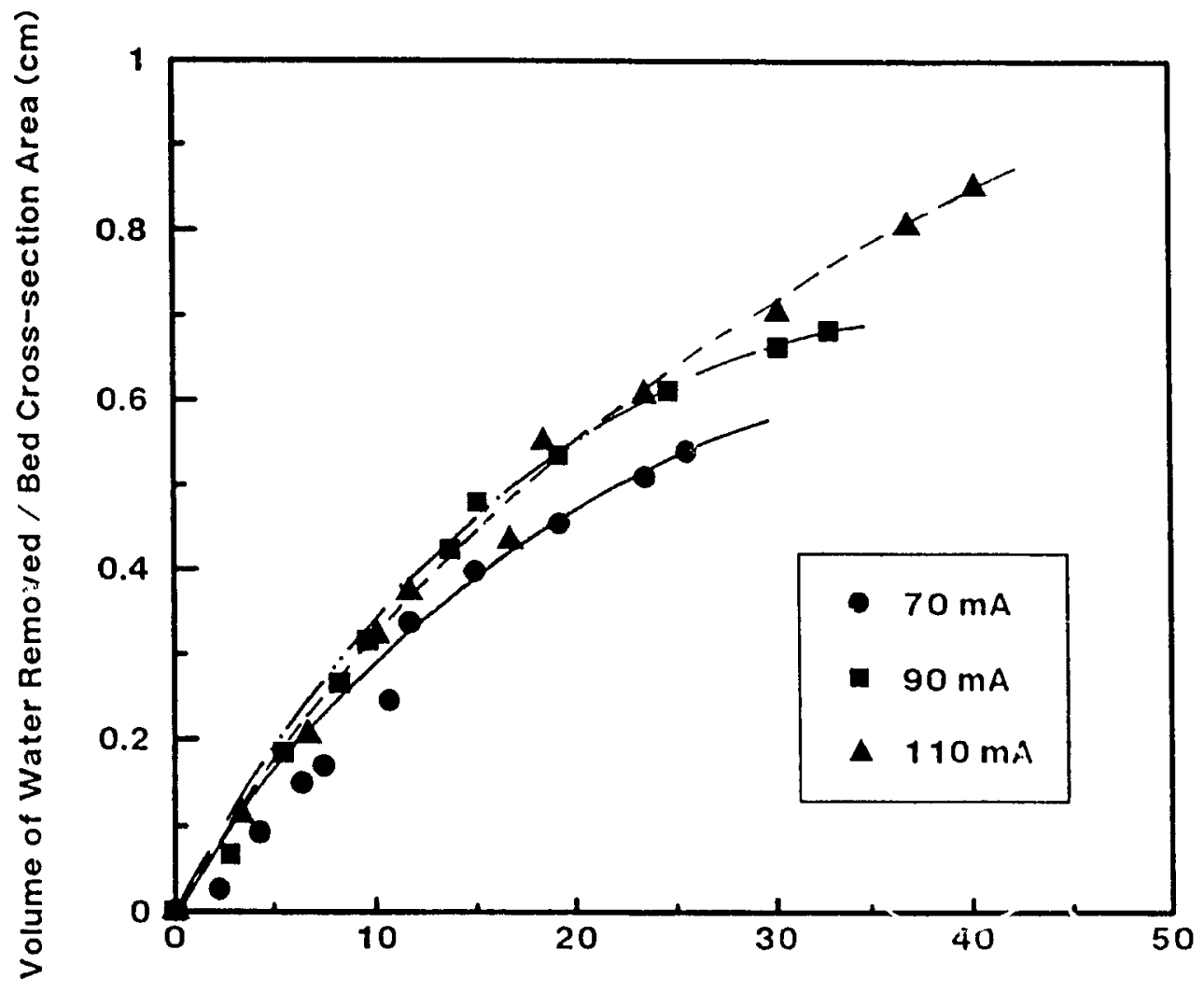

Total Charge Passed/Bed Cross-section Area $\left(A \cdot s / \mathrm{cm}^{2}\right)$

$$
\left(S_{0}=9.1 w t \% ; C_{0}=0 M ; H_{0}=2.0 \mathrm{~cm}\right)
$$

Figure 4-11 Variation of Water Removal with Total Charge 


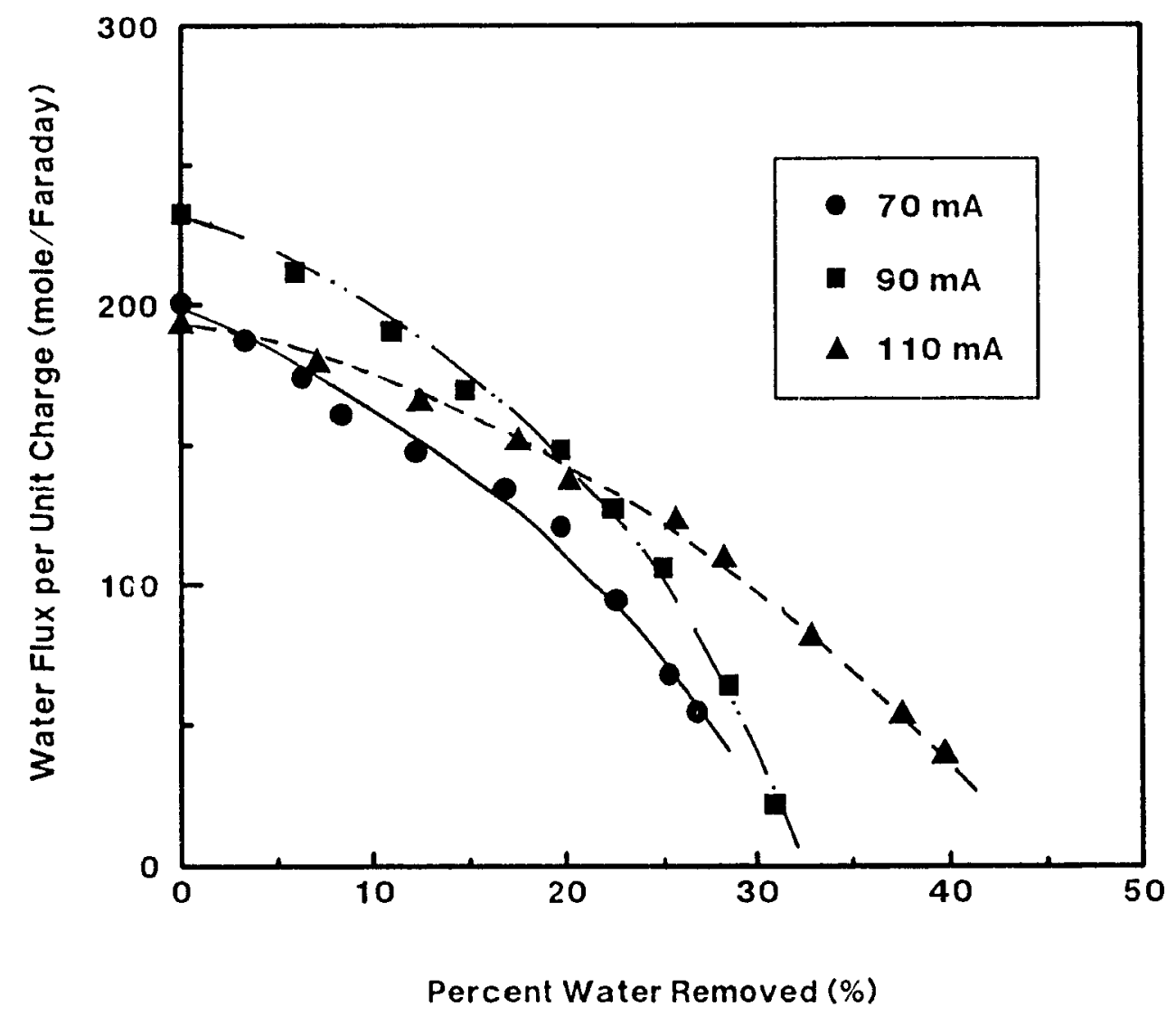

$\left(S_{0}=9.1 w t \% ; C_{0}=0 M ; H_{0}=2.0 \mathrm{~cm}\right)$

Figure 4-12 Variation of Water Transported per Unit Charge with Percent Water Removed 


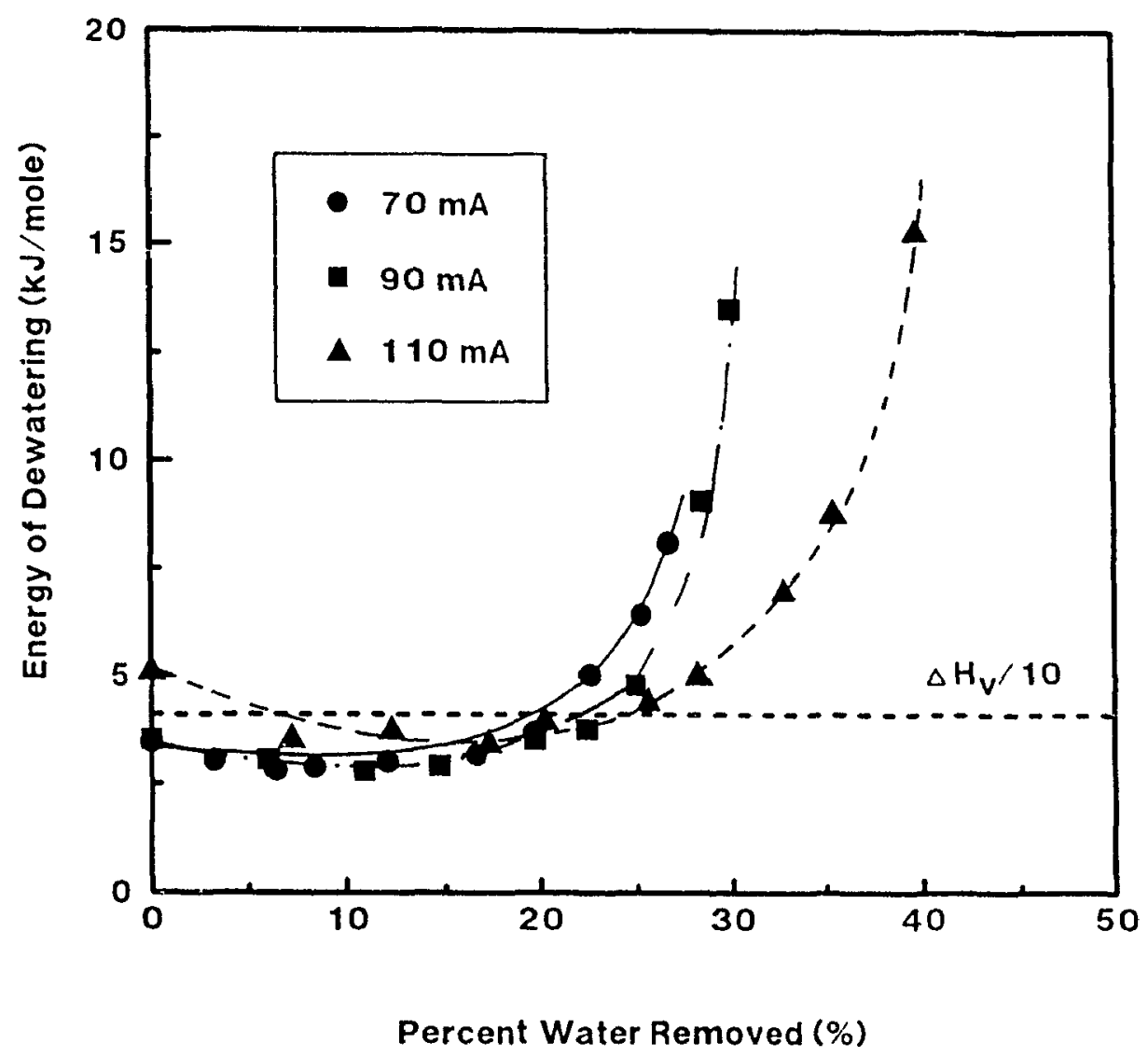

$\left(S_{0}=9.1 w t \% ; C_{0}=0 \mathrm{M} ; H_{0}=2.0 \mathrm{~cm}\right)$

Figure 4-13 Energy of Dewatering vs Percent Water Removed

F 


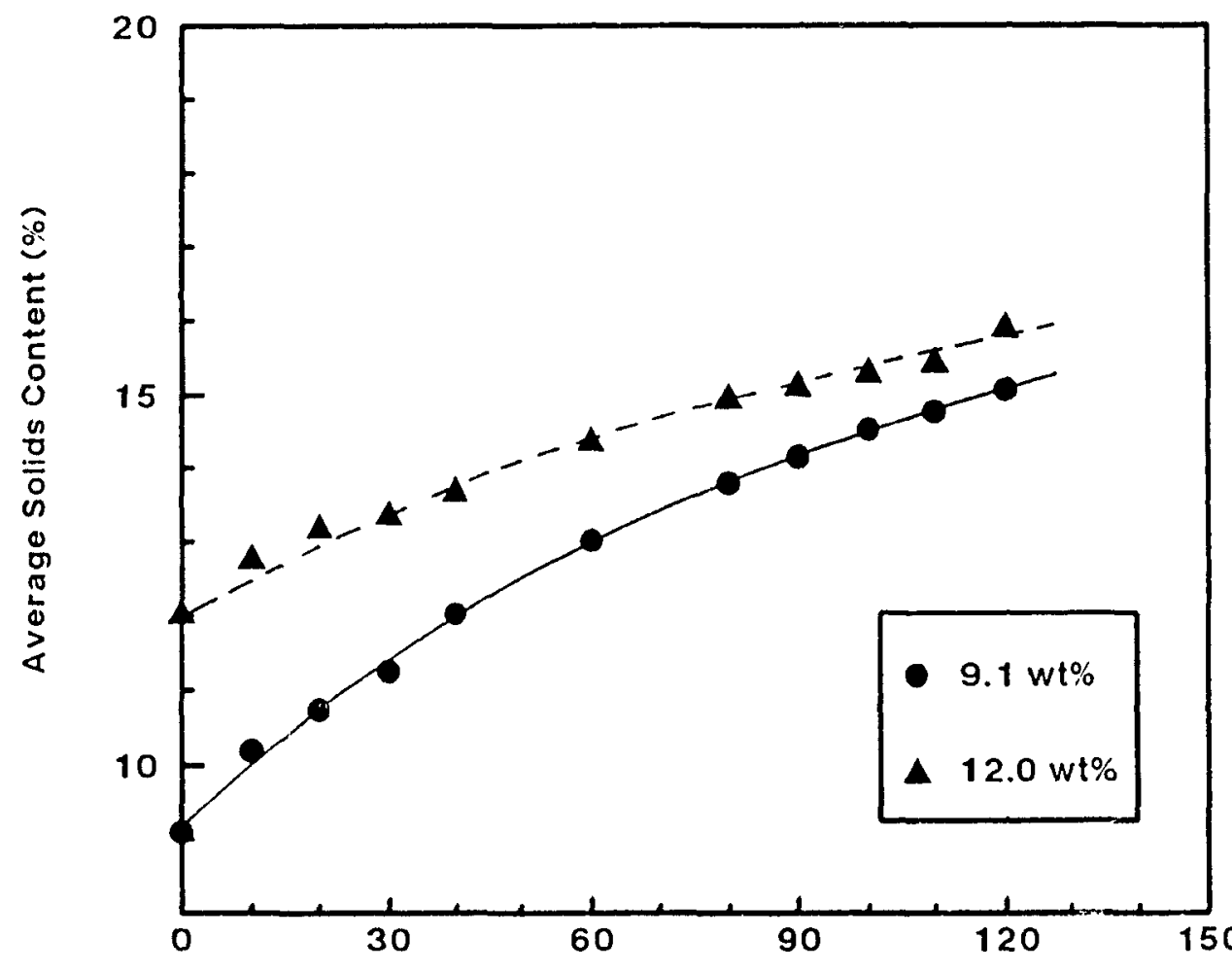

Time (min.)

$$
\left(C_{O}=10^{-2} \mathrm{M} ; H_{O}=2.0 \mathrm{~cm} ; 1=70 \mathrm{~mA}\right)
$$

Figure 4-14 Variation of Solids Content with Time 
removed much faster from the bed of low initial solid content, but simular average solid contents were obtained at 120 minutes for both runs. Figures 4-15 and 4-16 show that the water flux per unt charge and the energy of dewartering anc functions of the average solid content of the bed independent of the imital solud content. 


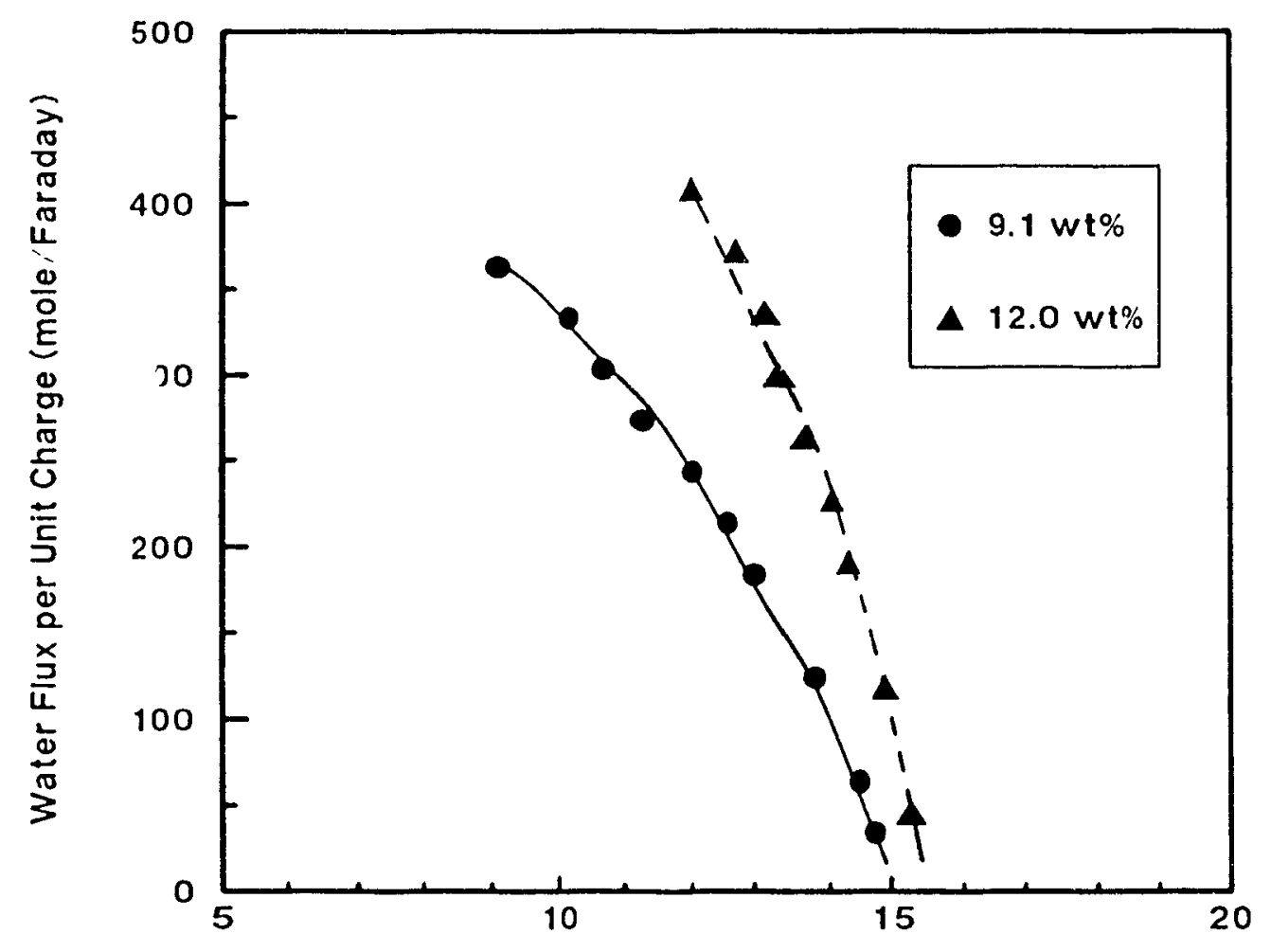

Average Solid Content (\%)

$$
\left(C_{0}=10^{-2} \mathrm{M} ; H_{0}=2.0 \mathrm{~cm} ; \mathrm{l}=70 \mathrm{~mA}\right)
$$

Figure 4-15 Variation of Water Transported per Unit Charge with Average Solid Content 


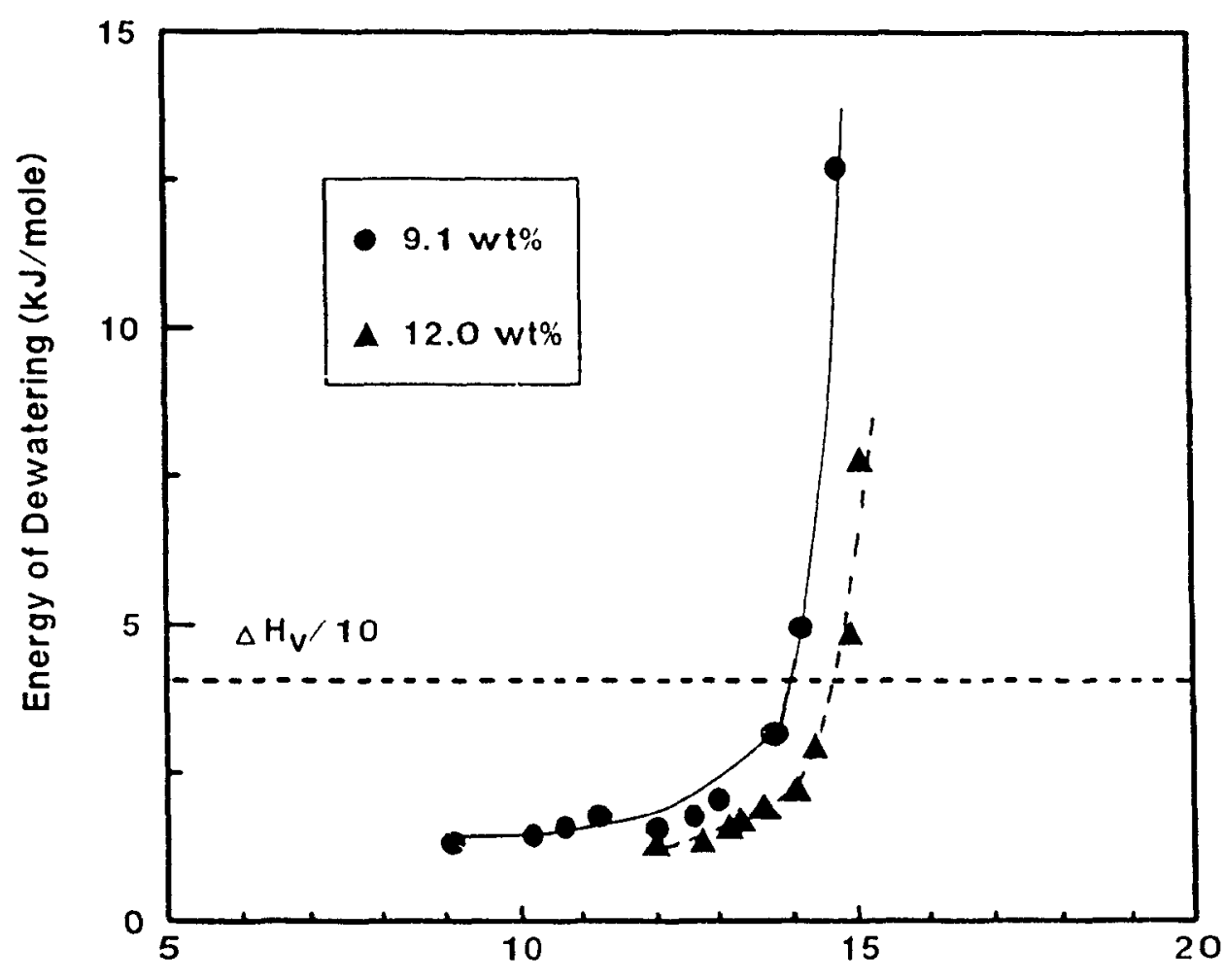

Average Solid Content (\%)

$\left(C_{0}=10^{-2} \mathrm{M} ; H_{0}=2.0 \mathrm{~cm} ; 1=70 \mathrm{~mA}\right)$

Figure 4-16 Energy of Dewatering vs Average Solid Content 


\section{CHAPTER 5}

\section{DISCUSSION \& CONCLUSIONS}

\section{1 lon Exchange \& Electrode Processes}

The Bentonite as received was largely in the sodium form. When suspended in distilled water, the following exchange reaction occurred:

$$
\mathrm{H}_{2} \mathrm{O}+\mathrm{R}-\mathrm{Na}+\mathrm{R}-\mathrm{H}+\mathrm{Na}^{+}+\mathrm{OH}^{-}
$$

where $\mathrm{R}$ denotes the clay. This was confirmed by measuring the $\mathrm{pH}$ of a freshly prepared suspension. If the suspension were made with $\mathrm{CaCl}_{2}$ in distilled water, a second, competing exchange reaction occurred as follows:

$$
\mathrm{Ca}^{+2}+2 \mathrm{R}-\mathrm{Na} \rightarrow \mathrm{R}_{2}-\mathrm{Ca}+2 \mathrm{Na}^{+}
$$

If only $\mathrm{Ca}^{+2}$ were exchanged, there would be no change in $\mathrm{pH}$. Table 3-1 shows the $\mathrm{pH}$ measured $\mathrm{n} .1$ freshly prepared suspensions containing $9.1 \mathrm{wt} \%$ Bentonite made with various concentrations of $\mathrm{CaCl}_{2}$. As the concentration of $\mathrm{Ca}^{+2}$ increased, reaction (5-2) became more important, less $\mathrm{OH}^{-}$was released and $\mathrm{pH}$ decreased.

Tabie 5-1 $\mathrm{pH}$ of $9.1 \mathrm{wt} \%$ Bentonite Suspension

\begin{tabular}{|c|c|}
\hline \hline $\mathrm{CaCl}_{2}$ Concentration, $\mathrm{M}$ & $\mathrm{pH}$ \\
\hline 0 & 9.1 \\
\hline $10^{3}$ & 9.3 \\
\hline $10^{2}$ & 9.7 \\
\hline $10^{1}$ & 7.6 \\
\hline 1 & 6.8 \\
\hline
\end{tabular}


During electroosmosis more sodium was displaced from the Bentomte as destribed below. The water removed from the bed was analyzed by atomic alsorption spectroscopy for iron, magnesium, calcium and sodum. The tirst three metals were present in trace amounts; all at concentrations below $10^{4} \mathrm{M}$. Only sodum wais present in large quantity. The concentration of $\mathrm{Na}^{*}$ was $5.2 \times 10^{2} \mathrm{M}$ when no $\mathrm{CaCl}$ was used in preparing the original suspension and $6.1 \times 10^{2} \mathrm{M}$ when $10^{3} \mathrm{M} \mathrm{CaC} \mathrm{C}_{2}$ was used. In all cases the $\mathrm{pH}$ of the water removed was above 12 due to the presence of the $\mathrm{OH}^{-}$necessary for charge neutrality.

When sufficient voltage was appled, electrochemical reactions occurred which released gas at each electrode. There was no anodic corrosion since the electrodes were platinum-plated. Figure 5-1, a schematic diagram of the bed, gives the principal electrode reactions. The upper electrode was the anode since the zeta potental of the Bentonite was negative (see Fig. 2-3).

At the cathode the following reaction occurred (Lockhart, 1983):

$$
\mathrm{H}_{2}+2 \mathrm{OH}^{-} \rightarrow 2 \mathrm{H}_{2} \mathrm{O}+2 e^{-} \quad \mathrm{E}_{\text {ox }}-0.83 \mathrm{~V}
$$

The reaction is written as an oxidation and $E_{o x}$ is the standard oxidation potential at $25^{\circ} \mathrm{C}$ (Handbook of Chemistry and Physics, 1989-1990). The standard states for $\mathrm{E}_{\text {, }}$ are gases at one atmosphere and electrolytes at infinite dilution. If $\mathrm{no} \mathrm{CaCl}_{2}$ were used in preparing the suspension, the anode reaction was:

$$
2 \mathrm{OH}^{-} \rightarrow \frac{1}{2} \mathrm{O}_{2}+\mathrm{H}_{2} \mathrm{O}+2 e^{-} \quad E_{0}--0.40 \mathrm{~V}
$$




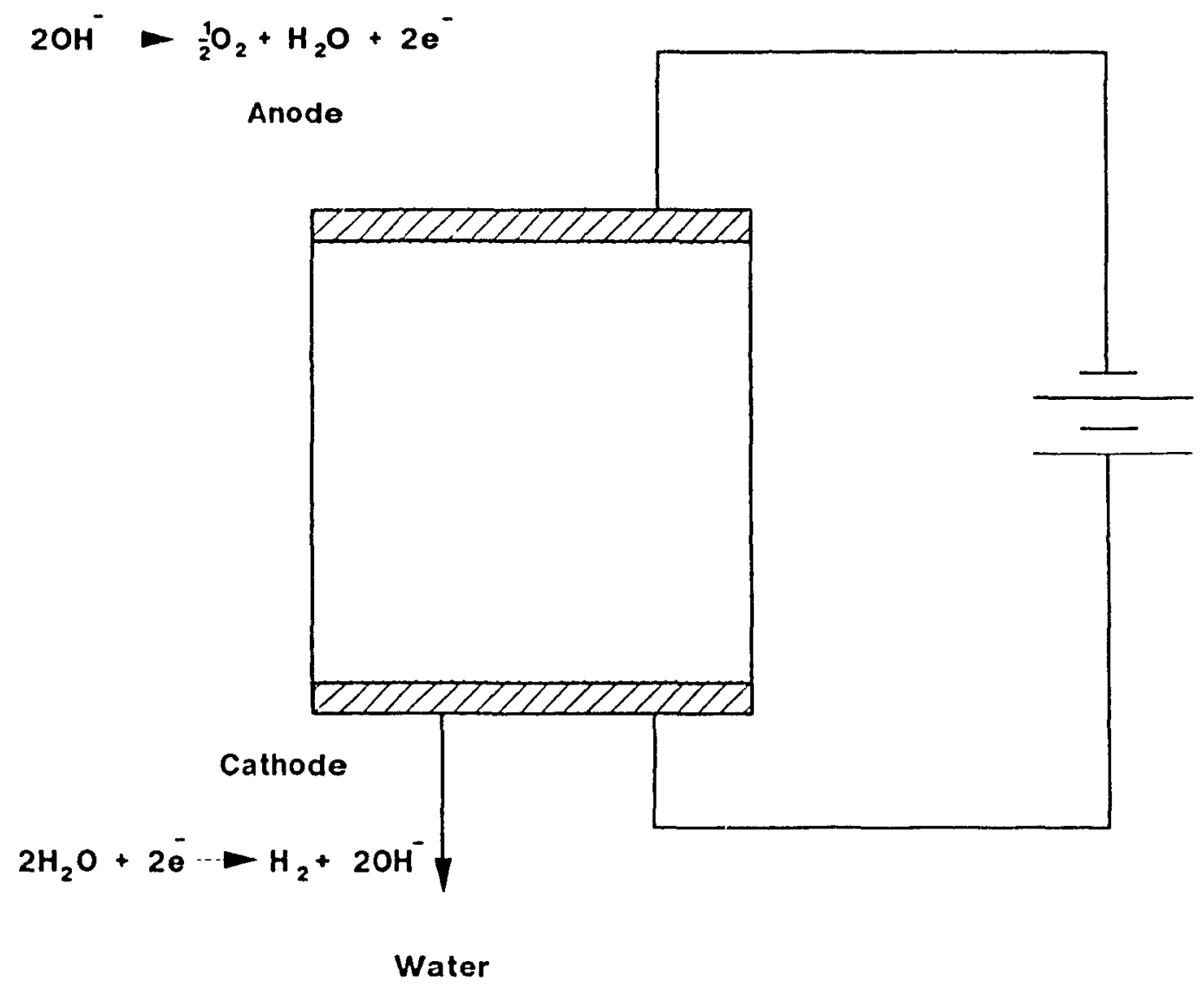

Figure 5-1 Schematic of Bed with Electrode Reactions 
However, when $\mathrm{Cl}^{-}$is present, another reaction might occur:

$$
2 \mathrm{Cl}^{-}+\mathrm{Cl}_{2}+2 e^{-} \quad \mathrm{E}_{\mathrm{ox}}--1.36 \mathrm{~V}
$$

At the chloride concentrations used here, however, the reaction releasing oxygen was favoured because of its larger $E_{\mathrm{ox}}$. Therefore, under all conditions hydroxyl sons wetc consumed at the anode following Eq. (5-4).

The removal of $\mathrm{OH}^{-}$at the anode allowed reaction (5-1) to proceed, thus liberattmg additional $\mathrm{Na}^{+}$which appeared in high concentration in the water removed from the bed. The ions released by reaction (5-1) increased the electrical conductivity of the liquid. This increased conductivity contributed to the increase of current (n constant voltage runs) or of the decrease of voltage (in constant current runs) during the lirst 30-40 minutes of a run.

\subsection{Comparison with Helmholtz/Smoluchowski Theory}

By rearranging eq. (1-6),

$$
\frac{u_{e} A}{i}-\frac{-\zeta D \epsilon_{o}}{\eta \lambda}
$$

The quantity $\mathrm{u}_{c} \mathrm{~A} / \mathrm{i}$ represents the volume of water transported in $\mathrm{m}^{3}$ per coulomb of charge. The water flux per unit charge, $\mathrm{W}$, is given by

$$
W=5.344 \times 10^{9}\left(\frac{u_{e} A}{i}\right) \quad \frac{\text { mole }}{\text { Faraday }}
$$

where the factor $5.344 \times 10^{9}$ has units of mole.C/m $\mathrm{m}^{3} \cdot$ Faraday. The energy of dewatering, $\mathbf{e}_{d}$, which is proportional to $\mathrm{V}_{\mathrm{o}} \mathrm{i} / \mathrm{u}_{\mathrm{c}} \mathrm{A}$, is given by 


$$
e_{d}=1.806 \times 10^{-8}\left(\frac{V_{o} i}{u_{e} A}\right) \quad \frac{k J}{\text { mole }}
$$

where the factor $1.806 \times 10^{8}$ has units of $\mathrm{m}^{3} \cdot \mathrm{kJ} / \mathrm{mole} \cdot \mathrm{J}$.

Equations (5-6) and (5-7) indicate that the water flux per unit charge should be independent of bed height and solid content. Since the addition of electrolytes decreases the zeta potential, 5 , and increases the conductance, $\lambda$, the water flux per unit charge should decrease with electrolyte concentration. Equations (5-6) and (5-8) indicate that the energy of dewatering should increase with applied voltage and that it should be independent of solid content.

Table 5-2 compares measured values of $W$ and $e_{d}$ at the start of electroosmotic dewatering with values calculated from eqs. (5-7) and (5-8). The first two entries in the table are for constant voltage runs in which the conductance of the collected water was measured. The third entry, which is taken from the literature, is for a different Bentonite which has a much higher zeta potential than the Bentonite used here. The agreement between the data and the predictions of the HelmholtzSmoluchowski theory is poor. In the present results (nos. 1 and 2) the values of W computed from eq. (5-7) are approximately one-half of the experimental values while the values of $e_{d}$ computed from eq. (5-9) are roughly a factor of three larger than the data. The agremınt with the literature data (no. 3) is even worse. The predicted values of $\mathrm{W}$ and $\mathrm{e}_{\mathrm{d}}$ differ by about a factor of 10 from the experimental values. 
Table 5-2 Comparison of Data with Eqs (5-7) and (5-8)

\begin{tabular}{|c|c|c|c|c|c|c|c|}
\hline \multirow{2}{*}{ Number } & \multirow{2}{*}{$\begin{array}{c}5 \\
(\mathrm{~V})\end{array}$} & \multirow{2}{*}{$\begin{array}{c}\lambda \\
(\mathrm{S} / \mathrm{m})\end{array}$} & \multirow{2}{*}{$\begin{array}{l}V_{0} \\
(V)\end{array}$} & \multicolumn{2}{|c|}{ W(moles/Faraday) } & \multicolumn{2}{|c|}{$e_{s}(k J / m o l e)$} \\
\hline & & & & Eq. (5-7) & Data & Eq. $(5-8)$ & D.atit \\
\hline 1 & -0.015 & 0.253 & 5.5 & 253 & 525 & 2.06 & 0.7 \\
\hline 2 & -0.015 & 0.292 & 2.8 & 219 & 480 & 1.23 & () 4 \\
\hline 3 & -0.066 & 0.142 & 5.0 & 1985 & 230 & 0.24 & 2.5 \\
\hline
\end{tabular}

$\star 1$ and 2 from this thesis $\left(S_{o}=9.1 \mathrm{wt} \% ; \mathrm{C}_{\mathrm{o}}=10^{2} \mathrm{M} ; \mathrm{H}_{\mathrm{o}}=2.0 \mathrm{~cm}\right)$

$\star 3$ from Yokawa $(1978)\left(\mathrm{S}_{\mathrm{o}}=20 \mathrm{wt} \% ; \mathrm{C}_{\mathrm{o}}=0 \mathrm{M} ; \mathrm{H}_{\mathrm{o}}=2.7 \mathrm{~cm}\right)$

\subsection{Effect of Voltage or Current}

Figure 5-2 shows the final percentage of water removed for runs with no $\mathrm{CaCl}_{2}$ added and an initial bed height of $2 \mathrm{~cm}$ for constant voltage and constant current. The highest voltage and current gave the most water removal. For comparison, the data of Yoshida et al. (1985) for a $20 \mathrm{wt} \%$ Bentonite suspension dewatered under constant voltage are included. The abscissa is the initial field strength for constant voltage and the current per unit cross sectional area for constant current. Yoshida found that an intermediate voltage gave the highest water removal. In the present experiments no optimum voltage (or current) was found, although there was a tendency toward a maximum for constant current.

Figures 5-3 and 5-4 show the variation of the water flux per unit charge and the energy of dewatering, respectively. The present data are shown along with those of Yoshida et al. (1985). Although the initial conditions are different, the variatoons of 


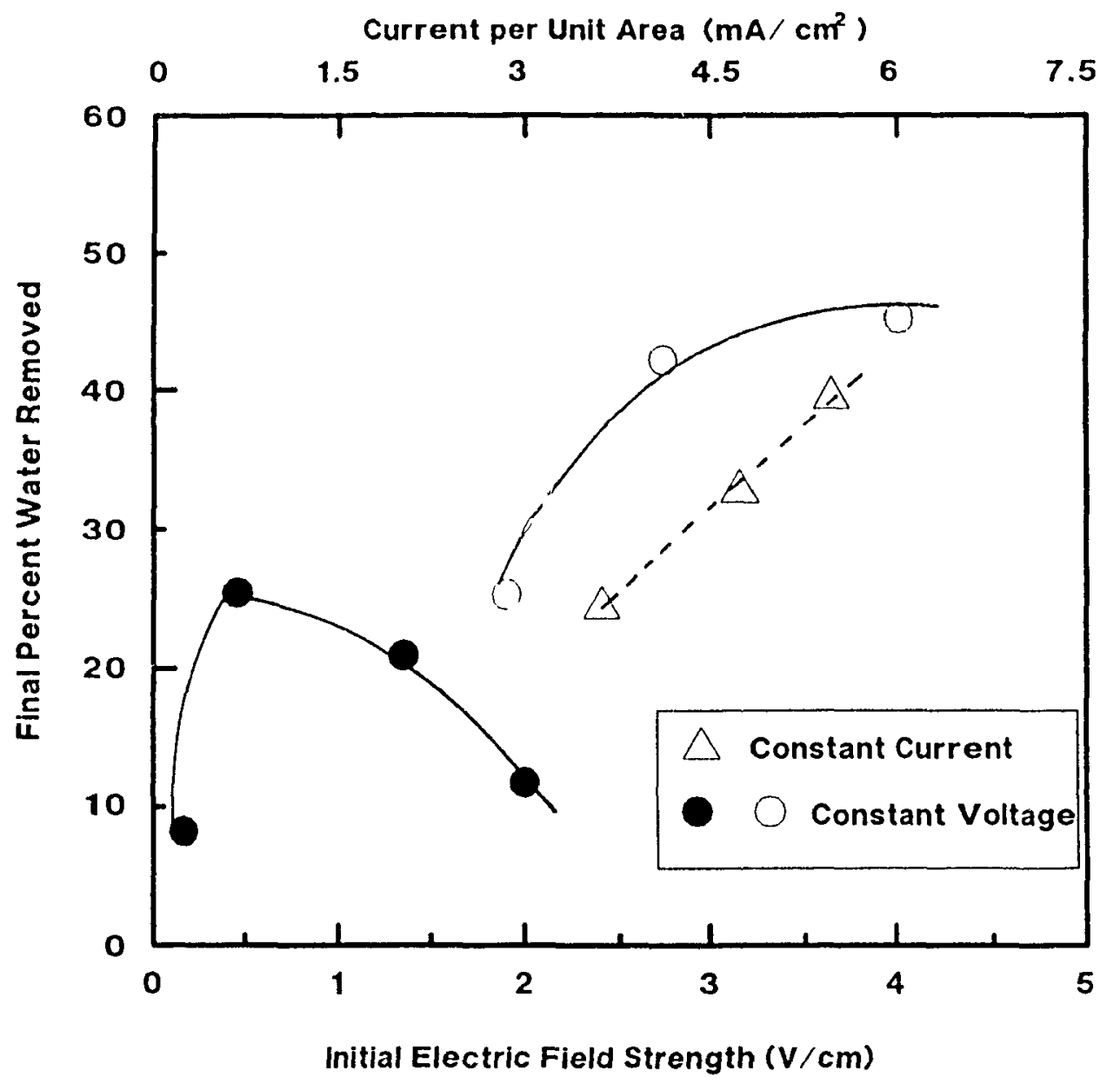

Figure 5-2 Relation Between Final Water Removal, Initial Field Strength and Current per Unit Area

[ Data of Yoshida (1985);O \& $\triangle$ Data of This Thesis] 


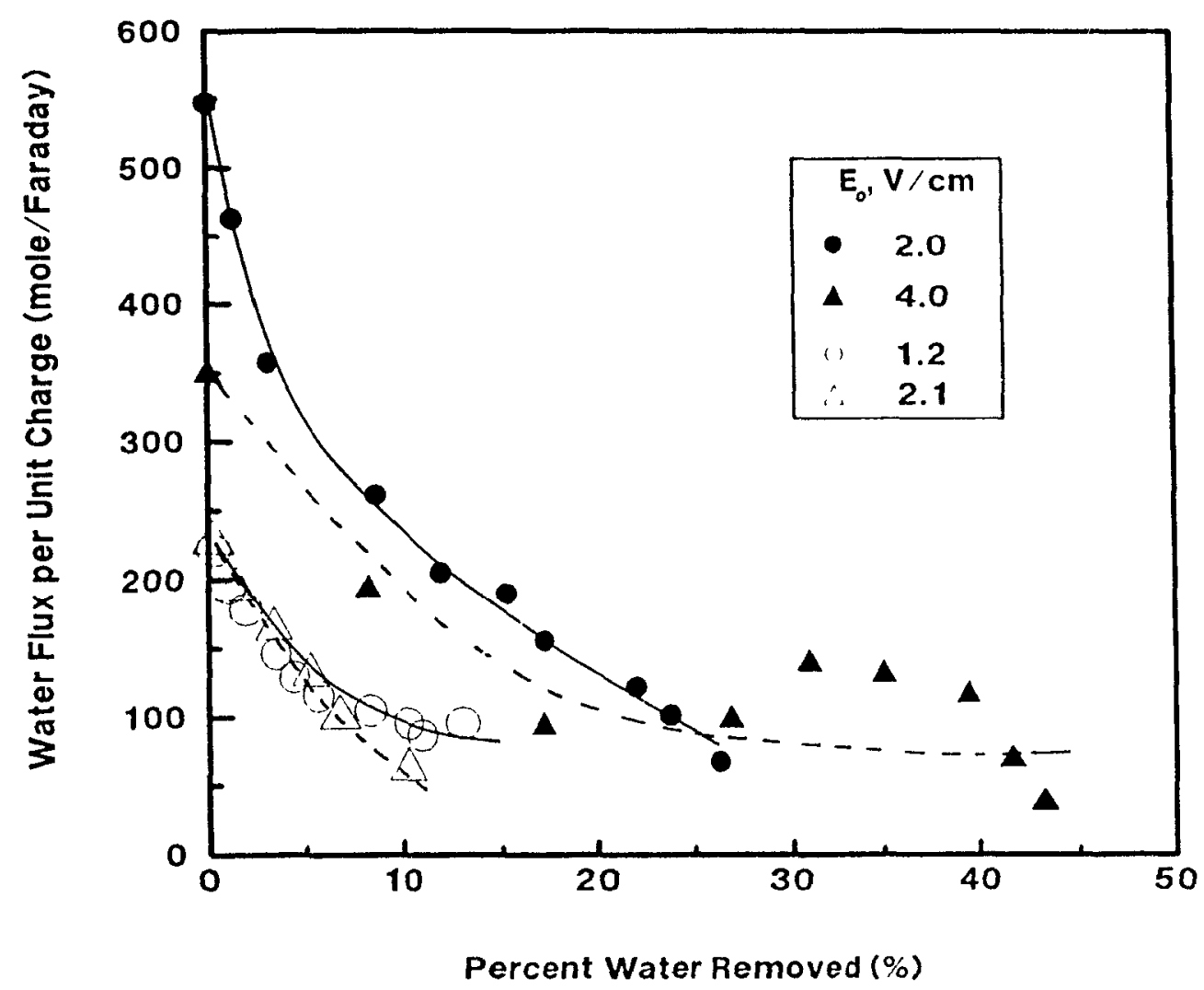

Figure 5-3 Water Flux per Unit Charge at Constant Voltage

Filled symbols for present data $\left(S_{0}=9.1 w t \% ; C_{0}=O M ; H_{0}=2.0 \mathrm{~cm}\right)$ Open symbols for Yoshida et al. (1985) ( $\left.S_{0}=20 w t \% ; C_{O}=O M ; H_{O}=5.4 \mathrm{~cm}\right)$ 


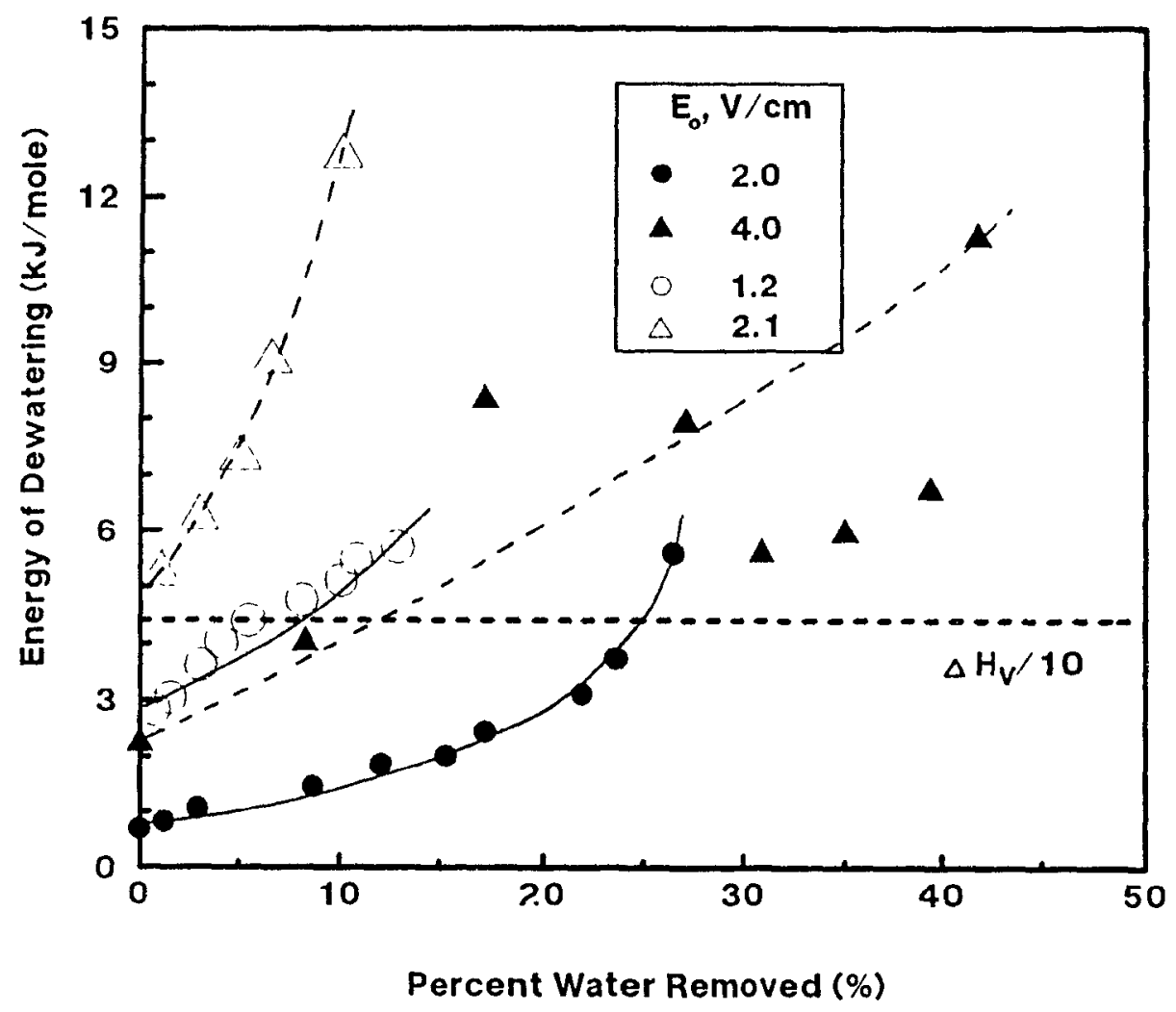

Figure 5-4 Energy of Dewatering at Constant Voltage

Filled symbols for present data $\left(S_{0}=9.1 \mathrm{wt} \% ; \mathrm{C}_{0}=0 \mathrm{M} ; \mathrm{H}_{0}=2.0 \mathrm{~cm}\right)$ Open symbols for Yoshida et al. (1985) $\left(S_{0}=20 w \notin \% ; C_{0}=O M ; H_{O}=5.4 \mathrm{~cm}\right)$ 
the ordinates with the percent water removed are similar and the orders of magnitude are similar. Yoshida et al. found a lower water thux per unt charge and a higher energy of dewatering than found here. The data indicate that the water llux per unit charge (Fig. 5-3) is independent of, or at most, weakly dependent upon voltage while the energy of dewatering (Fig. 5-4) is larger at larger voltage. These findings are in general agreement with eqs. (5-7) and (5-8).

Figure 5-5 gives the variation of the water flux per unit charge with the percent water removed for runs at constant current. The present data as well as Yoshida's data ate shown. The water flux per unit charge at the beginning of dewatering varies only slightly with current in general agreement with eq. (5-7).

\subsection{Effect of Electrolyte Concentration}

Figure 5-6 shows the average solid content of the bed at the end of dewatering as a function of the $\mathrm{CaCl}_{2}$ concentration for both constant current and constant voltage. The abscissa is the molarity of $\mathrm{CaCl}_{2}+0.001 \mathrm{M}$. This scale locates the data for distilled water $\left(0 \mathrm{M} \mathrm{CaCl}_{2}\right)$ at the left most point on the plot, yet retans the logarithmic nature of the abscissa. Since the final solid content was independent of the initial solid content, as noted in Chapters $3 \& 4$, data are plotted for different initial solid contents. Increasing the concentration of $\mathrm{CaCl}_{2}$ increased the final solid content with either constant voltage or constant current.

Figures 3-7 and 4-7 show that higher $\mathrm{CaCl}_{2}$ concentrations increased the rate of water removal as well as the final percentage of water removed. This finding is contrary to the Helmholtz/Smoluchowski theory (see Chapter 1 and section 5.2). Increasing

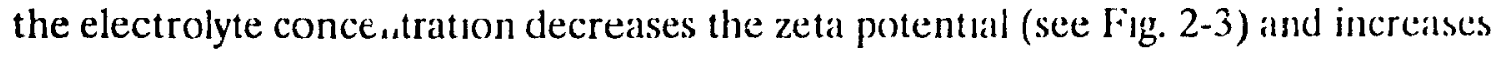




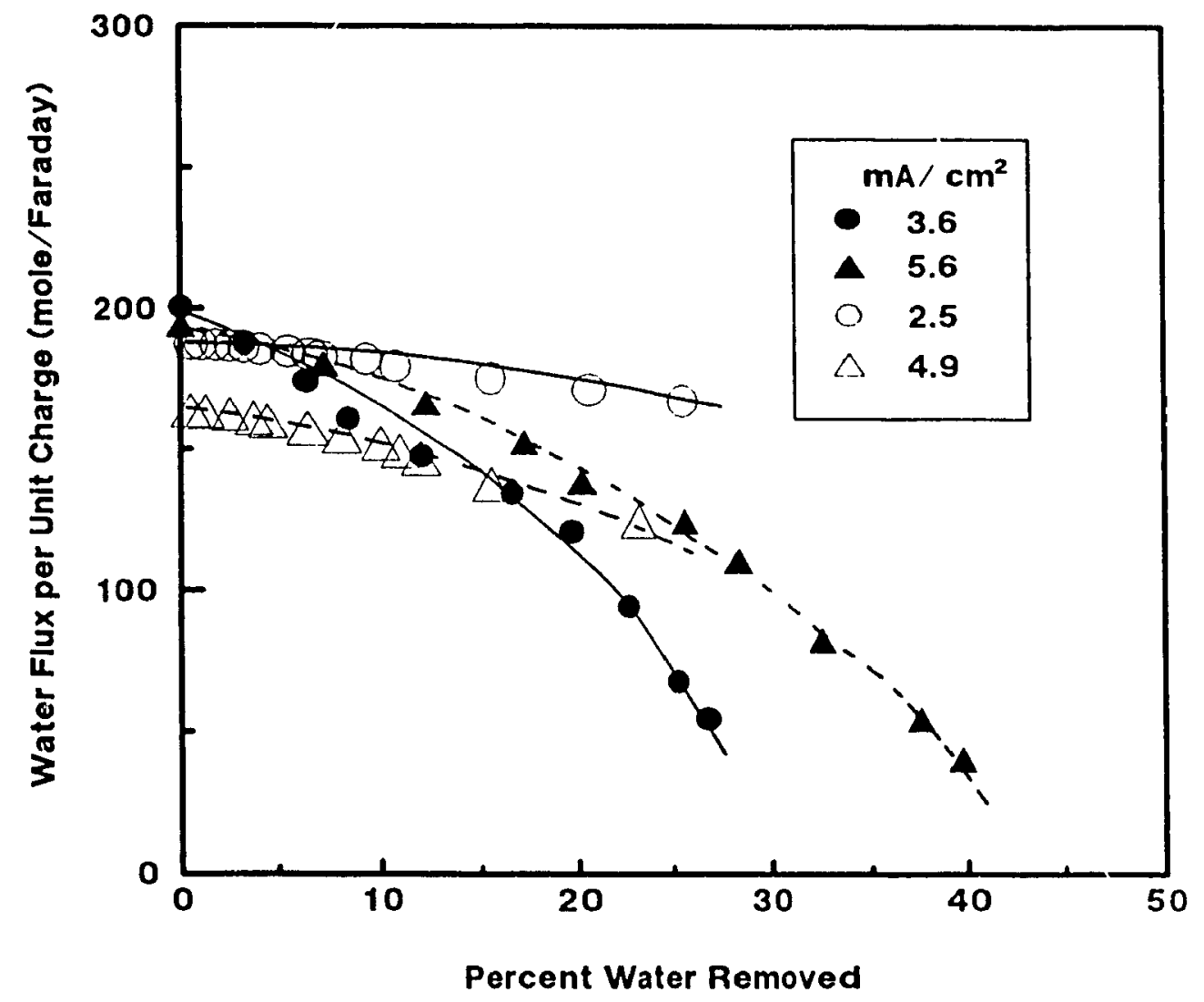

Figure 5-5 Water Flux per Unit Charge at Constant Current

Filled symbols for present data $\left(S_{0}=9.1 w t \% ; C_{O}=0 M ; H_{O}=2.0 \mathrm{~cm}\right)$

Open symbols for Yoshida et al. (1985) $\left(S_{0}=20 w t \% ; C_{0}=0 \mathrm{M} ; H_{0}=5.4 \mathrm{~cm}\right)$ 


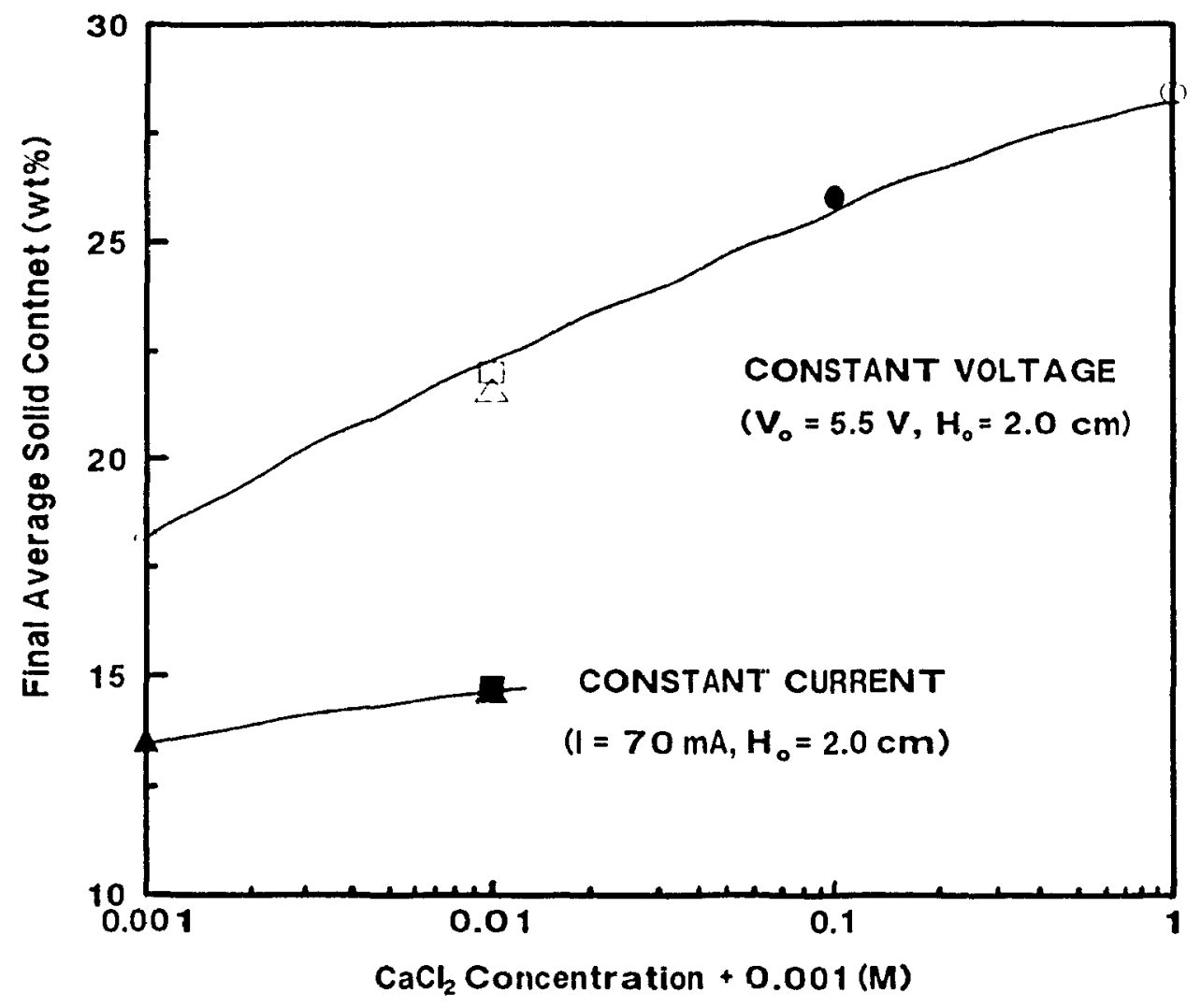

Figure 5-6 Final Solid Content vs $\mathrm{CaCl}_{2}$ Concentration Initial solld content: $\triangle \& \triangle 9.1 \% ; \square 12 \% ; \square 15 \% ; \bullet 19 \% ; \supset 26 \%$ 
the conductance of the liquid. Equations (1-6) and (1-8) show that these changes should reduce the e!ectroosmotic velocity and thus reduce the rate of watter removal for both constant voltage and constant current. These expectations are contradicted by the data. Lockhart (1983) obtained similar results for the effect of $\mathrm{NaCl}$ concentration on electroosmotic dewatering.

One set of data in this thesis for $10^{-2} \mathrm{M} \mathrm{CaCl}_{2}$ is comparable to a run from Lockhart's study, although the material he used was montmorillonite rather than Bentonite. The initial solid content for both runs was $9.1 \mathrm{wt} \%$. When the average soldd content reached $19.5 \mathrm{wt} \%$ the cumulative water flux per unit charge was 312 and 208 moles/Faraday for Lockhart's run and the run in this thesis, respectively. At the same point the cumulative energy expended for electroosmotsc dewatering was $1.7 \mathrm{~kJ} / \mathrm{mole}$ (Lockhart) and $2.5 \mathrm{~kJ} / \mathrm{mole}$ (this thesis).

\subsection{Effect of Initial Bed Height}

Figure 5-7 shows the final water removal as a function of bed height for runs at constant voltage. The initial applied field was the same for each height. For the two largest heights $(2.8 \mathrm{~cm}$ and $5.2 \mathrm{~cm})$ the upper part of the bed became dry and large cracks appeared. The electrical resistance of these beds also increased, possibly due to the large volumes of gas liberated at the electrodes. The largest amount of water was removed at an intermediate bed height. For heights up to $2.1 \mathrm{~cm}$ the final percent removal increased with height. This was probably the result of the increased field in the middle portion of the bed, as described in Chapter 3.

Figure 3-20 shows that the water flux per unit charge was very high for the smallest bed height immediately after dewatering began. This large flux may be related to the 


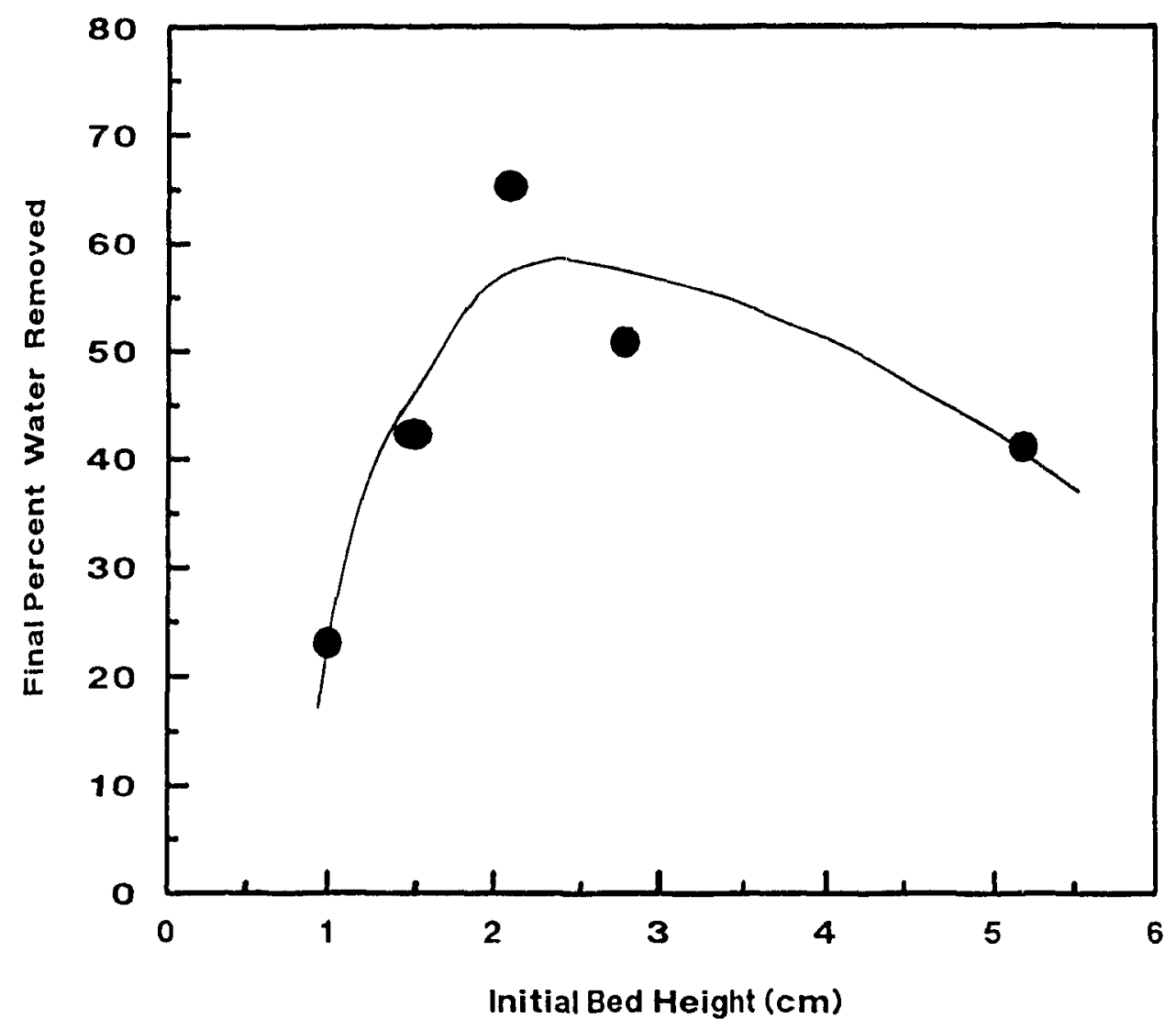

$$
\left(S_{0}=9.1 w t \% ; C_{0}=10^{3} M ; E_{0}=2.8 \mathrm{~V} / \mathrm{cm}\right)
$$

Figure 5-7 Final Water Removal vs Initial Bed Height at Constant Current 
low voltage applied across $1 \mathrm{~cm}$ bed. The current was low (see Fig. 3-19) and little gas was evolved. The lowest energy of dewatering was also acheved at the smallest height (see Fig. 3-21). These results suggest that the most effickent use of energy is obtained with the thinnest beds. However, the thinnest bed was not the driest alt the end of electroosmotic dewatering.

Figure 3-20 shows that the initial water flux per unit charge decreased with initial bed height. This result is at variance with the Helmholtz/Smoluchowskı theory which predicts that the flux per unit charge should be independent of bed height [see eqs. (5-6) and (5-7)]. Figure 3-21 shows that the energy of dewatering uncreased with bed height. The experiments were conducted at the same intial electric field strength, $E_{o}$, for each bed height. Noting that

$$
E_{0}-\frac{V_{0}}{H_{0}}
$$

and using eq. (5-6), the energy of dewatering can be written

$$
e_{d}-1.806 \times 10^{-8}\left(\frac{E_{o} \eta \lambda}{-\zeta D \epsilon_{o}}\right) H_{o}
$$

The Helmholtz/Smoluchowskı theory predicts that the energy of dewatering increases with bed height at constant field strength in agreement with the data in Fig. 3-21.

\section{$\underline{5.6 \text { Effect of Initial Solid Content }}$}

There is little effect of initial solid content on the solid content at the end of electroosmotic dewatering. It is known that Bentonite binds tightly 1-3 molecular layers of water, corresponding to approximately 0.1-(0.3 g water/g clay (Cebula and Thomas, 1978). This water is probably too tightly bound for removal by 
electroosmosis. Water layers beyond this are progressively less tightly held. For a fixed field a certain number of layers will be immobile; the larger the field, the fewer layers, untul only the irreversibly bound layers are left.

Figure $5-8$ shows the variation of the water flux per unit charge with the wt \% water. The data shown as open circles are inttial values of flux, i.e. values obtained when the composition of the sed was unform. The data presented as filled triangles show the variation of the flux per unit charge with the average water content of the bed for a single run with an initıal water content of $90.9 \mathrm{wt} \%$. In all cases the inital bed height was $2.0 \mathrm{~cm}$ and tile concentration of $\mathrm{CaCl}_{2}$ was $10^{2} \mathrm{M}$. Also shown in the figure are results of Gray (1966) for uniform illitic clay plugs in $10^{2} \mathrm{M} \mathrm{NaCl}$.

The water flux per Faraday showed a strong variation with water content for the Bentonite. Table 5-3 shows the solid content at the end of electroosmotic dewatering for a bed which was cut into three sections. In a single run the bed was drier at the top than the anode at the bottom. The variation of the final solid content about the average final solid content was not sufficient to change the relationship between the flux per unit charge and the water content. The Bentonite data and illitic clay data indicate that the water flux per unit charge decreased as the solıd content increased, but the Bentonite flux decreased much more rapidly. The Helmholtz/Smolchowski theory predicts that the flux per unit charge should be independent of the water (or solid) con.ent [see eqs. (5-6) and (5-7)]. Both sets of data contradict this. 


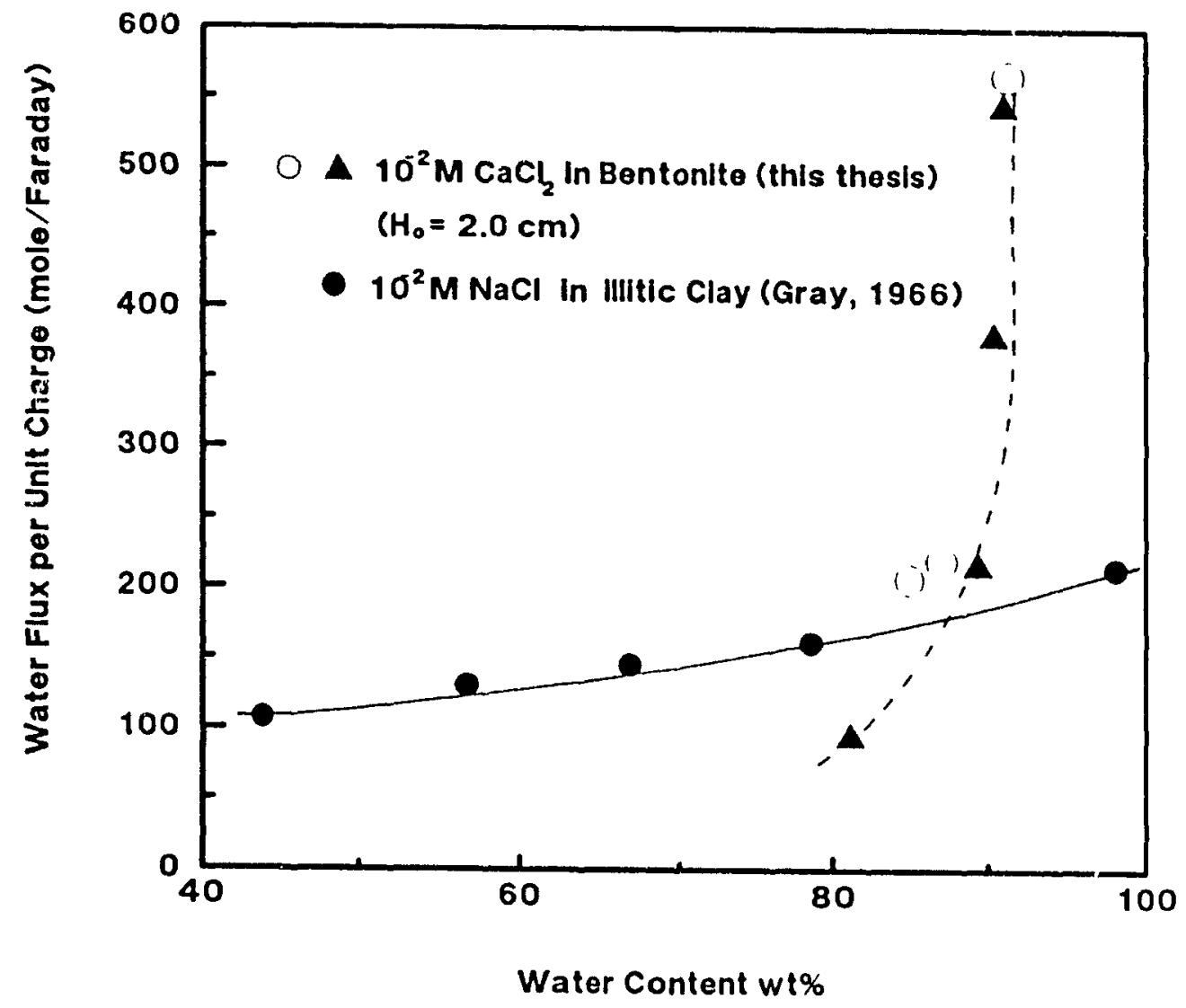

Figure 5-8 Variation of Water Flux per Unit Charge with Water Content

uniform bed composition

$\Delta$ data from a sir.gle run vs average water content 
Table 5-3 Final Solid Content in Different Layers of Dewatered Cake $\left(S_{o}=9.1 \mathrm{wt} \% ; \mathrm{C}_{\mathrm{o}}=10^{2} \mathrm{M} ; \mathrm{V}_{\mathrm{o}}=5.5 \mathrm{~V} ; \mathrm{H}_{\mathrm{o}}=2.0 \mathrm{~cm}\right)$

\begin{tabular}{|c|c|c|}
\hline Posituon in Cake & Thickness & Solid Content \\
\hline Upper Layer & $3 \mathrm{~mm}$ & 24.7 \\
Middle Layer & $5 \mathrm{~mm}$ & 23.4 \\
Lower Layer & $4 \mathrm{~mm}$ & 19.6 \\
\hline
\end{tabular}

\section{$\underline{5.7 \text { Conclusions }}$}

From experiments on electroosmotic dewatering of Bentonite under constant voltage or constant current the following conclusions are drawn:

1. Electroosmosis can remove significant amounts of water with an energy expenditure well below the energy required to vaporize the water.

2. At the end of dewatering $20-60 \%$ of the water was removed. Higher final water removals were obtaned with higher voltages or higher currents.

3. The water removal rate and the final solid content were increased with the addition of $\mathrm{CaCl}_{2}$.

4. At the constant intial field strength the smallest bed height $(1 \mathrm{~cm})$ gave the lowest energy of dewaterng and highest flux per unit charge. The driest bed was obtained at a medium height $(2.1 \mathrm{~cm})$.

5. The initial solid content had little effect on the final average solid content.

6. The Helmholtz/Smoluchowski theory did not agree with the experimental results for the effects of electrolyte concentration, bed height and solid content. 


\section{REFERENCES}

Cebula, D. J. \& Thomas R. K., "The Structure and Dynamics of Clay-water Systems studied by Neutron Scattering", International Clay Conference-11-120, 1978.

Ellis, D., \& Sunderland, J., "Dewatering Sewage Sludge by Electroosmosıs", N'TIS PB reports 276411 and 276412,1976 and 1977 .

Gray, D., "Coupled Flow Phenomena in Clay-Water Systems", Ph. D. Thesss, University of California, Berkeley, 1966.

Gray, D., \& Mitchell, J., "Fundamental Aspects of Electroosmosis in Souls", J. Soul. Mech. Found. Div. ASCE 93(SM6): 209-236, 1967.

Hiemenz, P. C., "Principles of Collond and Surface Chemistry". Second Fditum, Marcel Dekker, New York, 1986.

Lockhart, N., "Electroosmotic Dewaterıng of Clay. Part i-Influence of Voltage", Colicids and Surfaces, 6: 229-238, 1983.

Lockhart, N., "Electroosmotic Dewatering of Clay. Part II- Influence of Salt, Ackd and Flocculants", Colloids and Surfaces, 6: 239-251, 1983.

Lock!; -t, N., "Electroosmotic Dewatering of Clay Pant. III- Influence of Clay Type, Exchar, eable Cations, and Electrode Materials", Collonds and Surfaces, 0: 253-26\%, 1983.

O’Brien, R. W., "Electroosmosis in Porous Materials", Journal of Coilloid and Interface Science, 110: 477-487, 1986. 
Overbeck, J. Th. G., "Electrokinetic Phenomena", in "Colloid Science" (Kruyt, H. R., editor), Vol. I, Ch. V, Elsevier, Amsterdam, 1952.

Weast, R. C., "Handbook of Chemistry and Physics", CRC Press INC., Boca Raton, Floridi, 1989-1990.

Weber, M. E., Witwit, S. M. \& Mujumdar, A. S., "A Model for Electroosmotic Dewatering Under Constant Voltage", Drying Technology, 5: 467-474, 1987.

Yoshida, H., Shinkawa, T., \& Yukawa, H., "Water Content and Electric Potential Distribution in Gelatinous Bentonite Sludge with Electroosmotic Dewatering", J. Chem. Eng. Japan, 18: 337-342, 1985.

Yukawa, H., Yoshida, H., \& Kobayashi, K., "Electroosmotic Dewatering of Sludge under Condition of Constant Voltage", J. Chem. Eng. Japziil, 11: 475-480, 1978. 


\section{NOMENCLATURE}

\begin{tabular}{|c|c|c|}
\hline A & cross sectional area of the bed & {$\left[\mathrm{m}^{*}\right]$} \\
\hline $\mathbf{a}$ & cross sectional area of the capullary & {$\left[\mathrm{m}^{3}\right]$} \\
\hline$b$ & coefficient in Eq. (1-9) & \\
\hline $\mathrm{C}_{\mathrm{o}}$ & initial $\mathrm{CaCl}_{2} \mathrm{concentraton}$ & {$[\mathrm{M}]$} \\
\hline $\mathrm{D}$ & dielectric constant of bulk fluid & \\
\hline $\mathrm{D}_{0}$ & smallest diameter in size distribution & {$[\mathrm{m}]$} \\
\hline $\mathrm{D}_{\mathrm{m}}$ & largest diameter in size distribution & {$[\mathrm{m}]$} \\
\hline $\mathrm{d}$ & distance travelled by the particles & {$[\mathrm{m}]$} \\
\hline $\mathrm{E}$ & field strength & {$[\mathrm{V} / \mathrm{cm}]$} \\
\hline $\mathrm{E}_{\mathbf{a}}$ & apphed field strength & {$[\mathrm{V} / \mathrm{cm}]$} \\
\hline$E_{o}$ & initial field strength & {$[\mathrm{V} / \mathrm{cm}]$} \\
\hline$E_{o x}$ & standard oxidation potential & [volt] \\
\hline$e_{d}$ & energy of dewatering & {$[\mathrm{kJ} / \mathrm{mole}]$} \\
\hline $\mathrm{H}$ & bed height & {$[\mathrm{cm}]$} \\
\hline $\mathrm{H}_{\mathrm{o}}$ & initial bed height & {$[\mathrm{cm}]$} \\
\hline i & electric current & {$[\mathrm{mA}]$} \\
\hline $\mathrm{k}^{-1}$ & Debye thickness & {$[\mathrm{m}]$} \\
\hline 1 & distance between electrodes & [m] \\
\hline $\mathbf{M}$ & molecular weight of water & $|\mathrm{g} / \mathrm{mole}|$ \\
\hline $\mathrm{m}$ & coefficient in Eq. (1-9) & \\
\hline $\mathrm{n}(\mathrm{D})$ & number distribution & \\
\hline Q & volume of water removed by electroosmosis & {$\left[\mathrm{cm}^{\prime}\right]$} \\
\hline$\dot{\mathrm{Q}}$ & rate of water removal & {$\left[\mathrm{cm}^{1} / \mathrm{s}\right]$} \\
\hline $\mathrm{qr}_{\mathrm{r}}$ & total charge passed per unit area & {$\left[\mathrm{coulomb} / \mathrm{cm}^{2}\right]$} \\
\hline $\mathbf{R}$ & capillary radius & {$[\mathrm{m}]$} \\
\hline
\end{tabular}




$\begin{array}{llr}S_{n} & \text { initial solid content } & {[\mathrm{wt} \%]} \\ t & \text { time } & {[\mathrm{s}]} \\ t & \text { average time } & {[\mathrm{s}]} \\ u_{e} & \text { electroosmotic velocity } & {[\mathrm{m} / \mathrm{s}]} \\ V & \text { overall voltage } & {[\mathrm{volt}]} \\ V_{n} & \text { initial applied voitage } & {[\mathrm{volt}]} \\ W & \text { water flux per unit charge } & {[\mathrm{moles} / \mathrm{Faraday}]} \\ w & \text { water content } & {[\mathrm{wt} \%]} \\ \zeta & \text { zeta potential } & {[\mathrm{volt}]} \\ \epsilon & \text { permittivity of the bulk liquid } & {\left[\mathrm{c}^{2} / \mathrm{Jm}\right]} \\ \epsilon_{n} & \text { permittivity of free space } & {\left[\mathrm{c}^{2} / \mathrm{Jm}\right]} \\ \epsilon_{+} & \text {volume fraction of water } & \\ \eta & \text { fluid viscosity } & {[\mathrm{kJ} / \mathrm{m} \mathrm{s}]} \\ \lambda & \text { specific conductance of the bulk fluid } & {[\mathrm{S} / \mathrm{m}]} \\ \rho & \text { density of water } & {\left[\mathrm{kg} / \mathrm{m}^{\prime}\right]}\end{array}$

